Florida International University FIU Digital Commons

FIU Electronic Theses and Dissertations

University Graduate School

$11-10-2015$

\title{
The Role of Endothelin 3 in Melanoma Progression and Metastasis
}

Nikeisha L. Chin

Florida International University, nchin001@fiu.edu

DOI: $10.25148 /$ etd.FIDC000185

Follow this and additional works at: https://digitalcommons.fiu.edu/etd

Part of the Biology Commons, $\underline{\text { Cancer Biology Commons, and the Cell Biology Commons }}$

\section{Recommended Citation}

Chin, Nikeisha L., "The Role of Endothelin 3 in Melanoma Progression and Metastasis" (2015). FIU Electronic Theses and Dissertations. 2286.

https://digitalcommons.fiu.edu/etd/2286

This work is brought to you for free and open access by the University Graduate School at FIU Digital Commons. It has been accepted for inclusion in FIU Electronic Theses and Dissertations by an authorized administrator of FIU Digital Commons. For more information, please contact dcc@fiu.edu. 


\title{
FLORIDA INTERNATIONAL UNIVERSITY \\ Miami, Florida
}

\section{THE ROLE OF ENDOTHELIN 3 IN MELANOMA PROGRESSION AND METASTASIS}

\author{
A dissertation submitted in partial fulfillment of \\ the requirements for the degree of \\ DOCTOR OF PHILOSOPHY \\ in \\ BIOLOGY
}

by

Nikeisha Latoya Chin 
To: Dean Michael R. Heithaus

College of Arts and Sciences

This dissertation, written by Nikeisha Latoya Chin, and entitled The Role of Endothelin 3 in Melanoma Progression and Metastasis, having been approved in respect to style and intellectual content, is referred to you for judgment.

We have read this dissertation and recommend that it be approved.

$\begin{array}{r}\hline \text { Lou Kim } \\ \hline \text { M. Alejandro Barbieri } \\ \hline \text { Zhao-Jun Liu } \\ \hline \text { Lidia Kos, Major Professor }\end{array}$

Date of Defense: November 10, 2015

The dissertation of Nikeisha Latoya Chin is approved.

\begin{tabular}{r} 
Dean Michael R. Heithaus \\
College of Arts and Sciences \\
\hline Dean Lakshmi N. Reddi \\
University Graduate School
\end{tabular}

Florida International University, 2015 


\section{DEDICATION}

For the family I was born into, which helped shape me into the person I am, and for your enduring love, my father, Hubert, my mother, Gwenneth and my brothers Steven and Michael. Also to the family I have started, which make me strive to become an even better person every day, my husband Nicholas and our beautiful daughter Victoria. 


\section{ACKNOWLEDGMENTS}

I would like to express my heartfelt thanks to my mentor Dr. Lidia Kos, who first inspired me as a professor, and continued to do so after welcoming me into her lab. You are truly the paradigm of a supportive, dedicated and understanding mentor. Thank you, for not only leading me in my scientific endeavors, but also for allowing me to find my way, by not only pushing, but also by example, throughout all the peaks and valleys of my journey. I aim to achieve the same balance of professional achievement and family life that you make look so seemingly easy. I will hold dear the guidance and knowledge you have imparted over the years. Mostly though, I appreciate the personal kindness and concern you have always offered. I consider you not only as a mentor but also as a friend, and I know you will be there still as I pursue my future goals.

Thank you so much to my committee members, Dr. M. Alejandro Barbieri, Dr. Lou Kim, Dr. Zhao-Jun Liu and Dr. Nikolas Tsoukias for extending your time, patience, encouragement and expertise at full length of my project. You each helped to stimulate new ideas and helped me grow as a scientist. I wish to also thank the people who held the Biology Graduate Program Director position, including Dr. Maureen Donnelly, now Dean Maureen Donnelly, and Dr. Steve Oberbauer. Your guidance, confidence and understanding was also instrumental in me navigating through the Ph.D. program. I have learned something from each of you, in the way that you all have conducted yourselves as professionals and individuals that I can only hope to incorporate to make me just as estimable and amiable as you all are. 
It is with deepest gratitude, that I thank the undergraduates who worked with me for years dedicating their time and hard work with me on my project, Juan Carlos Gallegos, Rosy Cruz, Ruslan Garcia, Andrea Gonzalez, Manuel Borobia, Ricardo Villasmil, Juan Vallladeres and Joseph Palmer. I thank you for being another set of eyes, ears and hands on my dissertation project, for even sometimes working and going beyond what was expected of you and giving me new direction through your own observations and insight. You also helped to push me to become better in order to mentor you. Working closely together has allowed me to become acquainted with each of you, and to form very strong bonds and meaningful friendships with you, that I know will last for many years to come. It has been a pleasure to watch you all grow, mature and go on to pursue your own goals. I am so proud of you all, and wish that I have imparted as much to you, as you have to me.

What would I have done without my fellow labmates present and past, who I also happily call my friends? Amy Saldana Tavares, Ana Paula Benaduce, Natasha Fernandez, Flavia Brito, Marcy Lowenstein, Javier Pino, Xiaoshuang Li, Juliano Freitas, Alejandro Conde, Francois Rouzad, Erasmo Perera, Deannys Batista and Diana Cardero. My Kos lab experience was truly an enjoyable one. Thank you for all the advice, assistance with protocols and techniques, and most of all your support. I will always treasure the tears, laughs, frustration and small victories we shared together. You all mean so much to me, and I look forward to moving from labmates to fellow friends and colleagues in our field. Thank you also to Dr. Fernando Noriega and Marcella for allowing me to use their qRT-PCR 
machine, enabling me to complete a set of my experiments for my dissertation. Your kindness reminds me that amid all the competitiveness in our field, we are still all fellow scientists with a common goal for humankind.

I would like to recognize the Minority Biomedical Research Support Research Initiative for Scientific Enhancement (MBRS RISE) fellowship (NIH/NGMS) and the FIU Teaching Assistantship program for financial support during the pursuant of my degree. I am also much obliged to the staff of the MBRS RISE, Dr. Charles Bigger, Dr. Robert Lickliter, Aileen Landry, Courtney Aiken, Thelma Robles and the many others who aided in my time in the program as well as to Thomas Pitzer who administrates the TA program. Thank you also to the staff of the Biology Department who kindly assisted in any questions and formalities that I needed to complete.

To my loving family, my greatest supporters, I am so deeply indebted and immensely blessed to have you in my life. There are no words that could even remotely encompass how much I hold you in my heart. Mom, Dad, Steven, thank you for your unwavering love and encouragement. You have always made me believe I could achieve anything, and taught me that everything I do in life should be done with grace, kindness and to the best of my abilities. Thank you for all your prayers, praise, comfort and courage when I needed it the most. I hope to always make you proud. To my husband Nicholas, who has been with me for almost half of my life, and thus endured this chapter with me. It takes a strong and loving man to be as supportive and patient as you have been. I thank you for all the times you have stayed up late with me and reassured me. Thank you for 
making my dreams also a part of your own. As we embarked on our biggest journey, parenthood, I especially thank you for all the times you took on extra duties so that I could have the time to complete my degree. My dearest daughter Victoria, you will always be the greatest accomplishment of my life, and although you are still too young to understand how important this achievement is for me, I thank you, because every day you teach and remind me how wonderful life can be, motivate me to become a better person, and I strive to make this world a little bit better for you. I hope my success will inspire your own.

Last but not least I would like to also thank the FIU custodial staff who helped to maintain the conditions of our laboratory and offered friendly smiles. My working environment would not have been as comfortable if it were not for you. 


\title{
ABSTRACT OF THE DISSERTATION \\ THE ROLE OF ENDOTHELIN 3 IN MELANOMA PROGRESSION AND METASTASIS
}

\author{
by \\ Nikeisha Latoya Chin \\ Florida International University, 2015 \\ Miami, Florida \\ Professor Lidia Kos, Major Professor
}

Endothelin receptor b (Ednrb) and its ligand Endothelin 3 (Edn3) have been

implicated in melanoma. Several studies have shown an upregulation of EDNRB and EDN3 at both the protein and mRNA levels, as melanoma becomes more aggressive. This study investigated the putative role played by Edn3 overexpression in melanoma progression and angiogenesis in vivo. We crossed $T g(G r m 1) E p v$ transgenic mice that aberrantly express metabotropic glutamate receptor1 under the Dopachrome tautomerase promoter, leading to spontaneous melanocytic lesions in the ears and tails that do not metastasize, with transgenics that overexpress Edn3 under the Keratin 5 promoter (K5-Edn3) or overexpress Ednrb in melanocytes ( $T g(E d n r b) 1 L k)$. In both the $T g(G r m 1) E p v / K 5-E d n 3$ and $T g(G r m 1) E p v / T g(E d n r b) 1 L k$ mice, tumors appeared earlier and grew significantly larger and faster when compared to $T g(G r m 1) E p v$ mice. Approximately eightyone percent of $T g(G r m 1) E p v / K 5-E d n 3$ mice and $76 \%$ of $T g(G r m 1) E p v / T g(E d n r b) 1 L k$ mice had pigmented lesions in distant organs such as the lung and brain. Real-Time PCR analysis showed higher expression levels 
of genes involved in cell-cell and cell-matrix interactions and angiogenesis in lesions of $T g(G r m 1) E p v / K 5-E d n 3$ when compared to controls. Considering the rapid tumor growth rate of in the $T g(G r m 1) E p v / K 5-E d n 3$ mice, differences in the angiogenic response compared to control mice were investigated.

Immunofluorescence analysis with the endothelial cell marker CD31 showed that there were more endothelial cells per tumor area in the $T g(G r m 1) E p v / K 5-E d n 3$ mice than the controls. Proteome analysis showed that the Dct-Grm1/K5-Edn3 mice had significant increases in other angiogenic related genes such as Angiogenin, CXCL 16 and Endoglin, when compared to controls, while real time PCR analysis of tail tumors also showed higher expression levels of angiogenic related genes such as Hif-1a. The results of this study showed that the EDNRB/EDN3 axis is sufficient to alter the kinetics of melanocytic tumors' progression, lead them to a fully malignant state, and increase the tumor angiogenic response. 
CHAPTER

PAGE

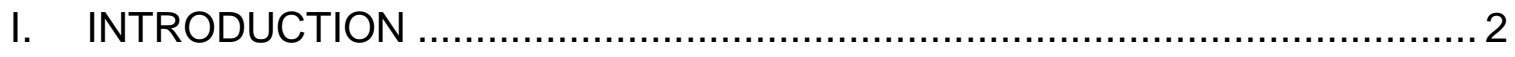

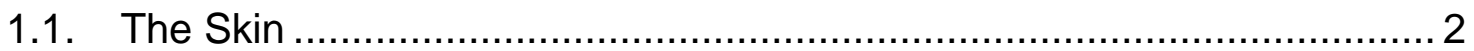

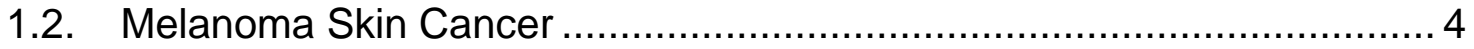

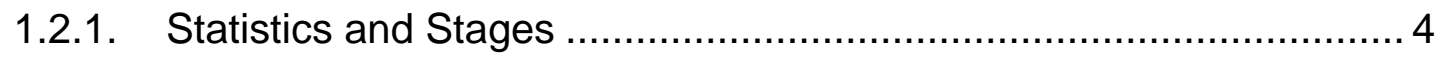

1.2.2. Genetic Factors of Melanoma .................................................... 7

1.2.3. Environmental Factors of Melanoma …......................................... 14

1.3. Melanoma and the Tumor Microenvironment ................................... 18

1.3.1. Altered Cell-Cell Communication ............................................... 19

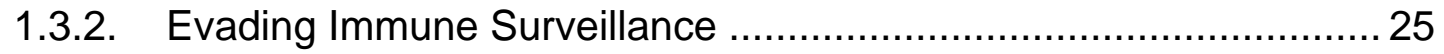

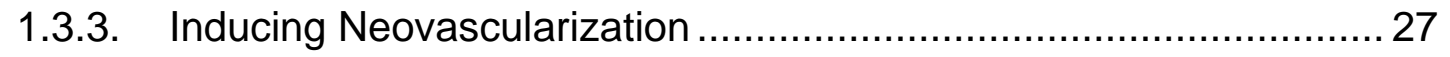

1.4. Melanoma Heterogeneity and Malignancy ...................................... 32

1.5. Melanoma and Endothelin Signaling ............................................... 36

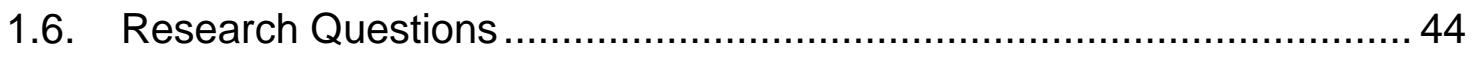

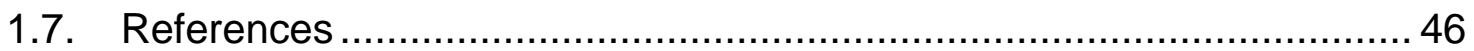

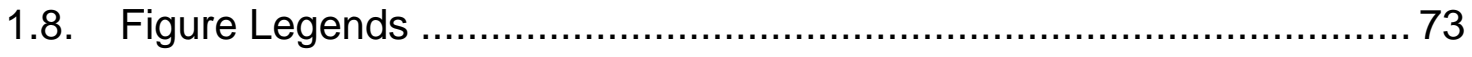

II. ENDOTHELIN SIGNALING PROMOTES TUMOR PROGRESSION AND METASTASIS IN A MOUSE MODEL OF MELANOMA .......................... 76

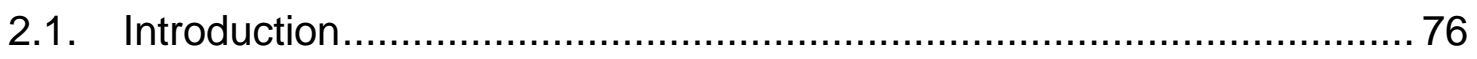

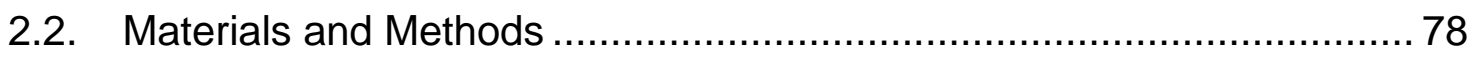

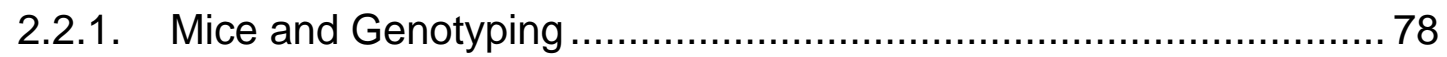

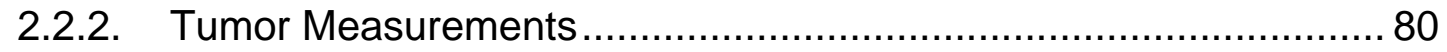

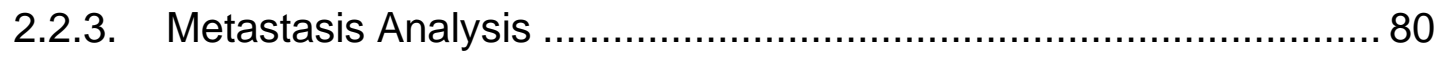

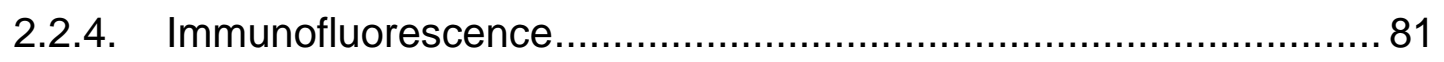

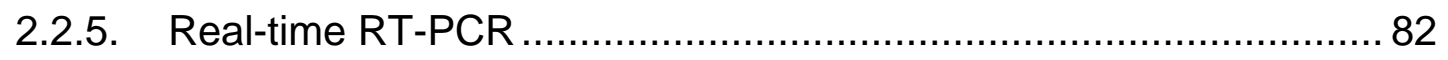

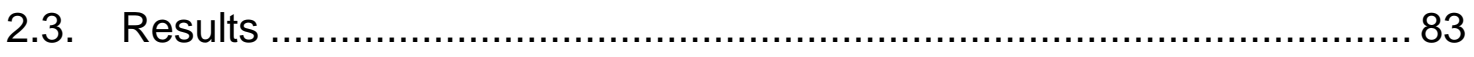

2.3.1. Edn3 Promotes Early and Rapid Melanoma Growth....................... 83

2.3.2. Edn3 Promotes the Formation of Dorsal Skin Tumors................... 84 
2.3.3. Edn3 Promotes Melanoma Metastasis to Lymph Nodes and

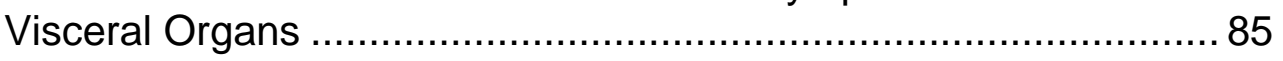

2.3.4. Edn3 Alters the Expression of Genes Involved in Metastasis ......... 86

2.3.5. EDNRB Promotes Early and Rapid Melanoma Growth, and

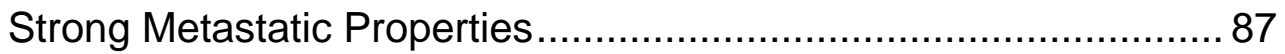

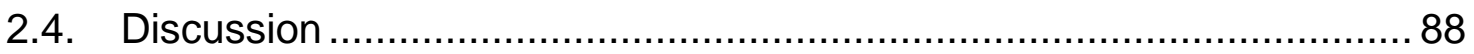

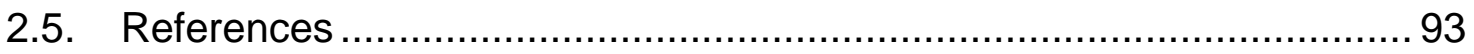

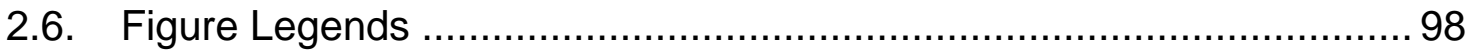

III. ENDOTHELIN 3 ENHANCES TUMOR ANGIOGENESIS IN AN EDN3 DEPENDENT MELANOMA MOUSE MODEL …............................... 113

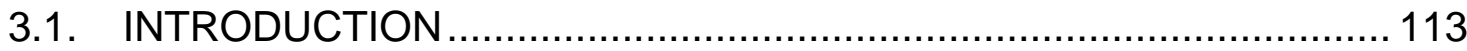

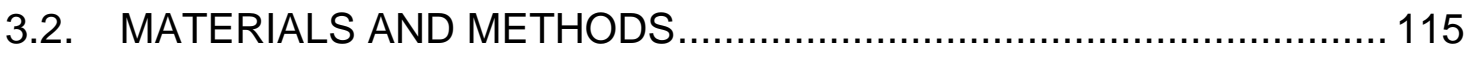

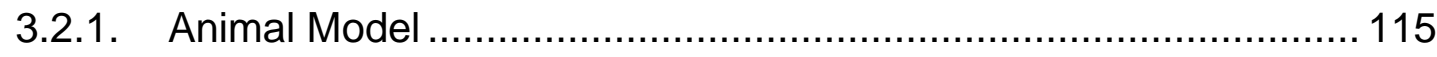

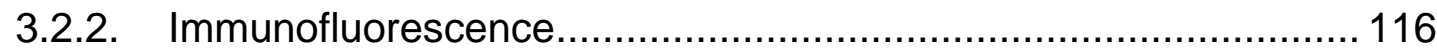

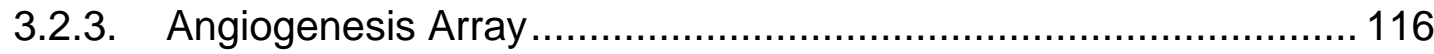

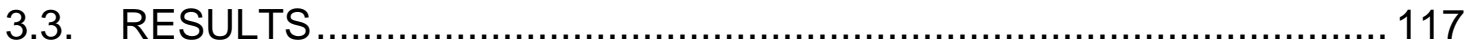

3.3.1. Edn3 Overexpression Increases the Vascular Density in Melanocytic Tumors........................................................... 117

3.3.2. Edn3 Overexpression Affects the Levels of Expression of Angiogenic Proteins........................................................... 117

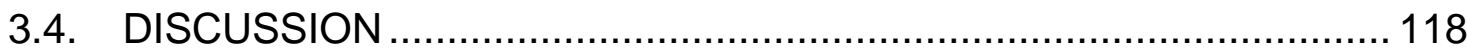

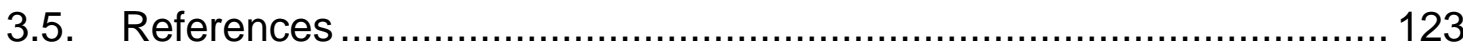

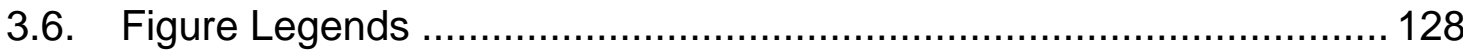

IV. CONCLUSIONS, FUTURE DIRECTIONS AND IMPLICATIONS ........... 132

4.1. Conclusions and Future Directions................................................ 132

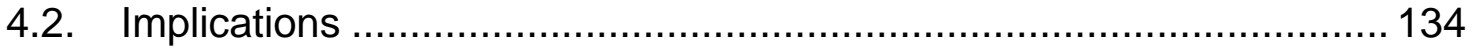

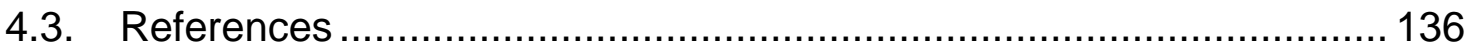

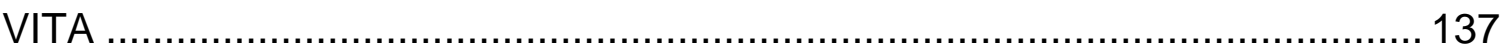




\section{LIST OF FIGURES}

FIGURE

PAGE

CHAPTER I

Figure 1: Melanoma Progression 74

Figure 2: Melanoma tumor microenvironment

CHAPTER II

Figure 1: Time to tumor appearance and tumor growth rate in Dct-Grm1/K5-Edn3 mice

Figure 2: Proliferation analysis of $D c t-G r m 1 / K 5-E d n 3$ mouse tumors 103

Figure 3: Metastatic lesions in Dct-Grm1/K5-Edn3 mice 104

Figure 4: Gene expression analysis of Dct-Grm-1/K5-Edn3 mouse tumors .. 105 Supplementary Figure 1: Tail tumor growth rate in Dct-Grm1/K5-Edn3 mice 106 Supplementary Figure 2: Dorsal tumors in Dct-Grm1/K5-Edn3 mice 106

Supplementary Figure 3: Lymph node metastasis 107

Supplementary Figure 4: Tail tumor growth rate in Dct-Grm1/Dct-Ednrb mice. 108

Supplementary Figure 5: Brain metastatic lesions in Dct-Grm1/Dct-Ednrb mice. 108

Supplementary Figure 6: Time to tumor appearance in Dct-Grm1/Dct-Ednrb mice.

Supplementary Table 1: Location of metastases found in Dct-Grm1/K5-Edn3 mice.

Supplementary Table 2: Primers used for Real-time PCR gene expression analysis 


\section{CHAPTER III}

Figure 1: Analysis of tumor vascular density in DctGrm1/K5-Edn3 mice....... 129

Figure 2: Example of angiogenic proteome profiling array ........................ 129

Figure 3: Proteome profiling of mouse angiogenic related proteins ............. 130 


\section{LIST OF ABREVIATIONS AND ACRONYMS}

$\mu \mathrm{M}$ Micrometer

64PP 6-4 photoproduct

A Adenine

$\mathrm{ACTH}$ Adrenocorticotropic hormone ARAF A-raf proto-oncogene serine/threonine protein kinase ARF Alternative reading frame $\operatorname{Arg}$ Argininine BCA Bicinchoninic acid assay BCL-2A1 B-cell lymphoma 2 related protein A1 bFGF Basic Fibroblast Growth Factor $\mathrm{BGH}$ bovine growth hormone? b-HLH-Zip Basic helix-loop-helix leucine zipper BMP Bone morphogenetic proteins Bp Base pair BRAF B-raf proto-oncogene serine/threonine protein kinase BSN Bassoon Presynaptic Cytomatrix Protein

CA California $\mathrm{Ca}^{2+}$ Calcium Ionized CAF Cancer-associated-fibroblasts

CAM Cell-cell adhesion molecule CAMP Cyclic adenosine monophosphate 
CCN ... cysteine rich protein 61 , connective tissue growth factor, Nephroblastoma Overexpressed

CD31 Cluster of differentiation 31

Cdc42 Cell division control protein 42 homolog CDK4 or Cdk4 Cyclin-dependent kinase 4 CDKN2A Cyclin-dependent kinase inhibitor 2A CDNA complimentary DNA COX-1 Cyclooxygenase 1 coX-2 Cyclooxygenase 2 CPD Cyclobutane pyrimidine dimers c-RAF1 proto-oncogene serine/threonine-protein kinase CREB ..........Cyclic adenosine monophosphate response element-binding protein CXCL1 Chemokine (C-X-C motif) ligand 1 CXCL16 Chemokine (C-X-C motif) ligand 16 CXCL2 .Chemokine (C-X-C motif) ligand 2

DAG Diacyl-glycerol DCT Dopachrome tautomerase Dil 1,1'-dioctadecyl-3,3,3',3'-tetramethylindocarbocyanine perchlorate DP Dimerization partners $\mathrm{E} 2 \mathrm{~F}$ E2F transcription factor EC Endothelial cell ECM Extracellular matrix EDN1 Endothelin 1 
EDN2 Endothelin 2

EDN3 or Edn3 Endothelin 3

EDNRA Endothelin receptor $A$ EDNRB Endothelin receptor B EMT Epithelial to mesenchymal transition Eph Ephrin ERK1 Extracellular signal-regulated protein kinases 1 ERK2 Extracellular signal-regulated protein kinases 2 FAMMM Familial atypical multiple mole melanoma syndrome FGF Fibroblast growth factor

Flk Mouse counterpart to kinase insert domain receptor Flt Fms-like tyrosine kinase-1 FVB Friend leukemia virus B G protein G-protein coupled receptors G protein Guanine nucleotide protein GAPDH Glyceraldehyde 3-phosphate dehydrogenase

Glut 1 Glucose transporter 1 GM-CSF Granulocyte macrophage colony-stimulating factor GPCR Guanine nucleotide protein coupled receptor GRM1 Glutamate receptor 1 GTPases Guanosine triphosphatases HB-EGF Heparin-binding Epidermal growth factor HGF Hepatocyte growth factor 
HIF-1a Hypoxia-inducible factor- $1 \alpha$

His Histidine

HRAS Harvey rat sarcoma viral oncogene homolog

HRE Hormone response element HRP Horseradish peroxidase

IACUC Institutional Animal Care and Use Committee IFN-Y Interferon gamma IGF-1 Insulin-like growth factor-1 IGFBP-2 Insulin-like growth factor-binding protein 2 IGFBP-3 Insulin-like growth factor-binding protein 3 IGF- $\beta$ Insulin like growth factor- $\beta$ IHC Immunohistochemistry IL-1 Interleukin 1

IL-10 Interleukin 10

IL-1 $\beta$ Interleukin $1 \beta$

IL-8 Interleukin 8

INHBA Inhibin, beta A INK4A Inhibitor of Cyclin-Dependent Kinase 4A K5 Keratin 5 KDR Kinase insert domain receptor KIT v-kit Hardy-Zuckerman 4 feline sarcoma viral oncogene homolog KRAS Kirsten rat sarcoma viral oncogene homolog Lle Isoleucine 
$\mathrm{mm}$ Millimeter

$\mathrm{mM}$ Millimolar

MMP Matrix metalloproteinases $\mathrm{MO}$ Missouri MSC Myeloid suppressor cells MXI1 MAX Interactor 1 MYC V-Myc Avian Myelocytomatosis Viral Oncogene Homolog NC Neural Crest NCC Neural Crest Cells NGF Nerve growth factor NK Natural killer NOS Nitric oxide synthases NOV Nephroblastoma Overexpressed 
NRAS Neuroblastoma RAS viral (v-ras) oncogene homolog NY New York

OCT Optimal cutting temperature

PARP-3 Poly (ADP-Ribose) Polymerase 3 PBS Phosphate buffer solution PCR Polymerase chain reaction PDGF Platelet-derived growth factor PECAM-1 Platelet endothelial cell adhesion molecule $\mathrm{PGE}_{2}$ Prostaglandin $\mathrm{E}_{2}$ $\mathrm{PH}$ Pleckstrin-homology PHD1-3 Prolyl hydroxylase domain protein 1-3 $\mathrm{PI} 3 \mathrm{~K}$ Phosphatidylinositol 3-kinase

PIGF Phosphatidylinositol-glycan biosynthesis class F protein PIP3 Phosphatidylinositol $(3,4,5)$-trisphosphate (Ptdlns(3,4,5) P 3)

PKB Protein kinase B

PKC Protein kinase C PTEN Phosphatase and tensin homolog

Rac Ras-Related C3 Botulinum Toxin Substrate 1 Raf Raf proto-oncogene serine/threonine protein kinase

RAS Rat sarcoma

$\mathrm{RB}$ Retinoblastoma RET 'Rearranged during transfection' proto oncogene RGP Radial growth phase 
$\mathrm{RHC}$ Red hair color phenotype

Rho Rhodopsin

ROS Reactive oxygen species rRNA Ribosomal ribonucleic acid RTK Receptor Tyrosine Kinase RT-PCR Real time- polymerase chain reaction

Ser Serine SF Scatter factor SNAI1 Snail family zinc finger 1 Snail1 Snail family zinc finger 1

SNAP21 Synaptosomal-Associated Protein 21 SNAP91 Synaptosomal-Associated Protein 91 SoX10 Sex determining region Y-box 10 $\mathrm{T}$ Thymine $\mathrm{Tg}$ Transgene TGF- $\beta$ Transforming growth factor beta TKO Triple knockout mutant mice

TME Tumor microenvironment TNF- $\alpha$ Tumor necrosis factor $\alpha$

Trp Tryptophan TRP-1 Tyrosinase related protein 1 TSC Tumor stem cell tTA Tetracycline-sensitive transcriptional activator 
t-test Test Statistic as per Student's t distribution Tyr Tyrosinase UPA Urokinase plasminogen activator UPAR Urokinase plasminogen activator receptor UV Ultraviolet UVA Ultraviolet radiation $\mathrm{A}$

UVB Ultraviolet radiation $\mathrm{B}$ UVC Ultraviolet radiation C Val Valine VE cadherin Vascular endothelial cadherin VEGF or Vegf Vascular endothelial growth factor VEGFB Vascular endothelial growth factor B VEGFC Vascular endothelial growth factor C VEGFD Vascular endothelial growth factor D VEGFR-1 Vascular endothelial growth factor receptor type 1 VEGFR-2 Vascular endothelial growth factor receptor type 2 VEGFR-3 Vascular endothelial growth factor 3 VGP Vertical growth phase VM Vascular mimicry vs versus WNT Wingless-type MMTV integration site family ZEB1 Zinc finger E-box-binding homeobox 1 $\alpha$ Alpha 
CHAPTER I

INTRODUCTION 


\section{INTRODUCTION}

\subsection{The Skin}

It is not unforeseen that skin cancer is the most prevalent of all human cancers, affecting approximately 1 million people in the United States each year, taking into consideration that the skin is the largest organ of the body. The skin forms the primary protective external barrier against foreign invaders and ultraviolet radiation (UV). There are three primary layers of the skin, the epidermis, the dermis with the basement membrane situated in between both, and the hypodermis or subcutis which is the deepest layer. Skin cancers develop primarily in the cells of the epidermis.

The epidermis is the outermost layer and thus the first level of protection. In the human skin this layer is $\sim 0.1-0.2 \mathrm{~mm}$ thick and consists of 5 separate strata. From outermost to innermost the sections are the stratum corneum, the stratum lucidum, the stratum granulosum, the stratum spinosum and the stratum basale. The four major types of cells found in the epidermal layer are keratinocytes, melanocytes, Merkel cells and Langerhans cells. Langerhans are antigen presenting immune cells found mainly in the stratum spinosum, while Merkel cells are receptor cells found in the stratum basal and are thought to be involved in somatosensory effects.

Keratinocytes are the most abundant type of cell in the epidermis. These cells begin as germinal cells in the stratum basal. Each of the other strata of the epidermis contain different maturation stages of the keratinocytes as they undergo cornification. Cornification is the process whereby these cells produce 
the fibrous structural protein, keratin. As the cells accumulate keratin, the organelles and nuclei are lost, finally generating a protective layer of dead cells filled with keratin in the stratum corneum layer.

Melanocytes are the dendritic pigment producing cells of the body that are responsible for the actual skin color phenotype in human beings ${ }^{1}$. Embedded in the epidermal-dermal junction of the skin, melanocytes execute a complex process of synthesizing and storing the pigment melanin in lysosome related organelles called melanosomes ${ }^{2}$. Melanocytes produce two types of pigment, eumelanin which is brownish-black in color and pheomelanin which is reddishyellow.

Melanosomes travel to the dendritic tips of the melanocytes where they are then released into the intercellular space, allowing endocytosis and phagocytosis of the melanosomes by the keratinocytes ${ }^{2-5}$. The melanin forms a cap over the nuclei of the keratinocytes, and protects the DNA from harmful UV by absorbing UVA (320-400nm) and UVB (260-320nm) rays ${ }^{4,5}$. One melanocyte distributes melanosomes to approximately 36 keratinocytes making up an 'epidermal melanin unit' ${ }^{4}$. This ratio of melanocytes to keratinocytes remains stable. Although keratinocytes have a high rate of growth and proliferation in the skin, melanocyte proliferation is strictly controlled by the keratinocytes. When melanocytes were co cultured with undifferentiated keratinocytes, the melanocytes were nonproliferative, however when the melanocytes were cultured with differentiated keratinocytes melanocytes proliferated at rates matching the keratinocytes and developed multiple dendrites ${ }^{6}$. During the few times melanocytes need to divide, the melanocyte 
has to first detach from the basement membrane and keratinocytes and retract their dendrites before being able to proliferate. Afterwards, the melanocytes must adhere once again to the matrix and establish reconnection with the keratinocytes ${ }^{4}$. Cross-talk between melanocytes and keratinocytes is multifaceted involving a number of keratinocyte derived factors such as hepatocyte growth factor (HGF), basic fibroblast growth factor (bFGF), prostaglandins and steel factor/KIT ligand ${ }^{7,8}$. This communication is very important in maintaining proper melanin production, and protection from UV damage. Dysregulation of any of these mechanisms can lead to various skin cancers, the most aggressive and terminal one being melanoma resulting from transformation of melanocytes.

\subsection{Melanoma Skin Cancer}

\subsubsection{Statistics and Stages}

Melanoma comprises less than $2 \%$ of all skin cancer cases, however it is responsible for most of the deaths caused by skin cancer. There have been reports that melanoma incidence has been considerably increasing over the past thirty years ${ }^{9,10}$. The American Cancer Society estimated that in 2015 approximately 74,000 individuals will be diagnosed with melanoma, about 43,000 of those diagnosed will be in men and 31,000 of those will be women. Although the risk of melanoma increases with age, it is one of the most common cancers seen in young adults ${ }^{11}$. There are several common elements that increase the lifetime risk of an individual being diagnosed with melanoma, the first, possessing acquired atypical moles/dysplastic nevi. Atypical moles are pigmented lesions that are usually benign, however if the moles change shape, color or size, they 
may be potential sites of melanoma ${ }^{12,13}$. The second risk is known as 'familial atypical multiple mole melanoma syndrome (FAMMM). This condition is inherited and is assessed when an individual has a number of dysplastic nevi and a least one family member that has had melanoma ${ }^{14,15}$. Hereditary melanoma accounts for about $10 \%$ of melanoma cases ${ }^{15}$. The third high risk element is 'phototype', an individual's skin color and proneness to $\tan ^{16}$. Caucasians are more than 20 times more likely to get melanoma than blacks ${ }^{9,17}$. Furthermore individuals with mutations in the melanocortin 1 receptor (MC1R) with very fair skin, red hair and light eyes are most at risk for acquiring melanoma ${ }^{18}$. The $\mathrm{MC} 1 \mathrm{R}$ receptor is a seven transmembrane G-protein coupled receptor found on the plasma membrane of melanocytes. Stimulation of MC1R by its ligand a-melanocyte stimulating hormone $(\mathrm{\alpha}-\mathrm{MSH})$ or other agonist adrenocorticotropic hormone (ACTH) by keratinocytes in response to UV, induces adenyl cyclase to produce cyclic AMP (CAMP) ${ }^{19,20}$. The increase in cAMP levels in turn phosphorylates and activates the cAMP responsive element binding protein (CREB) family of transcription factors. One important target of CREB is microphthalmia transcription factor (MITF), a basic helix-loop-helix leucine zipper (b-HLH-Zip) transcription regulator for genes encoding enzymes involved in melanin synthesis such as tyrosinase, Dopachrome tautomerase (DCT) and tyrosinase-related protein-1 (TRP-1) ${ }^{20-24}$.

The $M C 1 R$ gene is a major gene responsible for pigmentation phenotype 25. There are a number of polymorphisms and allelic variants of the gene leading to differences in skin color and phototype in humans ${ }^{26,27}$. The $M C 1 R$ variants 
R151C, R160W and D294H are linked to the 'red hair color phenotype' (RHC) ${ }^{28-}$ 30. These single amino acid substitutions results in mutants unable to bind or activate adenyl cyclase which results in an increase in pheomelanin synthesis, which is more cytotoxic and less protective from irradiation than eumelanin ${ }^{27-30}$.

The first stage of cutaneous melanoma is the common acquired and congenital nevi. This stage does not normally show any dysplastic changes ${ }^{31,32}$. The second stage is the formation of dysplastic nevi ${ }^{31-33}$. Dysplastic nevi have progressed to acquiring structural and architectural atypia. The radial growth phase (RGP) is the first malignant stage. At this stage the abnormal melanocytes start to spread laterally, but still remain close to the epidermis ${ }^{31-34}$. Although the tumor cells are locally invasive, they are not yet undergoing rapid growth. The RGP cells are still controlled by the exogenous growth factors of the keratinocytes. In the vertical growth phase (VGP) the melanoma cells are highly tumorigenic and clinically dangerous ${ }^{31-34}$. The tumor cells have gained metastatic potential and are now found in the basement membrane. The cells continue to invade both the upper and lower layer of the epidermis and dermis. The tumor cells in the area mostly form clusters of cells, with few cells breaking off and forming isolated regions. This stage of melanoma usually has poor clinical outcome, as the VGP melanomas increase their vascularization enabling them for the fifth stage ${ }^{31-34}$. At the metastasis stage the VGP cells are now completely free from keratinocyte signals, and have formed new interactions with other cells such as fibroblasts. The VGP's now proliferate rapidly, overcoming anchorage constraints. The VGP's are able to disperse to other organs in the 
body ${ }^{31-34}$. It is important to note that these steps in melanomagenesis do not always occur sequentially. Malignancy may occur from melanocytes that do not go through the nevus stage ${ }^{32}$. Melanomagenesis is triggered by a combination of key genetic factors, UV- exposure and the tumor microenvironment.

\subsubsection{Genetic Factors of Melanoma}

The cyclin dependent kinase inhibitor 2A (CDKN2A) gene located on the 9p21 locus has been generally accepted as a familial melanoma susceptibility gene ${ }^{33,35-37}$. Several linkage and meta- analysis studies have identified loss of heterozygosity and germline mutations of CDKN2A in families with two or more individuals that were diagnosed with melanoma $36,38,39$. Approximately $25-40 \%$ of melanoma prone families exhibit INK4A mutations, however $\sim 0.2-2 \%$ of individuals with sporadic melanoma have also been found to possess mutations in the gene ${ }^{40}$. The CDKN2A gene encodes two tumor suppressor proteins, Inhibitor of cyclin dependent kinase $4($ INK4A/p16 INK4A $)$ and the Alternative reading frame product (ARF/p14 $\left.{ }^{\mathrm{ARF}}\right)\left(\mathrm{p} 19^{\mathrm{ARF}}\right.$ in mice) using two different promoters, $1 \alpha$ and $1 \beta$ for INK4A and ARF, respectively, as well as different first exons. The two alternative transcripts share exons 2 and 3 , however the open reading frames in exon 2 are distinct for INK4A and ARF resulting in the translation of two proteins with no common amino acid homology ${ }^{41-43}$.

The protein INK4A inhibits cyclin dependent kinase 4 , a regulator of cell cycle progression utilizing retinoblastoma protein (RB). RB is a tumor suppressor protein that binds to and obstructs transcription factors of the E2F family. 
The E2F proteins along with their dimerization partners (DP) drive the cell cycle into the S phase. When RB binds to E2F forming a RB-E2F/DP complex, it inhibits excessive cell growth by resting the cell cycle in the G1 phase. When cell division needs to proceed, RB is hyper-phosphorylated by CDK4 which renders RB unable to bind to E2F and thus allowing the cell cycle to progress form $\mathrm{G} 1$ to the $\mathrm{S}$ phase. The INK4A gene is therefore a negative regulator of cell cycle progression as it blocks CDK4 from phosphorylating RB to induce cell division.

The importance of the INK4A/CDK4/RB- pathway is further evidenced by the finding of germline mutations for CDK4 in familial melanoma ${ }^{44-47}$. Alterations of CDK4 are attributed to Arg24Cys or Arg24His mutations that prevent inactivation of CDK4 by INK4A ${ }^{48}$. The CDK4 mutations are not paired with somatic INK4a activation, but both mutations can give rise to melanomas with similar incidence and progression mutually exclusive of each other ${ }^{49}$. Sotillo et al. (2001) reported that mice with a targeted 'knock in' mutation of Cdk4 developed melanomas after exposure to carcinogens ${ }^{50}$.

A number of familial melanoma cases ${ }^{51}$, metastatic cell lines ${ }^{52}$, as well as germline and sporadic deletions or mutations of $1 \beta$ in the ARF coding sequence have been presented. These mutations of $p 14^{A R F}$ are exclusive from INK4A mutations, suggesting an independent role for $\mathrm{p} 14^{\mathrm{ARF}}$ in melanomagenesis. Although in mice Ink4a deficiency results in the development of tumors ${ }^{53}$, when p14 ${ }^{A R F}$ haploinsufficiency was combined, the tumor phenotype was heightened ${ }^{53,54}$. 
In response to an increase in aberrant mitogenic and oncogenic signals p14 ${ }^{\mathrm{ARF}}$ acts as an important tumor suppressor ${ }^{55}$. Overexpression of mitogens MYC and RAS stimulate the increase in $p 14^{A R F}$ transcription and its accumulation in the nucleus where p14 ${ }^{A R F}$ binds to and inhibits MDM2, a ubiquitin ligase of $p 53^{56,57}$. Binding of $p 14^{\mathrm{ARF}}$ to MDM2 allows $\mathrm{p} 53$ to trigger cell growth arrest and apoptosis ${ }^{57,58}$. Loss of p14 ${ }^{\mathrm{ARF}}$ function results in an increase in MDM2 and a concomitant loss of p53 mediated cell cycle control, resulting in cancer progression. The $\mathrm{p} 14^{\mathrm{ARF}}$ protein can also inhibit proliferation independently of p53 by binding to nucleophosmin/B23, a ribosomal chaperone protein that prevents rRNA processing ${ }^{59}$. Triple 'knockout' mutant mice (TKO) nullizygous for rf p53 and Mdm2 acquired tumors significantly more than mice lacking only p53 or $p 53$ and Mdm2. When ARF was restored in TKO embryo fibroblasts, Weber and colleagues found that ARF could arrest the cell cycle in the absence of MDM2, thus confirming that ARF can act through other mechanisms for cell cycle control ${ }^{60}$.

Although mutations within the coding region of $p 53$ (Tp53) are often associated with most cancers, often p53 is not modified directly in human and murine melanomas. The mutation and subsequent targeted loss of $\mathrm{p} 14^{\mathrm{ARF}}$ in melanoma may be the means for the p53 pathway to be disrupted.

Recently a link between the $C D N K 2 A$ locus and MC1R has been established. A study on Australian families with individuals diagnosed with melanoma with CDKN2A mutations by Box and colleagues (2001) discovered that if a single MC1R polymorphism was present, the raw penetrance of the 
CDKN2A mutation would significantly increase as well as earlier onset ${ }^{61}$. van der Velden and colleagues (2001) also studied Dutch families with FAMM, and described that the number of MC1R mutations in the individuals with CDNK2A mutations increased melanoma penetrance ${ }^{62}$. The MC1R mutations can therefore act as modifiers of melanoma susceptibility in individuals with CDKN2A mutations.

Over activation of the receptor tyrosine kinase (RTK) pathway, especially that involving one of its most important mediators, the mitogen activated protein kinase (MAPK) pathway is identified in a number of cancers including melanoma 63. Receptor tyrosine kinase ligand binding activates the RAS family of GTPases (NRAS, HRAS, and KRAS). The protein RAS then activates the Raf family of serine threonine specific protein kinases (BRAF, ARAF and c-RAF1) which regulates the MAPK pathway to phosphorylate and activate extracellular signal regulated kinases 1 and 2 (ERK1 and ERK2) to promote transcription of genes participating in cell growth, differentiation, migration and senescence ${ }^{64,65}$. The majority of the BRAF constitutively active proto oncogene mutations, have been identified as a point mutation (T1799A), a T-A transversion (converts valine to glutamic acid) that encodes BRAF ${ }^{\mathrm{V} 600 \mathrm{E}}{ }^{66-71}$. Davies and colleagues (2002) genome wide cancer screening discovered activating BRAF mutations in approximately $60 \%$ of somatic melanoma cases ${ }^{68}$. Poynter and colleagues (2006) found the highest incidence of BRAF mutations in nevi (82\%), followed by invasive melanomas (29\%) with the least being in in-situ melanoma (5.6\%) ${ }^{72}$. Mutation analysis on melanoma and nevi samples by Pollock and colleagues 
(2003) as well as sequence analysis by Kumar and colleagues (2004) also detected BRAF mutations occurring mostly in benign or dysplastic nevi, thus suggesting that BRAF may be important in early transformation of melanocytes but other mechanisms may be necessary for complete melanoma progression ${ }^{73,74}$. Supporting this view are findings from Patton and colleagues (2005) that created a transgenic BRAF ${ }^{\mathrm{V} 600 \mathrm{E}}$ mutant expressing zebrafish model. The fish acquired patches of ectopic melanocytes which only became invasive melanomas after the activated BRAF ${ }^{\mathrm{V} 600 \mathrm{E}}$ was paired with p53 deficiency ${ }^{75}$.

The BRAF ${ }^{\mathrm{V} 600 \mathrm{E}}$ mutations occurrence in cutaneous melanomas have been correlated with UV exposure. Studies by Maldonado and colleagues (2003) and Curtin and colleagues (2005) examined cutaneous melanomas from different groups with different degrees of exposure to UV for alterations in BRAF. Both groups found that BRAF mutations were more common in melanomas that arose from skin exposed to intermittent high intensity UV exposure with very few BRAF mutations associated with melanomas from limited sun exposure such as mucosal melanomas and ones on the palms or soles of feet ${ }^{66,76}$. Although this would suggest a causal link for BRAF mutations by UV, the relationship is not as simple, as both groups also found that BRAF mutations were also rare in melanomas arising from chronic exposure to UV ${ }^{66,76}$. It has been suggested that BRAF mutations may be a result of cytotoxic, oxidizing or inflammatory response associated with intense sunlight exposure as opposed to being directly induced by UV ${ }^{77}$. 
Unlike BRAF mutations in melanoma NRAS mutations have been shown to manifest as a result of UV exposure. van Elsas and colleagues (1996) detected NRAS mutations in $26 \%$ of paraffin embedded DNA from melanoma samples exposed to chronic sunlight, with no NRAS mutations found in sun protected melanomas. The NRAS mutations occurred more frequently in individuals from the high sun exposed area, Australia, than individuals from North or Central Europe ${ }^{78}$. The NRAS point mutations are rarely found in dysplastic nevi, but are found in most stages of melanoma including congenital nevi, primary melanomas and metastatic melanoma indicating a progressive type role for NRAS in melanomagenesis ${ }^{78-81}$. The HRAS and KRAS mutations are seldom seen in melanoma ${ }^{69,72,78,81}$. In transgenic mice Hras mutations on an Ink4a deficient background developed non metastatic melanomas, however Nras mutations on a Ink4a deficient background led to those transgenic mice developing spontaneous cutaneous melanomas with high penetrance ${ }^{82,83}$. More studies are needed to fully understand the importance of RAS and RAF signaling in melanoma.

Hyperactivity of the phosphatidylinositol 3-kinase (PI3K)-AKT pathway is a common event in melanomagensis. Dai and colleagues (2005) examining phospho-Akt (p-Akt; Ser-473) in melanocytic lesions at different stages of progression found phospho-Akt expression increased as melanocytic lesions became more aggressive. Patient survival was also inversely correlated to pAKt expression ${ }^{84}$. The (PI3K)-AKT pathway can be activated by RTK's, RAS proteins, integrins or G-protein coupled receptors. Activation leads to production 
of phosphatidylinositol $(3,4,5)$ trisphosphates (PIP3), which serve as docking sites for other proteins with pleckstrin-homology $(\mathrm{PH})$ domains to phosphorylate the chief effector of the PI3K pathway, protein kinase B (PKB) also known as AKT ${ }^{85-87}$. AKT phosphorylates targets that can initiate or inhibit cell growth, proliferation, survival and migration $85,88,89,89$. Loss of heterozygosity (LOH) or mutations of the tumor suppressor phosphate and tensin homolog (PTEN) is perhaps the most studied regulator of PIP3 in melanoma ${ }^{84,89-92}$. The protein PTEN acts as a negative regulator of the PIP3 pathway, thus it is often found mutated in a number of cancers ${ }^{86,88,90,91}$. Expression analysis studies show LOH of the PTEN and MYC antagonist MXI1 locus 10q24 develops in about 50\% of sporadic melanomas ${ }^{88,92-95}$. Tsao and colleagues (2004) using mutated cell lines demonstrated BRAF activated mutations in conjunction with PTEN loss contribute to melanomagenesis ${ }^{96}$. Dankort and colleagues (2009) corroborated this phenomenon as their genetic altered mice expressing Braf ${ }^{\mathrm{V} 600 \mathrm{E}}$ only developed few metastatic melanoma lesions. However when the Braf ${ }^{\vee 600 E}$ mutation was combined with PTEN tumor suppressor gene silencing, the melanomas became $100 \%$ penetrant with short latency and formed distant metastatic lesions ${ }^{67}$. The aggressive nature of melanomas is in part due to the major mutations in these important tumor suppressor regulatory pathways. The intricacy of these pathways makes finding very effective therapeutic regimes targeting one of these players whether BRAF, PTEN, and others difficult. 


\subsubsection{Environmental Factors of Melanoma}

Ultraviolet radiation is the most well-known, although not fully characterized, epidemiological factor for melanoma. Sunlight is divided into three Ultraviolet light spectrum regions, UVA (320-400nm), UVB (290-320nm) and UVC (200-290nm). Ultraviolet light in the C spectrum (UVC) is absorbed completely by the ozone with no effect on terrestrial life, however both Ultraviolet light in the A spectrum (UVA) and Ultraviolet light in the B (UVB) spectrum reach Earth. Ultraviolet B rays are short wavelengths of light and are deemed to be more carcinogenic as they are able to damage DNA in two different ways; either by causing cyclobutane pyrimidine dimers (CPD's) between adjacent thymine or cytosine residues, or forming 6-pyrimidine-4-pyrimidone photoproducts (64PP). These abnormalities create specific DNA mutations (C to T and CC to TT) ${ }^{97-100 .}$ Ultraviolet light in the A spectrum are longer wavelengths and although they penetrate deeper into the skin than UVB rays, they mutate DNA indirectly, by creating reactive oxygen species (ROS) ${ }^{101,102}$. The impact of UV mediated effects working with genetic factors to induce melanoma was demonstrated by Kannan and colleagues (2003) with murine melanoma mouse models with HRAS activation and p19ARF loss. UV exposed Tyr-RAS p19ARF-/- mice developed more melanocytic lesions with significantly shorter latency than Tyr-RAS p19ARF-- mice not exposed to UV. Approximately, 50\% of the tumors in the Tyr-RAS p19ARF-/UV exposed mice also had amplification of cyclin dependent 6 (cdk6) implicating a UV induced mutagenic effect involving the Rb pathway ${ }^{103}$. Benaduce and colleagues (2014) using mice that overexpress EDN3 under the Keratin 5 
promoter (K5-tTA; TRE-Edn3-lacZ) and XPA deficiency $\left(\mathrm{Xpa}^{-/-}\right.$or $\left.\mathrm{Xpa}^{+/-}\right)$, showed that a single neonatal dose of UV radiation, was sufficient to induce melanomagenesis in mice constitutively over expressing End3, independent of XPA deficiency ${ }^{104}$. Xpa ${ }^{-/-}$mice over expressing EDN3 however, displayed significantly higher penetrance and shorter tumor free survival than $\mathrm{Xpa}^{+/-}$mice also over expressing EDN3 ${ }^{104}$. The K5-tTA; TRE-Edn3-lacZ mice have an increased number of melanocytes in the epidermal-dermal junction which closely resembles their placement in the human skin, unlike wild type mice whose melanocytes are confined to the hair follicles. Therefore, it is still unknown whether it is the presence of EDN3 in the microenvironement or the location of the melanocytes that permits melanomagenesis upon UV exposure ${ }^{104}$. Melanin's photo-protective mechanism involves the absorption of UV photons that can otherwise be damaging to DNA, and the absorption of free radical species generated as a result of UV exposure that can cause oxidative stress and a cytotoxic environment ${ }^{97}$. In addition to these mechanisms, UV photons can directly cleave diacylglycerol (DAG) that activates the PKC pathway to increase melanin synthesis.

Epidemiological data such as the pooled data analysis conducted by Chang and colleagues (2009) find strong positive correlation between intense intermittent UV exposure and the risk of developing melanoma ${ }^{102,105-108}$. Berking and colleagues (2001 and 2004) demonstrated this link using both 'in vivo' and 'in vitro' experiments that UVB radiation was necessary in addition to the expression of growth factors basic Fibroblast Growth Factor ( bFGF), Kit ligand 
(SCF/KITL) and endothelin to fully transform melanocytes to metastatic melanomas ${ }^{109} 110$. A meta-analysis by Whiteman and colleagues (2001) found that sun exposure in children posed a greater risk for developing melanoma than sun exposure in adulthood. Noonan and colleagues (2001) investigated the correlation between the age of UV exposure and melanoma risk by creating transgenic mice overexpressing Hepatocyte growth factor/scatter factor (HGF/SF) under the metallothionein promoter ${ }^{111}$. The HGF/SF ligand binds to the receptor tyrosinse kinase MET receptor located on epithelial cells and melanocytes ${ }^{112-116}$. The HGF/SF protein is normally secreted by mesenchymal cells in the skin where it promotes activation of mitogenic and morphogenic signals for epithelial cells ${ }^{112,114-118}$. In melanoma an autocrine signaling loop of HGF/SF/Met promoting melanocyte proliferation and migration has been identified in several studies ${ }^{113,119}$. Upregulation of HGF/SF ${ }^{112}$ and gain of function mutations of Met had been linked to mutations in melanoma ${ }^{118,120}$. The HGF/SF transgenic mice possess melanocytes located in the epidermal-dermal junction which more closely resembles the human skin phenotype as murine melanocytes are normally confined to the hair follicles ${ }^{111}$. Noonan and colleagues (2001) found that a single neonatal dose of UV radiation, 30 fold lower than that given in adult mice was sufficient to induce malignant melanomas with short latency, thus providing evidence that avoiding UV exposure in childhood is more important in preventing melanoma ${ }^{111}$.

Some studies negate the positive relationship between childhood UV exposure and melanoma ${ }^{98}$. Pfahlberg and colleagues (2001) contradicted these 
findings as their study on several melanoma case studies in Europe compiled with the history of sunburns in childhood and adulthood related to the cases, did not find a similar gradient for melanoma risk between childhood sunburns and those in adulthood. They did however find that more than five sunburns in life doubled the melanoma risk despite them being childhood or adulthood ${ }^{121,122}$. Whiteman and his group (2001) reviewing both case type studies and ecological studies that differed in this stance, stated that the way in which sun exposure was measured led to the contradictory findings and that it appears that the ecological type analysis studies were better and provided better quality evidence to support the importance of the threat of childhood sunburns ${ }^{123}$.

Another relationship between UV and melanoma that still needs to be examined further is the speculation as to whether UVB or UVA differ in the effect in causing DNA damage and inducing melanoma ${ }^{124}$. There is some evidence to suggest the importance of UVB as highly tumor initiating. Probing this phenomena Fabo and colleagues (2004) irradiated HGF/SF transgenic mice with either UVA, UVB or combined wavebands of radiation. The HGF/SF mice irradiated with UVB acquired cutaneous malignant melanomas more readily and efficiently than the HGF/SF transgenic mice exposed to just UVA ${ }^{124}$. Human newborn skin grafted onto 158Rag-1 transgenic mice also acquired melanocytic lesions when exposed to chronic UVB radiation regardless of application of the tumor initiating carcinogen DMBA ${ }^{105}$.

The tanning response in humans is a complex combined effect stemming from an increase in melanin production directed by melanocytes and mediated by 
keratinocytes, fibroblasts, neurons and mast cells in the immediate environment ${ }^{97,125}$. These cells in response to UV stress increase the production and release of various paracrine factors including bFGF, nerve growth factor (NGF), a-MSH, and endothelin1 (Edn1). Other factors such as inflammatory responses trigger receptors on the melanocyte to promote melanin synthesis, dendricity as well as survival and proliferation of the cells ${ }^{97,99,126}$. Thus the tumor microenvironment (TME) is instrumental in inducing changes to transformed melanocytes.

\subsection{Melanoma and the Tumor Microenvironment}

The importance of the TME in melanoma progression becomes very clear, considering that when melanoma cells are removed and placed into cultures, they become increasingly vulnerable to targets or treatments. This behavior differs remarkably from when these cells are in their TME in patients where they are highly resistant to therapeutic regimens. The TME refers to the extracellular matrix $(E C M)$ and the cellular environment in which the tumor is situated. The tumor milieu consists of, but not limited to, blood vessels, endothelial cells, pericytes, immune cells, fibroblasts and the surrounding ECM. The tumor and host environment are constantly communicating via a number of paracrine signals to promote tumor escape from the host immune system, formation of new vasculature and tumor heterogeneity which all facilitate growth, proliferation survival and migration of tumorigenic cells. The tumor host environment is primarily initiated by the tumorigenic cell, which then causes subsequent mutations and modifications in nearby cell types to promote malignancy, a 
process known as co-opting. Cancer cells must circumvent restrictions and environmental pressures in their environment, so that they can grow, survive, and metastasize ${ }^{127,128}$. Microenvironmental pressures include lack of oxygen or nutrients, low $\mathrm{pH}$, reactive oxygen species, and the inflammatory immune response of the body, all of which contributes to metastasis initiation and an increase in malignancy as the tumorigenic cells that can overcome these challenges end up being selected for and contribute to the aggressive phenotype 127. Melanomagenesis occurs not only because of an accumulation of genetic alterations, but also because of a complex coordinated network of events involving keratinocytes, fibroblasts, endothelial cells, pericytes and infiltrating immunocytes.

\subsubsection{Altered Cell-Cell Communication}

The first critical event in melanomagenesis that transforms and shapes the tumor microenvironment involves the severance of the symbiotic relationship between keratinocytes and melanocytes. The separation allows melanocytes to undergo an epithelial to mesenchymal transition (EMT). The EMT is the process by which epithelial cells undergo morphological and molecular changes that cause the cells to lose their polarity and cell-cell adhesion to gain migratory and invasive plasticity associated with mesenchyme ${ }^{127,129,130}$. The EMT normally occurs at different stages of embryonic development, but is induced again by cancer cells with the intention to surmount the constraints of the microenvironment. To facilitate EMT various signaling pathways such as

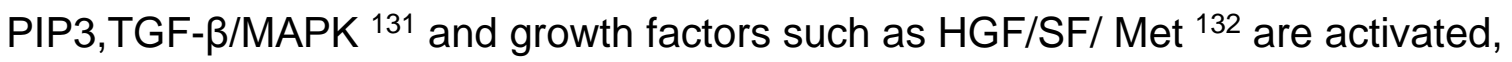


as well as changes in the expression of cell-cell adhesion molecules (CAMs) such as cadherins and integrins ${ }^{128}$.

Keratinocyte governance over melanocytes is principally maintained by contact-mediated regulatory mechanisms ${ }^{133}$. Melanocytes adhere to, and communicate with keratinocytes via Epithelial cadherin (E-cadherin) and desmoglein, both of which are expressed on the cell membranes of keratinocytes and melanocytes ${ }^{134,135}$. Co-culture experiments substantiate the control keratinocytes have on melanocyte behavior and phenotype. In mono-culture melanocytes are able to profusely proliferate, can exhibit bi-polar or tri-polar morphology unlike their normal multi dendritic morphology and begin to express proteases, growth factor receptors and melanoma associated antigens (MAA) that are not expressed by melanocytes 'in vivo' 6,136,137. The protein E-cadherin is expressed by melanocytes but not melanoma cells ${ }^{134,138}$. Danen and colleagues (1996) conducted flow cytometry experiments with normal and melanoma cell lines and immunohistochemistry on frozen sections of melanoma lesions, found E-cadherin expression only on normal melanocytes and naevus cells but none on invasive metastatic melanoma cell lines ${ }^{139}$. Thus transformed melanocytes have to liberate themselves from keratinocyte-melanocyte adhesions by downregulating E-cadherin during malignancy ${ }^{134}$. Studies by Hsu and colleagues (2000) showed that when E-cadherin expression was functionally restored to melanoma cells by gene transfer techniques, a normal melanocyte phenotype was re-established and invasion related antigens were downregulated 133,140,141. Cytogenic and molecular analysis do not detect mutations, methylation or 
deletions in E-cadherin during melanomagenesis suggesting that downregulation of E-cadherin may a result of the effects of growth factors ${ }^{142,143}$. Because HGF/SF/ MET signaling stimulates the proliferation and motility of melanocytes 144 and Met expression is found in melanoma ${ }^{145}, \mathrm{Li}$ and colleagues (2001) examined the effect of HGF/ MET on melanocyte transformation by inducing autocrine activation of HGF using an HGF-expressing adenovirus. The autocrine HGF signaling resulted in downregulation of both E-cadherin and desmoglein 1, promoting proliferation and invasiveness of the tumorigenic cells ${ }^{146}$. The downregulation of E-cadherin therefore involves cross talk between melanoma cells and HGF/ MET expressing cells such as fibroblasts. In addition to HGF, studies also show that the Snail family of transcription factors that repress Ecadherin during embryonic EMT are also expressed and directly correlate to the loss of E-cadherin in melanoma ${ }^{143,147}$. Moreover, Schneider and colleagues reported that UV-radiation of keratinocytes could induce paracrine release of EDN1, which can reduce E-cadherin expression in melanocytes ${ }^{148}$. In melanomas, down regulation of E-cadherin is concurrent with an increase in the mesenchymal protein neural cadherin ( $\mathrm{N}$-cadherin) ${ }^{146,149}$.

The $\mathrm{N}$-cadherin protein is normally expressed on endothelial, neuronal, and muscle cells as well as fibroblasts and endothelial cells ${ }^{150}$. The switch in cadherin expression from E-cadherin to $\mathrm{N}$-cadherin on melanoma cells alters the binding partners of the transformed melanocytes from keratinocytes to fibroblasts- and endothelial cells allowing the tumorigenic cells to now communicate with these other cell types to prompt changes in the 
microenvironment and incorporate and co-opt them as parts of the tumor, leading to tumor heterogeneity ${ }^{150}$. Wide global gene analysis techniques have demonstrated that aggressive melanoma cell lines express a number of factors that are affiliated with multiple cellular phenotypes such as fibroblasts, endothelial cells, and immune cells ${ }^{151-154}$. More importantly the transformed melanocytes can now respond to mitogenic signals and proliferate without the constraints of the keratinocytes and the upregulation of $\mathrm{N}$-cadherin in melanoma lesions confers a fibroblastic phenotype making the cells more motile and invasive than normal melanocytes ${ }^{149}$.

Additionally, transformed melanocytes display an upregulation of several integrins such as $\alpha_{v} \beta_{3}$ along with the cadherin switch to change intercellular signaling in the tumor microenvironment, as cadherins and integrins can regulate RTK signaling ${ }^{155-157}$, $\beta$-catenin/Wnt signaling ${ }^{158}$ and activators of several downstream targets such as small GTPases, Rho, Rac and Cdc42 ${ }^{8,150}$. These genetic adaptations facilitate the survival, growth and migratory capabilities of melanoma. $\alpha_{v} \beta_{3}$ Integrin expression in melanoma has also been linked to the progression from RGP to VGP ${ }^{159}$.

The EMT in melanoma not only permits tumor cell invasion and altered cell communication partners by modifying cell-cell contacts, but also plays an important role in remodeling the ECM making it conducive for invasion and migration and creating what is coined 'reactive stroma' 160,161 . The adaptation of this stromal-cancer cell environment manifests even before the tumor is clearly noticeable ${ }^{127,160}$. The 'reactive stroma' consists of the tumor 'in situ', ECM and 
mesenchymal cells, fibroblasts, vascular networks and associated cells, nerves and inflammatory cells resembling normal stroma when undergoing wound healing ${ }^{160-162 .}$

During wound healing there is a period of ischemia where blood supply is restricted accompanied by a shortage of oxygen and nutrients to the tissue, edema, followed by an influx of immune cells, and then a period of blood vessel growth and tissue repair ${ }^{163,164}$. Tumor progression for most cancers undergo all these phases of wound healing, generating the perception of cancers as 'wounds that do not heal' 160,165 .

Fibroblasts are the first main group of cells to accumulate at sites of wound repair, where they present a scaffold for inflammatory and other cells that mediate scar and tissue formation ${ }^{160}$. The primary function of fibroblasts is aiding in the formation of the basement membrane and synthesizing components of the ECM, in which they are also embedded, such as collagen (I, III, V) and fibronectin ${ }^{166,167}$. Fibroblasts also secrete several important paracrine factors such as Insulin-like growth factor 1 (IGF-1), transforming growth factor- $\beta$ (TGF- $\beta$ ), platelet derived growth factor (PDGF) and bFGF to maintain ECM homeostasis and act in wound healing responses ${ }^{159}$. After tumorigenic cells undergo EMT, they can recruit and co-opt fibroblasts to secrete factors that only potentiate the tumor microenvironment and promote tumor progression ${ }^{159}$. A specific population of fibroblasts has been identified as being directly involved in cancer progression, they are known as cancer-associated-fibroblasts (CAFs) ${ }^{160,168}$. The CAFs are also termed 'reactive stromal fibroblasts' because 
they begin to express $\alpha$-smooth-muscle actin similar to myofibroblasts.

Myofibroblasts are larger and more spindle-like in composition than regular fibroblasts; they also typically divide faster and produce more ECM ${ }^{159,169-171 . ~}$ Tumors can directly secrete signals such as growth factors and chemokines to dynamically recruit fibroblasts to the site of the tumor, while other fibroblasts may arrive at the tumor in response to the reactive stroma that mimics a wound. Melanomas can release a combination of bFGF, PDGF, and TGF- $\beta$ signals to stimulate and induct fibroblasts ${ }^{172,173}$. When human melanoma cells (A2058) were co-cultured with primary human fibroblasts (HS-68), the fibroblasts gene expression was altered. The co-cultured fibroblasts began to significantly release more CXCL1 and CXCL2 chemokines associated with melanoma growth and migration. Meanwhile, the melanoma cells began to show a pro-inflammatory response indicated by down regulation of Interleukin-11 and DNA binding domain-1 in the cells ${ }^{153}$. In a 3D co-culture model Flach and colleagues (2011) found that melanoma spheroids could recruit and incorporate fibroblasts. The presence of the melanoma cell soluble factors that recruited the fibroblasts also increased the rate of wound closure as much as $38 \%$, indicating an increase in the secretion of fibroblast associated factors ${ }^{171}$.

The CAFS in turn enhance the expression of the same signals as well as release other factors such as IL-1, HGF, PDGF and Endothelin 3 (EDN3) to promote melanoma growth, migratory capability and neovascularization 31,34,172. Fibroblasts elicit different effects on melanoma progression depending on the melanoma stage. Cornil and colleagues (1991) examined the effect dermal 
fibroblasts had on melanoma cells taken from different stages of melanoma progression ${ }^{174}$. When early metastatic incompetent melanoma cells taken from RGP and VGP stages were co-cultured with fibroblasts, melanoma cell growth was repressed. However when 9 out of 11 cell lines from metastatic phases were co-cultured with fibroblasts, growth of the aggressive cell lines was stimulated ${ }^{174}$. It is speculated that the more aggressive tumor types may secrete factors that can induce and recruit fibroblasts to then release paracrine factors in favor of melanoma progression ${ }^{159}$. Thus fibroblast activation may be induced by more aggressive cell types within the tumor, moreover fibroblasts may aid in selection and enhancement of the very aggressive melanoma cells ${ }^{174}$.

Recently fibroblasts have been recognized as important components of the body's immune response at wounds or sites of inflammation ${ }^{175}$. Fibroblasts can secrete various cytokines and chemokines to initiate chronic inflammation and regulate inflammatory infiltrates ${ }^{160,176}$. When fibroblasts are co-opted by melanoma cells, these inflammatory CAFs can maintain chronic inflammation that characterizes the tumor microenvironment and aid in the tumor's escape from the hosts immune surveillance which is a major hallmark in tumor progression ${ }^{165,175,177}$.

\subsubsection{Evading Immune Surveillance}

Chronic inflammation in the TME creates tumor promoting effects as the microenvironment is teeming with mediators of inflammation such as cytokines, chemokines, growth factors, reactive oxygen species (ROS), nitrogen species (NOS) and prostaglandins produced by the either the tumor or associated stroma 
cells ${ }^{178179}$. The abnormal growth of a tumor summons immune effector cells to the site of the tumor to deal with what is initially seen as a foreign invader, however the TME has been altered so much that the anti-tumor functions of the immune cells are downregulated, and instead tumor derived signals such as TGF- $\beta$, Interleukin 8 (IL-8), bFGF and tumor necrosis factor- $\alpha$ (TNF- $\alpha$ ) successively recruit the inflammatory cells to support tumor progression ${ }^{165}$. Many of the inflammatory cells of both adaptive immunity such as Tlymphocytes, dendritic cells, and B cells and innate immunity including macrophages, leukocytes and natural killer (NK) cells can even infiltrate the tumor itself, favoring tumor survival and protection from subsequent immune reactions outside of the TME ${ }^{165}$. Another important group of immune cells found in the TME are myeloid suppressor cells (MSCs) ${ }^{180}$. Meyer and colleagues (2011) using the ret transgenic melanoma mouse model showed high numbers of myeloid suppressor cells infiltrating tumors and an increase in immune factors IL$1 \beta$, granulocyte macrophage colony- stimulating factor-1 (GM-CSF), and Interferon gamma (IFN-ү), in melanocytic lesions and lymph node metastases correlating with tumor progression ${ }^{177}$. Other studies demonstrated that, dysplastic nevi and RGP have considerable numbers of lymphocyte infiltrates. It is believed that melanoma cells can actively recruit lymphocytes by secreting several chemoattractants namely IL-8, GM-CSF and monocyte chemoattractant protein-1 (MCP-1) ${ }^{31,181}$. Melanomas are able to further escape tumor surveillance by promoting the release of immunosuppressants such as insulin like growth factor- $\beta$ (IGF- $\beta$ ) and IL-10 into the microenvironment ${ }^{31}$. 
The recruitment of immune cells into the tumor microenvironment tricks the host's immune response into recognizing the tumor as 'self' rather than as a dangerous group of cells. Melanoma is well known for its ability to escape the host's immune surveillance. The tumor escape from the immune system is one of the features of the skin cancer that makes it very difficult to treat. The tumor response mechanisms are complex and not yet fully characterized or understood.

\subsubsection{Inducing Neovascularization}

Perhaps one of the most studied part of the TME response in tumor progression is tumor angiogenesis. As the tumor grows and co-opts various cell types into the tumor microenvironment and the tumor itself, oxygen and nutrients become limiting, thus creating an increasingly hypoxic and unfavorable tumor microenvironment ${ }^{182}$. The tumor and the TME respond by triggering angiogenesis, a mechanism described as the 'tumor angiogenic switch' 182-184. Srivastava and colleagues (1988) found that the amount of staining for vessels could indicate the probability of metastasis ${ }^{185}$.

Tumor angiogenesis is the formation of new blood vessels from preexisting ones ${ }^{186,187}$. The process is one of the most significant events of tumor progression, as tumors cannot grow more than $2-3 \mathrm{~mm}^{3}$ without vascularization supplying the tumor with sufficient oxygen and nutrients as well as collecting wastes from the tumor $182,187,188$. Tumor angiogenesis follows several general sequential steps. Angiogenesis begins with modifications and degradation of the basement membrane by proteases, like matrix metalloproteinases (MMPs), 
permitting the detachment of pericytes which are contractile cells that cover endothelial cells lining blood vessels ${ }^{182,188,189}$. The detachment of pericytes allows the directional migration of endothelial cells (ECs) into the interstitial space towards angiogenic signals secreted by the tumor and TME. The ECs proliferate and follow each other while forming attachments to each other, subsequently forming a lumen and vessel branches, a process known as sprouting ${ }^{188,189}$. To end with, the basement membrane re-forms and pericytes then re-attach to the newly formed vessels and blood flow begins $184,189,190$.

Tumor blood vessel structure is uniquely different from those formed during normal angiogenesis ${ }^{188} 189$. The blood vessels of the tumor tend to be irregularly shaped, deflated, very twisted and circuitous with some having dead ends. Tumor blood vessels also lack definite organization into vein, arteries and capillaries, moreover the vessels are often characterized as 'leaky' or hemorrhagic, with poorly connected vessel walls, possibly due to the overproduction of the vascular permeability factor, vascular endothelial growth factor (VEGF). Blood flow is often irregular and slower in tumor vasculature than in normal blood vessels ${ }^{188} 189$. The abnormal properties of the tumor vessels aids in preventing proper administration of drug therapies to tumors.

The 'angiogenic switch' encompasses a delicate balance between the upregulation of positive angiogenic related factors such as VEGF family, bFGF, HGF and IL-8 negative regulators of angiogenesis including thrombospondin-1 and angiostatin ${ }^{183,184}$. The switch is prompted by tumor induction, hypoxic conditions and oncogenic pathways ${ }^{186}$. Tumor secreted autocrine growth factors 
stimulates tumor growth which then stimulates paracrine pro-angiogenic factors that recruit stromal blood vessels ${ }^{182,186}$. Transformed melanocytes, especially those undergoing the VGP produce high amounts bFGF and VEGF both important angiogenic factors. The vascular endothelial growth factor family includes the key angiogenic regulator VEGF along with VEGFB, VEGFC, VEGFD and placental growth factor which bind with various affinities to the VEGF receptors Flt/VEGFR-1, Flk/KDR/VEGFR-2 and VEGFR-3. The VEGF receptors are found primarily on endothelial cells, but can be located on macrophages, bone marrow derived cells, vascular smooth muscle cells, hematopoietic cells and on some malignant cells ${ }^{191-193}$. The VEGF protein acts as a potent mitogen for endothelial cells (ECs) by activating phosphatidylinositol signal transduction pathways and the MAPK pathway in endothelial cells. The Vascular endothelial growth factor along with bFGF and other angiogenic factors, angiopoietins and their tie receptors also mediate chemotaxis of ECs and are responsible for EC survival, vessel sprouting and proper vessel formation ${ }^{193-195}$. Melanoma production of MMPs can release bFGF from the ECM, while cells in the TME such as fibroblasts can produce VEGF along with melanoma cells ${ }^{196}$.

Other angiogenic factors, placental growth factor (PIGF) ${ }^{197}$ and IL-8 ${ }^{198}$ which aid in EC recruitment and vessel formation have also been found to be expressed by primary and metastatic melanomas to enhance tumor angiogenesis ${ }^{199}$. Secretion of IL-8 by endothelial cells in the TME can also promote melanoma cell migration ${ }^{199,200}$. Expression of urokinase plasminogen activator and its receptor (UPA/UPAR) and MMPs which promote melanoma cell 
migration, invasion and metastasis can at the same time influence EC migration and neovascularization ${ }^{201,202}$.

Tumors can initially co-opt pre-existing vasculature until hypoxic conditions trigger the secondary angiogenic response to create new vasculature ${ }^{203}$. Long diffusion distances in tumors creates chronic hypoxia and necrotic regions in tumors, leading to the up regulation of angiogenic regulators such as VEGF $186,188,195$. Under normoxic conditions, oxygen sensing prolyl hydroxylase domain proteins (PHD1-3) target the a-subunits of the hypoxic regulator, Hif-1 $\alpha$, for degradation via ubiquitination ${ }^{182}$. When conditions become hypoxic however the $\alpha$-subunit is stabilized and translocated to the nucleus where it dimerizes with the $\beta$-subunit. The $\alpha / \beta$ complex then binds to hypoxia response elements (HRE) in the promoter regions to activate the transcription of angiogenic related genes such as VEGF, UPAR and MMP2 ${ }^{204,205}$. Hif-1a expression has been confirmed in melanoma by immunohistochemical and immunofluorescence of melanoma cells and biopsies and verified with western blots and PCR ${ }^{206-208}$. Increased expression of hypoxic inducible factors have also been shown in metastatic melanomas when compared to benign nevi ${ }^{209}$. Treviño-Villarreal and colleagues (2011) demonstrated that cells in the TME like stromal cells and pericytes expressed HIf-1a with the transformed melanocytes ${ }^{210}$.

Hypoxic conditions in the TME promote melanoma malignancy in two ways; (1) stimulating tumor angiogenesis leading to increased vasculature in which melanoma cells can enter into the circulatory and lymphatic system to 
invade and colonize distant organs and (2) provide an environment that selects for the more aggressive cells that can withstand increased hypoxic conditions ${ }^{182}$. Liu and colleagues (2011) reported that hypoxia could up-regulate Snail1, a mediator of decreased E-cadherin expression, thus aiding in EMT and melanoma migration ${ }^{211}$. Expression of Hif-1 $1 \alpha$ is capable of actuating proto oncogenic effects through pathways such as HGF/SF ${ }^{212}$. Bedgoni and colleagues (2005) found that constitutive PKB activity resulting from loss in PTEN could transform melanocytes but only when exposed to hypoxic conditions. NRAS induced melanocyte transformation was also favored by hypoxia ${ }^{213}$. In aggressive and highly metastatic melanomas an interesting group of microcirculation patterns formed by the tumorigenic cells themselves has recently been described as vasculogenic mimicry (VM) ${ }^{214}$. The aggressive transformed melanocytes showing great tumor plasticity, form cell lined channels with the ECM to create their own tubular capillary-like network ${ }^{152,214,215}$. Probst and coworkers (2012) observing xenografts of human melanoma cell lines in nude mice, found that some of the endothelial cells from microvessels formed in the tumors were positive for human chromosome $17 / \mathrm{Her}-2$, indicating that the endothelial cells were melanoma in origin ${ }^{216}$. The endothelial cell marker, CD31 and human Y chromosome 'in situ' and immunofluorescence labeling verified that the melanoma cells acquired the vascular endothelial like morphology and could contribute to creating neovascularization ${ }^{216}$. The presence of VM in melanomas is connected to poor prognosis and survival in patients ${ }^{217,218}$. The exact mechanism allowing VM is poorly understood. Vasculogenic mimicry modulating 
genes are generally categorized into pathways associated with not only vascular signaling such as VE cadherin and VEGF but embryonic/stem cell signaling including NOTCH and hypoxia signaling as well ${ }^{219}$.

\subsection{Melanoma Heterogeneity and Malignancy}

Tumor cell heterogeneity in the TME therefore not only defines the presence of different cell types such as immune cells, pericytes etc. but heterogeneity amongst the cancer cells themselves due to genetic and epigenetic variations ${ }^{220}$. Cancer tissues often consist of a sub-population of cells that have adopted a 'embryonic stem like' phenotype which makes it easier for them to adjust to the environment, and emit embryonic developmental factors to alter the environment around them ${ }^{221}$. The tumor stem cell (TSC) can self-renew and transdifferentiate to adopt the roles of neighboring stromal cells ${ }^{221-223}$. It was originally thought that during melanoma progression, changes in genetic expression of the tumor leading to TSCs or other melanoma cell phenotypes were unidirectional. Recently, new studies are challenging that idea as it appears that melanoma cells and its interaction with the TME allows for considerable plasticity of the tumorigenic cells defined by different transcription signatures. These interchangeable states alternate from a dominantly proliferative phenotype to an invasive state and possible other intermediate stages in between ${ }^{224}$.

Hoeck and coworkers (2012) used expression profiling of various melanoma cell lines to identify transcription signatures for proliferative and invasive melanoma cell states ${ }^{224}$. Proliferative signatures include expression of melanocytic related genes MITF, Tyrosinase (TYR) and Dopachrome 
Tautomerase $(D C T)$, as well as neural crest factors associated with melanoblast development such as SOX10 and Endothelin receptor $b$ (EDNRB). The invasive signature states included the up-regulation of Serpine1 and inhibin beta $A$ (INHBA) which are involved in TME modification ${ }^{224}$. Hoeck and colleagues (2012) then injected the DNA microarray characterized melanoma cell lines into immunocompromised mice, after which immunohistochemistry was performed on tumors to identify proliferative vs. invasive signatures. They showed that melanoma cells could switch back and forth between different genetic signatures as both proliferative and invasive cell types were found in the tumor despite what the original seed cell signature was ${ }^{224}$.

The phenotype switching of melanoma cells may facilitate the special requirements of the cells in different melanoma states, from proliferative when growth is necessary, to invasive, then back again to proliferative when at distant metastatic sites. Phenotype switching may also explain why melanomas are resistant to cancer regimens and often re-appear. Tumorigenic cells that are not susceptible to chemotherapy may manipulate the TME to switch back to a proliferative state and initiate tumor progression again. The key to revolutionizing therapies for melanoma thus lies in understanding the dynamics of the tumor microenvironment and targeting the important signals that maintain the malignant cells.

The fact that malignant melanoma cells can alter their gene expression, and subsequently the gene expression of neighboring cells, proves their ability to adopt a 'stem-cell likeness', and become immortal, undifferentiated and invasive. 
The plasticity makes it easy for the cells to leave their origin and occupy other regions. During melanomagenesis expression of genes involved with the development of their early embryonic progenitors, melanoblasts, has been observed. All melanocytes except for those found in the retina of the eye originate from the neural crest (NC) during embryonic development. Neural crest cells (NCC) are a transient and multipotent population of cells that are highly migratory ${ }^{225,226}$. The neural crest cells develop from the dorsal tip of the pseudostratified dorsal epithelium of the neural tube, giving rise to most cells of the peripheral nervous system forming neurons and glial cells, bones and craniofacial cartilage cells of the skeletal system, endocrine system derivatives for the adrenal and thyroid glands, adipose tissue, vascular smooth muscle tissues as well as mesenchymal dermal cells and melanocytes ${ }^{227,228}$.

During neurulation, the NCCs undergo EMT whereby they separate from the neural tube and begin to stereotypically migrate extensively ${ }^{229-231}$. As the NCC migrate they are subjected to an interplay of signals including BMP, NOTCH, WNT and FGF from the non-neural ectoderm and mesoderm that not only aids in their migration but also helps determine their cell fate $228,232,233$. Neural crest cells that migrate dorsolaterally become melanoblasts, progenitor cells for melanocytes ${ }^{227}$. Melanoblast specification and differentiation depends on a complex system of signaling pathways including WNT, BMP, and EDN3. Proper melanoblast development does not take place in the absence of any of these signals $21,234,235$. Melanoblasts eventually migrate into the ectoderm where they become melanocytes and produce the pigment melanin. 
Melanomas may be intrinsically prone to metastasize because of their EMT transformation and high migratory capability associated with their developmental program ${ }^{236-239}$. Bailey and colleagues (2012) transplanted aggressive human melanoma cells (c8161), poorly invasive human melanoma cells (c81-61) and human primary melanocytes into a chick embryonic NCC environment ${ }^{237}$. Laser capture microdissection and genetic analysis techniques were used to compare the gene and signaling pathways exploited by the c8161, c81-61 and primary melanocytes ${ }^{237}$. They reported that the malignant melanoma cells, c8161, responded more vigorously to the NCC environmental cues than the poorly invasive melanoma cells and primary melanocytes, indicating that receptors for NCC development were present and active in the c8161 cells ${ }^{237}$. The $\mathrm{c} 8161$ cells also commandeered the embryonic NCC invasion program to enhance their own invasiveness and plasticity ${ }^{237}$. A number of c8161 cells responded to the NCC microenvironment and migrated along NCC migration routes from the graft sites, while none of the non-invasive and primary melanocytes migrated ${ }^{237}$. The expression patterns of migrating c8161 cells did not exactly mirror that of the NCC suggesting that the tumor cells can manipulate the NCC development program to suit their own agenda ${ }^{237}$. Furthermore $40 \%$ of the analyzed NC-related genes were induced by the aggressive cell line compared to only $8 \%$ induction in the poorly invasive cells. The invasive cells also re-expressed approximately 12 NC-related genes not seen in the primary melanocytes such as SNAI1, ZEB1 and members of the Eph family and silenced others involved in differentiation ${ }^{237}$. 
Because of the dynamic regulation of both stemness and a highly complex microenvironment it is important to identify and fully characterize potential biomarkers for melanoma to improve diagnosis and treatment. One such target that has been implicated is EDNRB and its ligand EDN3.

\subsection{Melanoma and Endothelin Signaling}

Endothelins (EDN) are twenty one amino acid (aa) peptides that act as powerful vasoconstrictors and vasodilators ${ }^{240-242}$. Preproendothelin transcription yields the 203aa prepro-endothelins which are further modified by furin-like proteases to produce 37-41aa big-EDN intermediates which are biologically inactive. The big-EDNs are finally cleaved by membrane bound zinc metalloproteases known as endothelin converting enzymes (ECE) at the Trp-21Val/lle-22 peptide bond to form the active peptides EDN1, Endothelin 2 (EDN2) and EDN3 ${ }^{240-247}$. The EDN1 protein is produced by vascular endothelial and smooth muscle tissue, as well as fibroblasts, cardiac myocytes and brain neurons, with EDN2 mainly secreted by ovaries and intestinal cells and Edn3 by endothelial cells, vascular smooth muscle cells, brain neurons, intestinal epithelial cells, hepatocytes and adventitial fibroblasts $241,242,248$.

In humans, the EDNs bind to two different rhodopsin-type G-protein coupled receptors (GPCRs), Endothelin receptor A (EDNRA) and EDNRB with different affinities. Endothelin 1 and Endothelin 2 preferably bind to EDNRA, however EDNRB is non-selective and binds all three peptides with similar affinity 240,249 . Binding of EDN1 activates the heterotrimeric $G$ proteins $G_{q} / G_{11}$ and $\mathrm{G}_{12} / \mathrm{G}_{13}$ while $E D N 3$ triggers $\mathrm{G}_{\mathrm{i}} / \mathrm{G}_{0}$ and $\mathrm{G}_{13}$ to activate phospholipase $C \beta$ and 
signal through several different pathways including PKC and MAPK ${ }^{249-254 .}$ Endothelin receptor A and Endothelin receptor B can form homodimers or heterodimers which modifies not only ligand binding but receptor activation, and transmembrane signaling as well ${ }^{250}$.

The structure, function and importance of the EDNRA/EDN1 axis in vasoconstriction, proliferation of melanocytes and as a melanogenic factor have been extensively characterized, however not as much is known about the role of the EDNRB/Edn3 axis. The human EDNRB gene is situated on chromosome 13, and has seven exons and introns. Approximately $64 \%$ of its sequence homology is shared with EDNRA ${ }^{242}$. Found mostly in ECs, EDNRB facilitates the release of NO and prostacycline, acting mainly as a vasodilator as opposed to EDNRA's vasoconstrictor effects in response to $\mathrm{Ca}^{2+}$ influx that results from stress on ECs during cardiovascular stress or hypoxia ${ }^{248,255,256}$. Endothein receptor B and EDN3 have a profound effect on melanocyte development and have been recently identified as a potential relevant factor in melanomagenesis.

Waardenburg syndrome IV is associated with mutations in EDNRB and EDN3 that disrupt proper development of enteric nerves and melanocytes resulting in hearing loss, skin, eye, and hair color abnormalities as well as blockage of the intestines known as Hirschsprung disease ${ }^{257-259}$. Targeted mutations of EDNRB and EDN3 in mice results in similar phenotypes such as aganglionic megacolon and pigmentation defects which corroborate the necessity for EDNRB and EDN3 signaling in proper melanoblast development ${ }^{260-263,264}$. 
Lee and colleagues (2003) used the tetracycline inducible system to control EDNRB expression to reveal that EDNRB is required during E10.5-E12 for melanoblast migration and proliferation ${ }^{265}$. Hou and colleagues (2004) used tissue re-combination experiments 'in vitro' with NCC cultures and mouse embryos carrying a EDNRB null allele with the LacZ reporter gene to further show that EDNRB is required for melanoblast differentiation as it is needed for melanoblasts to express the melanogenic enzyme tyrosinase ${ }^{265}$. Endothelin receptor B acts in an autocrine manner as mammalian melanoblasts themselves begin to express EDNRB along the mediolateral pathway ${ }^{265-267}$, while the indispensable role of EDN3 is believed to act in a paracrine fashion as EDN3 is expressed by the dermal mesenchyme and the ectoderm ${ }^{265,268}$.

Studies carried out with avian NCCs show that EDN3 acts as a potent mitogen for both melanoblasts and differentiated melanocytes and promotes melanoblast proliferation and survival ${ }^{269-271}$. Absence of EDNRB and EDN3 in murine and avian NC cultures give rise to melanoblasts that are unable to differentiate properly as they lack the melanogenic markers involved in pigment production such as tyrosinase ${ }^{272}$ or simply cannot produce pigment unless stimulated with EDNs ${ }^{273}$. Interestingly however, exposure of epidermal melanocytes to a strong treatment of EDN3 'in vitro' could stimulate the proliferation of not only pigmented melanocytes but a population of cells coexpressing melanin and glial markers and unpigmented cells expressing glial markers or early NC cell markers ${ }^{271}$. Thus continuous exposure of EDN3 can initiate transdifferentiation of differentiated melanocytes and maintain the 
multipotent progeny ${ }^{271}$. The influence EDN3 has on melanocyte dedifferentiation may be important during melanomagenesis however more studies are needed to examine this relationship.

Endothelin receptor B signaling has been implicated as a melanoma progression marker. Although studies such as Kikuchi et al. (1996) and Eberle et al. (1999) communicated that EDNRB expression decreased in more malignant melanoma cell lines they examined, other studies such as that conducted by Bittner et al (2000) and Demunter et. al (2000) examining more melanoma cell lines found that ENDRB expression was instead upregulated ${ }^{274-277 . ~ L a h a v ~ a n d ~}$ colleagues (1999) further explored the effect of ENDRB on melanoma progression 'in vitro' and 'in vivo'. The 'in vitro' experiments showed that exposure of 7 different melanoma cell cultures to the EDNRB antagonist BQ788, could inhibit cell growth and induce dendricity and increase pigmentation of the cells, thus conferring a phenotype more similar to mature melanocytes than melanoma cells ${ }^{278}$. When the A375 melanoma cell line was injected into nude mice, the resulting tumors were subjected to BQ788, after which the tumors showed either slowed tumor growth or slowed tumor growth with tumor shrinkage and complete growth arrest ${ }^{278}$. Later Lahav and colleagues (2004) used human melanoma cell lines from various stages of melanoma progression to support that EDNRB may be important in melanoma progression. Inhibition of EDNRB using BQ788 in the melanoma cell lines induced apoptosis and decreased cell viability of the metastatic melanoma cell lines more than that found in primary and cutaneous cell lines ${ }^{279}$. The inhibition of EDNRB may possibly trigger 
apoptosis because of decreased expression of the survival factor, BCL-2A1and the PARP-3 enzyme which is aids in DNA repair ${ }^{279}$. Inhibition of the EDNRB axis both 'in vivo' and 'in vitro' in other studies likewise found reduction of melanoma growth ${ }^{280}$.

Endothelin 3 activation of EDNRB may be the key factor in EDNRB mediated effects on melanoma growth as Nengxing et al. (2007) showed 'in vitro' that EDN3 prompted increased proliferation of A375 melanoma cells in a time and concentration dependent manner ${ }^{281}$. Cruz-Muñoz and colleagues (2012) used lentiviral vectors to upregulate EDNRB in stable variant human melanoma cell line models that spontaneously develop visceral metastasis (113/6-4L) and brain metastasis (131/4-5B1 and 131/4-5B2) ${ }^{282}$. Increased levels of EDNRB in both the visceral and brain metastatic cell lines boosted their metastatic potential leading to shorter median survival in those with the visceral metastasis and an increased number of brain metastases in the brain metastatic variant ${ }^{282}$. CruzMuñoz and colleagues (2012) identified EDN3, which is also highly expressed in the brain microenvironment, to be the major factor in the EDNRB mediated enhanced brain metastatic events ${ }^{282}$.

Tang and colleagues (2008) gene expression profiling analysis comparing normal nevi biopsies to metastatic tissues identified abnormal expression of EDN3 in melanoma ${ }^{283}$. Quantitative PCR analysis showed an up-regulation over 10 fold of EDN3 in the metastatic melanoma biopsies than normal nevi biopsies ${ }^{283}$. Melanoma specific EDN3 immunohistochemistry (IHC) staining was also observed only in the metastatic tissues ${ }^{283}$. Six out of seven melanoma cell 
lines, examined by Tang and his associates (2012), showed EDN3 expression while normal melanocyte cultures did not. Their data suggest that not only is the EDNRB/EDN3 axis involved in melanoma but also that the melanoma cells themselves may be the source of EDN3 ${ }^{283}$.

The EDNRB/EDN3 axis may aid in melanoma progression by influencing mechanisms in the tumor microenvironment. Bagnato and colleagues (2004), Rosanò and colleagues (2004) and Jamal and colleagues (2002) used melanoma cell lines exposed to EDN1 and EDN3 to show that after treatment, the cell lines had decreased E-cadherin levels ${ }^{148,284,285}$. Bagnato and colleagues (2004) also showed a concomitant upregulation of N-cadherin and that mRNA of the EMT transcription factor, Snail, that negatively controls E-cadherin expression was observed in the primary melanoma cell line thus suggesting a potential role for EDNs in EMT ${ }^{280}$. Exposure of primary cell line (1007) and metastatic melanoma cell line (M10) to EDN1 and EDN3 resulted in the increased secretion of ECM proteases MMP-2 and MMP-9 and the integrins $\alpha_{2} \beta 1$ and $\alpha_{v} \beta_{3}$ all important players in the tumor microenvironment ${ }^{280}$.

The association of endothelins with endothelial cells, makes the EDNRB/EDN3 axis worth examining for any prospective roles in tumor angiogenesis. Endothelins are often secreted at sites of wounds or injured vessels ${ }^{286}$. Endothelin 1 and Endothelin 3 can stimulate production of NO and stimulate migration of endothelial cells ${ }^{287}$, in addition, they are expressed by endothelial cells of lymphatic vessels, which is also important in cancer metastasis ${ }^{288}$. Spinella and colleagues (2007) research on primary melanoma 
(1007) and metastatic melanoma (M10) cell lines conveyed that both EDN1 and EDN3 could increase Hif-1 $\alpha$ mediated upregulation of VEGF and angiogenic factors, COX-1, COX-2 and $\mathrm{PGE}_{2}$ in a concentration dependent manner ${ }^{289}$. The expression of COX-2, Hif-1a, VEGF and MMP-2 were also decreased in M10 tumor bearing mice in response to EDNRB inhibition with A-19262 ${ }^{289}$. Zbytec and colleagues (2013) used bioinformatics to also identify putative hypoxia response elements (HRE's) in EDNRB ${ }^{209}$. Spinella and colleagues (2013) further revealed that EDNRB/EDN1 axis could induce VEGF-3 signaling to activate MAPK and AKT to promote cell migration and vasculogenic mimicry of primary and metastatic melanoma cell lines ${ }^{290}$. Wren and colleagues (1993) showed that EDN3 could specifically support wound healing by stimulating endothelial cell proliferation without activation of either EDNRA or EDNRB in an 'in vitro' endothelial cell injury model, thus potentially calling into question other mediated mechanisms of EDN3 signaling ${ }^{291}$.

Conversely, previous studies by Lahav and colleagues inferred negative effects of EDNRB on melanoma angiogenesis ${ }^{279}$. When they inhibited EDNRB in melanoma cell lines, microarray and real time RT-PCR analysis disclosed significant increased levels of VEGF and Hif-1a along with decreased levels of the angiogenic suppressor gravin ${ }^{279}$. A majority of the studies examining the relationship between the EDNRB axis and melanoma have been performed using 'in vitro' methods. However, it is well known that melanoma cells behave very differently in culture from when they are situated in their tumor microenvironment where they are affected by the induced changes in the host. It 
is therefore important to examine the effects of EDNRB/EDN3 in an 'in vivo' model.

Mayuko and colleagues (2010) used a RET mouse model that form melanomas de novo (do not arise from pre-existing benign lesions) to study the status of EDNRB in melanoma progression ${ }^{292}$. They found a negative correlation between levels of EDNRB with tumor progression. Transgenic Ednrb(+/-);RET mice acquired their tumors significantly later but metastasized earlier and had shorter survival ratios when compared to Ednrb(+/+); RET mice ${ }^{292}$. Kumasaka and colleagues (2015) later described that the enhanced malignant phenotype in the Ednrb(+/-);RET mice was the result of reduced levels of Plexin C1 (PIxnC1) a protein normally involved in melanocyte adhesion that has been labeled as a melanoma suppressor protein ${ }^{293}$.

Still, studies such as Soufir and colleagues (2005) who explored whether germline mutations in EDNRB associated with Hirschsprung disease could predispose individuals for malignant melanoma, found that fourteen out of fifteen malignant melanoma (MM) patients had EDNRB mutations found in Hirschsprung disease ${ }^{294}$. When the variables such as skin type and number of nevi were considered by multivariable logistic regression analysis, they still found a significant relationship between mutations in EDNRB and MM incidence ${ }^{294}$. Moreover, both 'in vitro' and clinical trials using the EDNRB antagonist bosentan to treat melanoma cell lines ${ }^{295}$ and metastatic melanomas in patients ${ }^{296}$ aided in apoptosis of melanoma cells and may have stabilization effects of metastatic disease ${ }^{295-297}$. 


\subsection{Research Questions}

Seemingly contradictory influences of the EDNRB/EDN3 axis on melanoma could be attributable to the use of 'in vitro' methods that expose the cells to unnatural and stressful tissue culture conditions as well as the lack of an 'in vivo' model that closely parallels melanoma progression in humans. Much is still unknown about the exact role played by EDNRB/EDN3 signaling in melanomagenesis. My overall hypothesis is that EDNRB/EDN3 signaling acts in a paracrine manner to promote melanoma growth and metastasis. I tested this hypothesis by asking three major questions.

\section{Question 1: Is the up-regulation of the Endothelin 3/Ednrb signaling pathway} sufficient to lead hyperproliferative melanocytic lesions to fully malignant metastasis?

Studies on the role that EDN3 plays in melanoma progression have mainly been conducted using melanoma biopsies and cells from different stages of melanoma progression. Although this has been instrumental in identifying EDN3 upregulation in more malignant melanoma stages, it is still not clear whether EDN3 signaling is a driving force in actual melanoma malignancy. In order to address this question in vivo I established a melanoma mouse model by crossing $\operatorname{Tg}(\mathrm{Grm1})$ Epv mice that aberrantly express metabotropic glutamate 1 (Grm1) exclusively in melanocytes under the regulation of the Dopachrome tautomerase promoter with K5-tTA-Edn3 (here referred to as K5-Edn3) transgenic mice that over-express Edn3 in the skin or $T g(E d n r b) 1 L k$ (here referred to as Dct-Ednrb) transgenic mice that over-express Ednrb in melanocytes. The Tg (Grm1) Epv mice develop melanocytic hyperplasia with limited metastatic capability ${ }^{298,299}$. I 
hypothesize that the presence of more Edn3 in the tumor microenvironment or Ednrb in melanocytes of the $T g$ (Grm1) Epv mice will lead hyperproliferative melanocytic lesions to fully malignant metastasis and contribute to melanoma progression.

\section{Question 2: What are the gene expression changes caused by the over- expression of Edn3 in the tumor microenvironment?}

During embryogenesis, Ednrb and Edn3 are involved in proper melanoblast development and migration. Melanoma cells share specific characteristics with melanoblasts that allow them to be malignant. These characteristics include high proliferative capabilities, a lack of differentiation and reduced intercellular adhesion. I hypothesize that the over-expression of Edn3 in the tumor microenvironment in the K5-Edn3/ Tg (Grm1) Epv mice will alter gene expression of adhesion factors such as cadherins, integrins, and connexins and those involved in differentiation and proliferation such as Mitf and HGF that have been shown to occur 'in vitro' during melanoma progression.

Question 3: Is the Edn3 pathway involved in promoting changes in the tumor microenvironment that enhances melanoma malignancy?

Metastasis is a multistep process involving neighboring cells in the tumor microenvironment being reprogrammed by tumorigenic cells to express factors that aid in the tumor's survival, proliferation, immune escape and invasiveness. The angiogenic cascade is affected by multiple factors in the tumor microenvironment including tumor hypoxic conditions, and a host of bi-directional signaling among tumor and neighboring cells. Thus in order to investigate the true role of EDNRB/EDN3 in 
angiogenesis, it is best to do so in an 'in vivo' model where the Edn3 axis can affect its specific targets or be influenced by other complement of factors that may be needed for it to mediate its effects. I hypothesize that the over-expression of Edn3 will have a significant effect in melanoma angiogenic response.

\subsection{References}

1. Lin JY, Fisher DE. Melanocyte biology and skin pigmentation. Nature 2007;445:843-50.

2. Wasmeier C, Hume AN, Bolasco G, Seabra MC. Melanosomes at a glance. J Cell Sci 2008;121:3995-9.

3. Raposo G, Marks MS. Melanosomes - dark organelles enlighten endosomal membrane transport. Nat Rev Mol Cell Biol 2009;8:786-97.

4. Seiberg M. Keratinocyte - Melanocyte Interactions During Melanosome Transfer. Pigment Cell Res 2001;236-42.

5. Cardinali G, Ceccarelli S, Kovacs D, Aspite N, Lotti LV, Torrisi MR, Picardo M. Keratinocyte growth factor promotes melanosome transfer to keratinocytes. J Invest Dermatol 2005;125:1190-9.

6. Valyi-Nagy IT, Hirka G, Jensen PJ, Shih IM, Juhasz I, Herlyn M. Undifferentiated keratinocytes control growth, morphology, and antigen expression of normal melanocytes through cell-cell contact. Lab Invest 1993;69:152-9.

7. Hirobe T. Role of keratinocyte-derived factors involved in regulating the proliferation and differentiation of mammalian epidermal melanocytes. Pigment Cell Res 2005;18:2-12.

8. Haass NK, Smalley KS, Li L, Herlyn M. Adhesion, migration and communication in melanocytes and melanoma. Pigment Cell Res.2005;18:150-9.

9. Jemal A, Devesa SS, Hartge P, Tucker MA. Recent trends in cutaneous melanoma incidence among whites in the United States. J Natl Cancer Inst 2001;93:678-83. 
10. McLaughlin CC, Wu XC, Jemal A, Martin HJ, Roche LM, Chen VW. Incidence of noncutaneous melanomas in the U.S. Cancer 2005;103:1000-7.

11. Purdue MP, Freeman LEB, Anderson WF, Tucker MA. Recent trends in incidence of cutaneous melanoma among US Caucasian young adults. $J$. Invest. Dermatol.2008;128:2905-8.

12. Miller AJ, Mihm MC. Melanoma. N. Engl. J. Med.2006;355:51-65.

13. Lomuto M, Calabrese P, Giuliani A. Prognostic signs in melanoma: State of the art. J. Eur. Acad. Dermatology Venereol.2004;18:291-300.

14. Kraehn GM, Schartl M, Peter RU. Human malignant melanoma: A genetic disease? Cancer 1995;75:1228-37.

15. Greene MH, Clark WH Jr, Tucker MA, Kraemer KH, Elder DE, Fraser MC. High risk of malignant melanoma in melanoma-prone families with dysplastic nevi. Ann Intern Med 1985;102:458-65.

16. Fitzpatrick TB. The validity and practicality of sun-reactive skin types I through VI. Arch Dermatol 1988;124:869-71.

17. Crombie IK. Racial differences in melanoma incidence. $\mathrm{Br} \mathrm{J}$ Cancer 1979;40:185-93.

18. Mitra D, Luo X, Morgan A, Wang J, Hoang MP, Lo J, Guerrero CR, Lennerz JK, Mihm MC, Wargo JA, Robinson KC, Devi SP, et al. An ultraviolet-radiation-independent pathway to melanoma carcinogenesis in the red hair/fair skin background. Nature 2012;491:449-53.

19. Mountjoy KG, Robbins LS, Mortrud MT, Cone RD. The cloning of a family of genes that encode the melanocortin receptors. Science 1992;257:124851.

20. Yang $Y$. Structure, function and regulation of the melanocortin receptors. Eur. J. Pharmacol.2011;660:125-30.

21. Levy C, Khaled M, Fisher DE. MITF: master regulator of melanocyte development and melanoma oncogene. Trends Mol. Med.2006;12:406-14.

22. Costin GE, Valencia JC, Wakamatsu K, Ito S, Solano F, Milac AL, Vieira WD, Yamaguchi Y, Rouzaud F, Petrescu AJ, Lamoreux ML, Hearing VJ. Mutations in dopachrome tautomerase (Dct) affect eumelanin/pheomelanin 
synthesis, but do not affect intracellular trafficking of the mutant protein. Biochem J 2005;391:249-59.

23. Fang $D$, Setaluri $V$. Role of microphthalmia transcription factor in regulation of melanocyte differentiation marker TRP-1. Biochem Biophys Res Commun 1999;256:657-63.

24. Abdel-Malek ZA. Melanocortin receptors: their functions and regulation by physiological agonists and antagonists. Cell Mol Life Sci 2001;58:434-41.

25. Rees JL. Genetics of hair and skin color. Annu Rev Genet 2003;37:67-90.

26. Walker WP, Gunn TM. Shades of meaning: The pigment-type switching system as a tool for discovery. Pigment Cell Melanoma Res.2010;23:48595.

27. Robbins LS, Nadeau JH, Johnson KR, Kelly MA, Roselli-Rehfuss L, Baack E, Mountjoy KG, Cone RD. Pigmentation phenotypes of variant extension locus alleles result from point mutations that alter $\mathrm{MSH}$ receptor function. Cell 1993;72:827-34.

28. Rees JL. The melanocortin 1 receptor (MC1R): more than just red hair. Pigment Cell Res 2000;13:135-40.

29. Ringholm A, Klovins J, Rudzish R, Phillips S, Rees JL, Schiöth HB. Pharmacological characterization of loss of function mutations of the human melanocortin 1 receptor that are associated with red hair. J Invest Dermatol 2004;123:917-23.

30. Healy E, Jordan SA, Budd PS, Suffolk R, Rees JL, Jackson IJ. Functional variation of MC1R alleles from red-haired individuals. Hum Mol Genet 2001;10:2397-402.

31. Hsu MY, Meier F, Herlyn M. Melanoma development and progression: A conspiracy between tumor and host. Differentiation 2002;70:522-36.

32. Gaggioli C, Sahai E. Melanoma invasion - Current knowledge and future directions. Pigment Cell Res 2007;20:161-72.

33. Chin L. The genetics of malignant melanoma: lessons from mouse and man. Nat Rev Cancer 2003;3:559-70.

34. Halaban R. Growth factors and melanomas. Semin Oncol 1996;23:673-81. 
35. Bishop DT, Demenais F, Goldstein AM, Bergman W, Bishop JN, Bressacde Paillerets B, Chompret A, Ghiorzo P, Gruis N, Hansson J, Harland M, Hayward N, et al. Geographical variation in the penetrance of CDKN2A mutations for melanoma. J Natl Cancer Inst 2002;94:894-903.

36. Monzon J, Liu L, Brill H, Goldstein AM, Tucker MA, From L, McLaughlin J, Hogg D, Lassam NJ. CDKN2A mutations in multiple primary melanomas. $N$ Engl J Med 1998;338:879-87.

37. Flores JF, Pollock PM, Walker GJ, Glendening JM, Lin AH, Palmer JM, Walters MK, Hayward NK, Fountain JW. Analysis of the CDKN2A, CDKN2B and CDK4 genes in 48 Australian melanoma kindreds. Oncogene 1997;15:2999-3005.

38. Hussussian CJ, Struewing JP, Goldstein AM, Higgins PA, Ally DS, Sheahan MD, Clark WH, Tucker MA, Dracopoli NC. Germline p16 mutations in familial melanoma. Nat Genet 1994;8:15-21.

39. Romagosa C, Simonetti S, López-Vicente L, Mazo A, Lleonart ME, Castellvi J, Ramon y Cajal S. p16(Ink4a) overexpression in cancer: a tumor suppressor gene associated with senescence and high-grade tumors. Oncogene 2011;30:2087-97.

40. Aitken J, Welch J, Duffy D, Milligan A, Green A, Martin N, Hayward N. CDKN2A variants in a population-based sample of Queensland families with melanoma. J Natl Cancer Inst 1999;91:446-52.

41. Serrano M, Hannon GJ, Beach D. A new regulatory motif in cell-cycle control causing specific inhibition of cyclin D/CDK4. Nature 1993;366:7047.

42. Ortega S, Malumbres M, Barbacid M. Cyclin D-dependent kinases, INK4 inhibitors and cancer. Biochim. Biophys. Acta 2002;1602:73-87.

43. Nobori T, Miura K, Wu DJ, Lois A, Takabayashi K, Carson DA. Deletions of the cyclin-dependent kinase-4 inhibitor gene in multiple human cancers. Nature 1994;368:753-6.

44. Wölfel T, Hauer M, Schneider J, Serrano M, Wölfel C, Klehmann-Hieb E, De Plaen E, Hankeln T, Meyer zum Büschenfelde KH, Beach D. A p16INK4a-insensitive CDK4 mutant targeted by cytolytic T lymphocytes in a human melanoma. Science 1995;269:1281-4. 
45. Sabir M, Baig RM, Mahjabeen I, Kayani MA. Novel germline CDK4 mutations in patients with head and neck cancer. Hered Cancer Clin Pract 2012;10:11.

46. FitzGerald MG, Harkin DP, Silva-Arrieta S, MacDonald DJ, Lucchina LC, Unsal H, O'Neill E, Koh J, Finkelstein DM, Isselbacher KJ, Sober AJ, Haber DA. Prevalence of germ-line mutations in p16, p19ARF, and CDK4 in familial melanoma: analysis of a clinic-based population. Proc Natl Acad Sci U S A 1996;93:8541-5.

47. Soufir N, Avril MF, Chompret A, Demanais F, Bombled J, Spatz A, StoppaLyonnet D, Bénard J, Bressac-de Paillerets B, Bachollet B, Boitier F, Césarini JP, et al. Prevalence of p16 and CDK4 germline mutations in 48 melanoma-prone families in France. Hum Mol Genet 1998;7:209-16.

48. Russo AA, Tong L, Lee JO, Jeffrey PD, Pavletich NP. Structural basis for inhibition of the cyclin-dependent kinase Cdk6 by the tumour suppressor p16INK4a. Nature 1998;395:237-43.

49. Goldstein AM, Struewing JP, Chidambaram A, Fraser MC, Tucker MA. Genotype-phenotype relationships in U.S. melanoma-prone families with CDKN2A and CDK4 mutations. J Natl Cancer Inst 2000;92:1006-10.

50. Sotillo R, García JF, Ortega S, Martin J, Dubus P, Barbacid M, Malumbres M. Invasive melanoma in Cdk4-targeted mice. Proc Natl Acad Sci U S A 2001;98:13312-7.

51. Piccinin S, Doglioni C, Maestro R, Vukosavljevic T, Gasparotto D, D'Orazi C, Boiocchi M. p16/CDKN2 and CDK4 gene mutations in sporadic melanoma development and progression. Int J Cancer 1997;74:26-30.

52. Kumar R, Sauroja I, Punnonen K, Jansen C, Hemminki K. Selective deletion of exon 1 beta of the p19ARF gene in metastatic melanoma cell lines. Genes Chromosomes Cancer 1998;23:273-7.

53. Krimpenfort P, Quon KC, Mooi WJ, Loonstra A, Berns A. Loss of p16Ink4a confers susceptibility to metastatic melanoma in mice. Nature 2001;413:83-6.

54. Sharpless NE, Bardeesy N, Lee KH, Carrasco D, Castrillon DH, Aguirre AJ, Wu EA, Horner JW, DePinho RA. Loss of p16Ink4a with retention of p19Arf predisposes mice to tumorigenesis. Nature 2001;413:86-91.

55. Sherr CJ. Divorcing ARF and p53: an unsettled case. Nat Rev Cancer 2006;6:663-73. 
56. Sherr CJ, Weber JD. The ARF/p53 pathway. Curr Opin Genet Dev 2000;10:94-9.

57. Zhang $Y$, Xiong $Y$, Yarbrough WG. ARF promotes MDM2 degradation and stabilizes p53: ARF-INK4a locus deletion impairs both the Rb and p53 tumor suppression pathways. Cell 1998;92:725-34.

58. Pomerantz J, Schreiber-Agus N, Liégeois NJ, Silverman A, Alland L, Chin L, Potes J, Chen K, Orlow I, Lee H, Cordon-Cardo C, Depinho RA. The Ink4a tumor suppressor gene product, p19 Arf , interacts with MDM2 and neutralizes MDM2's Inhibition of p53. Cell 1998;92:713-23.

59. Bertwistle D, Sugimoto M, Sherr CJ. Physical and functional interactions of the Arf tumor suppressor protein with nucleophosmin/B23. Mol Cell Biol 2004;24:985-96.

60. Weber JD, Jeffers JR, Rehg JE, Randle DH, Lozano G, Roussel MF, Sherr CJ, Zambetti GP. p53-independent functions of the p19(ARF) tumor suppressor. Genes Dev 2000;14:2358-65.

61. Box NF, Duffy DL, Chen W, Stark M, Martin NG, Sturm RA, Hayward NK. MC1R genotype modifies risk of melanoma in families segregating CDKN2A mutations. Am J Hum Genet 2001;69:765-73.

62. van der Velden PA, Sandkuijl LA, Bergman W, Pavel S, van Mourik L, Frants RR, Gruis NA. Melanocortin-1 receptor variant R151C modifies melanoma risk in Dutch families with melanoma. Am J Hum Genet 2001;69:774-9.

63. Corcoran RB, Settleman J, Engelman JA. Potential therapeutic strategies to overcome acquired resistance to BRAF or MEK inhibitors in BRAF mutant cancers. Oncotarget 2011;2:336-46.

64. Montagut C, Settleman J. Targeting the RAF-MEK-ERK pathway in cancer therapy. Cancer Lett.2009;283:125-34.

65. Yoon S, Seger R. The extracellular signal-regulated kinase: Multiple substrates regulate diverse cellular functions. Growth Factors 2006;24:2144.

66. Curtin JA, Fridlyand J, Kageshita T, Patel HN, Busam KJ, Kutzner H, Cho $\mathrm{KH}$, Aiba S, Bröcker EB, LeBoit PE, Pinkel D, Bastian BC. Distinct sets of genetic alterations in melanoma. N Engl J Med 2005;353:2135-47. 
67. Dankort D, Curley DP, Cartlidge RA, Nelson B, Karnezis AN, Damsky WE Jr, You MJ, DePinho RA, McMahon M, Bosenberg M. BRAF (V600E) cooperates with Pten loss to induce metastatic melanoma. Nat Genet 2009;41:544-52.

68. Davies H, Bignell GR, Cox C, Stephens P, Edkins S, Clegg S, Teague J, Woffendin H, Garnett MJ, Bottomley W, Davis N, Dicks E, et al. Mutations of the BRAF gene in human cancer. Nature 2002;417:949-54.

69. Kumar R, Angelini S, Hemminki K. Activating BRAF and N-Ras mutations in sporadic primary melanomas: an inverse association with allelic loss on chromosome 9. Oncogene 2003;22:9217-24.

70. Papp T, Schipper H, Kumar K, Schiffmann D, Zimmermann R. Mutational analysis of the BRAF gene in human congenital and dysplastic melanocytic naevi. Melanoma Res 2005;15:401-7.

71. Thomas NE. BRAF somatic mutations in malignant melanoma and melanocytic naevi. Melanoma Res 2006;16:97-103.

72. Poynter JN, Elder JT, Fullen DR, Nair RP, Soengas MS, Johnson TM, Redman B, Thomas NE, Gruber SB. BRAF and NRAS mutations in melanoma and melanocytic nevi. Melanoma Res 2006;16:267-73.

73. Pollock PM, Harper UL, Hansen KS, Yudt LM, Stark M, Robbins CM, Moses TY, Hostetter G, Wagner U, Kakareka J, Salem G, Pohida T, et al. High frequency of BRAF mutations in nevi. Nat Genet 2003;33:19-20.

74. Kumar R, Angelini S, Snellman E, Hemminki K. BRAF Mutations Are Common Somatic Events in Melanocytic Nevi. J Invest Dermatol 2004;122:342-8.

75. Patton EE, Widlund HR, Kutok JL, Kopani KR, Amatruda JF, Murphey RD, Berghmans S, Mayhall EA, Traver D, Fletcher CDM, Aster JC, Granter SR, et al. BRAF mutations are sufficient to promote nevi formation and cooperate with p53 in the genesis of melanoma. Curr Biol 2005;15:249-54.

76. Maldonado JL, Fridlyand J, Patel H, Jain AN, Busam K, Kageshita T, Ono T, Albertson DG, Pinkel D, Bastian BC. Determinants of BRAF mutations in primary melanomas. J Natl Cancer Inst 2003;95:1878-90.

77. Dhomen N, Marais R. New insight into BRAF mutations in cancer. Curr Opin Genet Dev 2007;17:31-9. 
78. van Elsas A, Zerp SF, van der Flier S, Krüse KM, Aarnoudse C, Hayward NK, Ruiter DJ, Schrier PI. Relevance of ultraviolet-induced N-ras oncogene point mutations in development of primary human cutaneous melanoma. Am J Pathol 1996;149:883-93.

79. Ball NJ, Yohn JJ, Morelli JG, Norris DA, Golitz LE, Hoeffler JP. Ras mutations in human melanoma: a marker of malignant progression. $J$ Invest Dermatol 1994;102:285-90.

80. Demunter A, Stas M, Degreef H, De Wolf-Peeters C, Van den Oord JJ. Analysis of $\mathrm{N}$ - and $\mathrm{K}$-ras mutations in the distinctive tumor progression phases of melanoma. J Invest Dermatol 2001;117:1483-9.

81. Jafari M, Papp T, Kirchner S, Diener U, Henschler D, Burg G, Schiffmann D. Analysis of ras mutations in human melanocytic lesions: activation of the ras gene seems to be associated with the nodular type of human malignant melanoma. J Cancer Res Clin Oncol 1995;121:23-30.

82. Chin L, Pomerantz J, Polsky D, Jacobson M, Cohen C, Cordon-Cardo C, Horner JW 2nd, DePinho RA. Cooperative effects of INK4a and ras in melanoma susceptibility in vivo. Genes Dev 1997;11:2822-34.

83. Ackermann J, Frutschi M, Kaloulis K, McKee T, Trumpp A, Beermann F. Metastasizing melanoma formation caused by expression of activated $\mathrm{N}$ RasQ61K on an INK4a-deficient background. Cancer Res 2005;65:400511.

84. Dai DL, Martinka M, Li G. Prognostic significance of activated Akt expression in melanoma: A clinicopathologic study of 292 cases. J Clin Oncol 2005;23:1473-82.

85. Bhaskar PT, Hay N. The Two TORCs and Akt. Dev. Cell 2007;12:487-502.

86. Blanco-Aparicio C, Renner O, Leal JF, Carnero A. PTEN, more than the AKT pathway. Carcinogenesis2007;28:1379-86.

87. Bozulic L, Hemmings BA. PIKKing on PKB: regulation of PKB activity by phosphorylation. Curr. Opin. Cell Biol.2009;21:256-61.

88. Salmena L, Carracedo A, Pandolfi PP. Tenets of PTEN Tumor Suppression. Cell 2008;133:403-14.

89. Liu P, Cheng H, Roberts TM, Zhao JJ. Targeting the phosphoinositide 3kinase pathway in cancer. Nat Rev Drug Discov 2009;8:627-44. 
90. Carnero A, Blanco-Aparicio C, Renner O, Link W, Leal JFM. The PTEN/PI3K/AKT signalling pathway in cancer, therapeutic implications. Curr Cancer Drug Targets 2008;8:187-98.

91. Carracedo A, Pandolfi PP. The PTEN-PI3K pathway: of feedbacks and cross-talks. Oncogene 2008;27:5527-41.

92. Isshiki K, Elder DE, Guerry D, Linnenbach AJ. Chromosome 10 allelic loss in malignant melanoma. Genes Chromosomes Cancer 1993;8:178-84.

93. Stahl JM, Cheung M, Sharma A, Trivedi NR, Shanmugam S, Robertson GP. Loss of PTEN promotes tumor development in malignant melanoma. Cancer Res 2003;63:2881-90.

94. Pollock PM, Walker GJ, Glendening JM, Que Noy T, Bloch NC, Fountain JW, Hayward NK. PTEN inactivation is rare in melanoma tumours but occurs frequently in melanoma cell lines. Melanoma Res 2002;12:565-75.

95. Guldberg P, thor Straten P, Birck A, Ahrenkiel V, Kirkin AF, Zeuthen J. Disruption of the MMAC1/PTEN gene by deletion or mutation is a frequent event in malignant melanoma. Cancer Res 1997;57:3660-3.

96. Tsao H, Goel V, Wu H, Yang G, Haluska FG. Genetic Interaction between NRAS and BRAF Mutations and PTEN/MMAC1 Inactivation in Melanoma. J Invest Dermatol 2004;122:337-41.

97. Gilchrest BA, Eller MS. DNA photodamage stimulates melanogenesis and other photoprotective responses. J Investig Dermatol Symp Proc 1999;4:35-40.

98. Mark Elwood J, Jopson J. Melanoma and sun exposure: an overview of published studies. Int J Cancer 1997;73:198-203.

99. Wicks NL, Chan JW, Najera JA, Ciriello JM, Oancea E. UVA phototransduction drives early melanin synthesis in human melanocytes. Curr Biol 2011;21:1906-11.

100. Zaidi MR, Day CP, Merlino G. From UVs to metastases: modeling melanoma initiation and progression in the mouse. $J$ Invest Dermatol 2008;128:2381-91.

101. Zaidi MR, De Fabo EC, Noonan FP, Merlino G. Shedding light on melanocyte pathobiology in vivo. Cancer Res 2012;72:1591-5. 
102. Jhappan C, Noonan FP, Merlino G. Ultraviolet radiation and cutaneous malignant melanoma. Oncogene 2003;22:3099-112.

103. Kannan K, Sharpless NE, XU J, O'Hagan RC, Bosenberg M, Chin L. Components of the Rb pathway are critical targets of UV mutagenesis in a murine melanoma model. Proc Natl Acad Sci U S A 2003;100:1221-5.

104. Benaduce A, Batista D, Grilo G, Jorge K, Cardero D, Milikowski C, Kos L. Novel UV-induced melanoma mouse model dependent on Endothelin3 signaling. Pigment Cell Melanoma Res 2014;5:839-42.

105. Atillasoy ES, Seykora JT, Soballe PW, Elenitsas R, Nesbit M, Elder DE, Montone KT, Sauter E, Herlyn M. UVB induces atypical melanocytic lesions and melanoma in human skin. Am J Pathol 1998;152:1179-86.

106. Chang YM, Barrett JH, Bishop TD, Armstrong BK, Bataille V, Bergman W, Berwick M, Bracci PM, Elwood MJ, Ernstoff MS, Gallagher RP, Green AC, et al. Sun exposure and melanoma risk at different latitudes: a pooled analysis of 5700 cases and 7216 controls. Int J Epidemiol 2009;38:814-30.

107. Zaidi MR, Davis S, Noonan FP, Graff-Cherry C, Hawley TS, Walker RL, Feigenbaum L, Fuchs E, Lyakh L, Young HA, Hornyak TJ, Arnheiter H, et al. Interferon- $\gamma$ links ultraviolet radiation to melanomagenesis in mice. Nature 2011;469:548-53.

108. Jang HS, Kim JH, Park KH, Lee JS, Bae JM, Oh BH, Rha SY, Roh MR, Chung KY. Comparison of Melanoma Subtypes among Korean patients by Morphologic Features and Ultraviolet Exposure. 2014;26:485-90.

109. Berking C, Takemoto R, Satyamoorthy K, Shirakawa T, Eskandarpour M, Hansson J, VanBelle PA, Elder DE, Herlyn M. Induction of melanoma phenotypes in human skin by growth factors and ultraviolet B. Cancer Res 2004;64:807-11.

110. Berking C, Takemoto R, Satyamoorthy K, Elenitsas R, Herlyn M. Basic fibroblast growth factor and ultraviolet $B$ transform melanocytes in human skin. Am J Pathol 2001;158:943-53.

111. Noonan FP, Recio JA, Takayama H, Duray P, Anver MR, Rush WL, De Fabo EC, Merlino G. Neonatal sunburn and melanoma in mice. Nature 2001;413:271-2. 
112. Natali PG, Nicotra MR, Di Renzo MF, Prat M, Bigotti A, Cavaliere R, Comoglio PM. Expression of the c-Met/HGF receptor in human melanocytic neoplasms: demonstration of the relationship to malignant melanoma tumour progression. Br J Cancer 1993;68:746-50.

113. Vande Woude GF, Jeffers M, Cortner J, Alvord G, Tsarfaty I, Resau J. MetHGF/SF: tumorigenesis, invasion and metastasis. Ciba Found Symp 1997;212:119-30; discussion 130-2, 148-54.

114. Sonnenberg E, Meyer D, Weidner KM, Birchmeier C. Scatter factor/hepatocyte growth factor and its receptor, the c-met tyrosine kinase, can mediate a signal exchange between mesenchyme and epithelia during mouse development. J Cell Biol 1993;123:223-35.

115. Bottaro DP, Rubin JS, Faletto DL, Chan AM, Kmiecik TE, Vande Woude GF, Aaronson SA. Identification of the hepatocyte growth factor receptor as the c-met proto-oncogene product. Science 1991;251:802-4.

116. Gherardi E, Youles ME, Miguel RN, Blundell TL, lamele L, Gough J, Bandyopadhyay A, Hartmann G, Butler PJ. Functional map and domain structure of MET, the product of the c-met protooncogene and receptor for hepatocyte growth factor/scatter factor. Proc Natl Acad Sci U S A 2003;100:12039-44.

117. Cruz J, Reis-Filho JS, Silva P, Lopes JM. Expression of c-met tyrosine kinase receptor is biologically and prognostically relevant for primary cutaneous malignant melanomas. Oncology 2003;65:72-82.

118. Bastian BC, LeBoit PE, Hamm H, Bröcker EB, Pinkel D. Chromosomal gains and losses in primary cutaneous melanomas detected by comparative genomic hybridization. Cancer Res 1998;58:2170-5.

119. Li G, Schaider H, Satyamoorthy K, Hanakawa Y, Hashimoto K, Herlyn M. Downregulation of E-cadherin and Desmoglein 1 by autocrine hepatocyte growth factor during melanoma development. Oncogene 2001;20:8125-35.

120. Wiltshire RN, Duray P, Bittner ML, Visakorpi T, Meltzer PS, Tuthill RJ, Liotta LA, Trent JM. Direct visualization of the clonal progression of primary cutaneous melanoma: application of tissue microdissection and comparative genomic hybridization. Cancer Res 1995;55:3954-7.

121. Pfahlberg A, Schneider D, Kölmel KF, Gefeller O. Ultraviolet exposure in childhood and in adulthood: which life period modifies the risk of melanoma more substantially? Soz Praventivmed 2000;45:119-24. 
122. Pfahlberg A, Kölmel KF, Gefeller O, Febim Study Group. Timing of excessive ultraviolet radiation and melanoma: epidemiology does not support the existence of a critical period of high susceptibility to solar ultraviolet radiation-induced melanoma. Br J Dermatol 2001;144:471-5.

123. Whiteman DC, Whiteman CA, Green AC. Childhood sun exposure as a risk factor for melanoma: a systematic review of epidemiologic studies. Cancer Causes Control 2001;12:69-82.

124. De Fabo EC, Noonan FP, Fears T, Merlino G. Ultraviolet B but not Ultraviolet A radiation initiates melanoma. Cancer Research 2004;64:6372-6.

125. Gilchrest BA, Park HY, Eller MS, Yaar M. Mechanisms of ultraviolet lightinduced pigmentation. Photochem. Photobiol.1996;63:1-10.

126. Tada A, Suzuki I, Im S, Davis MB, Cornelius J, Babcock G, Nordlund JJ, Abdel-Malek ZA. Endothelin-1 is a paracrine growth factor that modulates melanogenesis of human melanocytes and participates in their responses to ultraviolet radiation. Cell Growth Differ 1998;9:575-84.

127. Chiange AC, Massagué J. Molecular basis of metastasis. N Engl J Med 2008;359:2814-23.

128. Geiger TR, Peeper DS. Metastasis mechanisms. Biochim Biophys Acta 2009;1796:293-308.

129. Janda E, Lehmann K, Killisch I, Jechlinger M, Herzig M, Downward J, Beug $\mathrm{H}$, Grünert S. Ras and TGF[beta] cooperatively regulate epithelial cell plasticity and metastasis: dissection of Ras signaling pathways. J Cell Biol 2002;156:299-313.

130. Slack JM, Tosh D. Transdifferentiation and metaplasia--switching cell types. Curr Opin Genet Dev 2001;11:581-6.

131. Grände M, Franzen A, Karlsson JO, Ericson LE, Heldin NE, Nilsson M. Transforming growth factor-beta and epidermal growth factor synergistically stimulate epithelial to mesenchymal transition (EMT) through a MEK-dependent mechanism in primary cultured pig thyrocytes. $J$ Cell Sci 2002;115:4227-36.

132. Potempa S, Ridley AJ. Activation of both MAP kinase and phosphatidylinositide 3-kinase by Ras is required for hepatocyte growth factor/scatter factor-induced adherens junction disassembly. Mol Biol Cell 1998;9:2185-200. 
133. Hsu MY, Meier FE, Nesbit M, Hsu JY, Van Belle P, Elder DE, Herlyn M. Ecadherin expression in melanoma cells restores keratinocyte-mediated growth control and down-regulates expression of invasion-related adhesion receptors. Am J Pathol 2000;156:1515-25.

134. Hsu MY, Wheelock MJ, Johnson KR, Herlyn M. Shifts in cadherin profiles between human normal melanocytes and melanomas. J Investig Dermatol Symp Proc 1996;1:188-94.

135. Tang A, Eller MS, Hara M, Yaar M, Hirohashi S, Gilchrest BA. E-cadherin is the major mediator of human melanocyte adhesion to keratinocytes in vitro. J Cell Sci 1994;107:983-92.

136. Herlyn M, Rodeck U, Mancianti M, Cardillo FM, Lang A, Ross AH, Jambrosic J, Koprowski H. Expression of melanoma-associated antigens in rapidly dividing human melanocytes in culture. Cancer Res 1987;47:305761.

137. Eisinger $M$, Marko $O$. Selective proliferation of normal human melanocytes in vitro in the presence of phorbol ester and cholera toxin. Proc Natl Acad Sci U S A 1982;79:2018-22.

138. Scott GA, Cassidy L. Rac1 mediates dendrite formation in response to melanocyte stimulating hormone and ultraviolet light in a murine melanoma model. J Invest Dermatol 1998;111:243-50.

139. Danen EH, de Vries TJ, Morandini R, Ghanem GG, Ruiter DJ, van Muijen GN. E-cadherin expression in human melanoma. Melanoma Res 1996;6:127-31.

140. Hsu M, Andl T, Li G, Meinkoth JL, Herlyn M. Cadherin repertoire determines partner-specific gap junctional communication during melanoma progression. J Cell Sci 2000;113:1535-42.

141. Hsu M, Meier FE, Nesbit M, Hsu J, Belle P Van, Elder DE, Herlyn M. E-cadherin expression in melanoma cells restores keratinocyte-mediated growth control and down-regulates expression of invasion-related adhesion receptors. Am J Pathol 2000;156:1515-25.

142. Balaban GB, Herlyn M, Clark WH, Nowell PC. Karyotypic evolution in human malignant melanoma. Cancer Genet Cytogenet 1986;19:113-22. 
143. Poser I, Domínguez D, de Herreros AG, Varnai A, Buettner R, Bosserhoff AK. Loss of E-cadherin expression in melanoma cells involves upregulation of the transcriptional repressor Snail. J Biol Chem 2001;276:24661-6.

144. Kos L, Aronzon A, Takayama H, Maina F, Ponzetto C, Merlino G, Pavan W. Hepatocyte growth factor/scatter factor-MET signaling in neural crestderived melanocyte development. Pigment Cell Res 1999;12:13-21.

145. Otsuka T, Takayama H, Sharp R, Celli G, LaRochelle WJ, Bottaro DP, Ellmore N, Vieira W, Owens JW, Anver M, Merlino G. c-Met autocrine activation induces development of malignant melanoma and acquisition of the metastatic phenotype. Cancer Res 1998;58:5157-67.

146. Li G, Satyamoorthy K, Herlyn M. N-cadherin-mediated intercellular interactions promote survival and migration of melanoma cells. Cancer Res 2001;61:3819-25.

147. Cano A, Pérez-Moreno MA, Rodrigo I, Locascio A, Blanco MJ, del Barrio MG, Portillo F, Nieto MA. The transcription factor snail controls epithelialmesenchymal transitions by repressing E-cadherin expression. Nat Cell Biol 2000;2:76-83.

148. Jamal S, Schneider RJ. UV-induction of keratinocyte endothelin-1 downregulates E-cadherin in melanocytes and melanoma cells. J Clin Invest 2002;110:443-52.

149. Derycke LD, Bracke ME. N-cadherin in the spotlight of cell-cell adhesion, differentiation, invasion and signalling. Int. J. Dev. Biol.2004;48:463-76.

150. Haass NK, Smalley KSM, Herlyn M. The role of altered cell-cell communication in melanoma progression. J Mol Histol 2004;35:309-18.

151. Seftor EA, Meltzer PS, Kirschmann DA, Pe'er J, Maniotis AJ, Trent JM, Folberg R, Hendrix MJ. Molecular determinants of human uveal melanoma invasion and metastasis. Clin Exp Metastasis 2002;19:233-46.

152. Hendrix MJC, Seftor EA, Hess AR, Seftor REB. Vasculogenic mimicry and tumour-cell plasticity: lessons from melanoma. Nat Rev Cancer 2003;3:411-21.

153. Gallagher PG, Bao Y, Prorock A, Zigrino P, Nischt R, Politi V, Mauch C, Dragulev B, Fox JW. Gene expression profiling reveals cross-talk between melanoma and fibroblasts: implications for host-tumor interactions in metastasis. Cancer Res 2005;65:4134-46. 
154. Seftor EA, Meltzer PS, Kirschmann DA., Margaryan NV, Seftor REB, Hendrix MJC. The epigenetic reprogramming of poorly aggressive melanoma cells by a metastatic microenvironment. J Cell Mol Med 2006;10:174-96.

155. Cavallaro U, Dejana E. Adhesion molecule signalling: not always a sticky business. Nat Rev Mol Cell Biol 2011;12:189-97.

156. Pece S, Gutkind JS. Signaling from E-cadherins to the MAPK pathway by the recruitment and activation of epidermal growth factor receptors upon cell-cell contact formation. J Biol Chem 2000;275:41227-33.

157. Takahashi K, Suzuki K. Density-dependent inhibition of growth involves prevention of EGF receptor activation by E-cadherin-mediated cell-cell adhesion. Exp Cell Res 1996;226:214-22.

158. Logan CY, Nusse R. The Wnt signaling pathway in development and disease. Annu Rev Cell Dev Biol 2004;20:781-810.

159. Lee JT, Herlyn M. Microenvironmental influences in melanoma progression. J. Cell. Biochem.2007;101:862-72.

160. Kalluri R, Zeisberg M. Fibroblasts in cancer. Nat Rev Cancer 2006;6:392401.

161. Rønnov-Jessen L, Petersen OW, Bissell MJ. Cellular changes involved in conversion of normal to malignant breast: importance of the stromal reaction. Physiol Rev 1996;76:69-125.

162. Kalluri R. Basement membranes: structure, assembly and role in tumour angiogenesis. Nat Rev Cancer 2003;3:422-33.

163. Carrico TJ, Mehrhof AI Jr, Cohen IK. Biology of wound healing. Surg Clin North Am 1984;64:721-33.

164. Broughton G 2nd, Janis JE, Attinger CE. Wound healing: an overview. Plast Reconstr Surg 2006;117:1e - S - 32e - S.

165. Whiteside TL. The tumor microenvironment and its role in promoting tumor growth. Oncogene 2008;27:5904-12.

166. Chang HY, Chi JT, Dudoit S, Bondre C, van de Rijn M, Botstein D, Brown PO. Diversity, topographic differentiation, and positional memory in human fibroblasts. Proc Natl Acad Sci U S A 2002;99:12877-82. 
167. Simian M, Hirai Y, Navre M, Werb Z, Lochter A, Bissell MJ. The interplay of matrix metalloproteinases, morphogens and growth factors is necessary for branching of mammary epithelial cells. Development 2001;128:3117-31.

168. Haviv I, Polyak K, Qiu W, Hu M, Campbell I. Origin of carcinoma associated fibroblasts. Cell Cycle 2009;8:589-95.

169. Gabbiani G. The myofibroblast in wound healing and fibrocontractive diseases. J. Pathol 2003;200:500-3.

170. Tsukada T, McNutt MA, Ross R, Gown AM. HHF35, a muscle actinspecific monoclonal antibody. II. Reactivity in normal, reactive, and neoplastic human tissues. Am J Pathol 1987;127:389-402.

171. Flach EH, Rebecca VW, Herlyn M, Smalley KSM, Anderson AR. Fibroblasts contribute to melanoma tumor growth and drug resistance. $\mathrm{Mol}$ Pharm 2011;8:2039-49.

172. Ruiter D, Bogenrieder T, Elder D, Herlyn M. Melanoma-stroma interactions: structural and functional aspects. Lancet Oncol.2002;3:35-43.

173. Lazarov M, Kubo Y, Cai T, Dajee M, Tarutani M, Lin Q, Fang M, Tao S, Green CL, Khavari PA. CDK4 coexpression with Ras generates malignant human epidermal tumorigenesis. Nat Med 2002;8:1105-14.

174. Cornil I, Theodorescu D, Man S, Herlyn M, Jambrosic J, Kerbel RS. Fibroblast cell interactions with human melanoma cells affect tumor cell growth as a function of tumor progression. Proc Natl Acad Sci U S A 1991;88:6028-32.

175. Flavell SJ, Hou TZ, Lax S, Filer AD, Salmon M, Buckley CD. Fibroblasts as novel therapeutic targets in chronic inflammation. Br J Pharmacol 2008;153 Suppl :S241-6.

176. Parsonage G, Falciani F, Burman A, Filer A, Ross E, Bofill M, Martin S, Salmon M, Buckley CD. Global gene expression profiles in fibroblasts from synovial, skin and lymphoid tissue reveals distinct cytokine and chemokine expression patterns. Thromb Haemost 2003;90:688-97.

177. Meyer C, Sevko A, Ramacher M, Bazhin AV, Falk CS, Osen W, Borrello I, Kato M, Schadendorf D, Baniyash M, Umansky V. Chronic inflammation promotes myeloid-derived suppressor cell activation blocking antitumor immunity in transgenic mouse melanoma model. Proc Natl Acad Sci 2011;108:17111-6. 
178. Allavena P, Sica A, Solinas G, Porta C, Mantovani A. The inflammatory micro-environment in tumor progression: the role of tumor-associated macrophages. Crit Rev Oncol Hematol 2008;66:1-9.

179. Mantovani A, Allavena P, Sica A, Balkwill F. Cancer-related inflammation. Nature 2008;454:436-44.

180. Ochoa AC, Zea AH, Hernandez C, Rodriguez PC. Arginase, prostaglandins, and myeloid-derived suppressor cells in renal cell carcinoma. Clinical Cancer Research 2007;13:721s-726s.

181. Herlyn M, Shih IM. Interactions of melanocytes and melanoma cells with the microenvironment. Pigment Cell Res 1994;7:81-8.

182. Gupta MK, Qin RY. Mechanism and its regulation of tumor-induced angiogenesis. World J Gastroenterol 2003;9:1144-55.

183. Ribatti D, Nico B, Crivellato E, Roccaro AM, Vacca A. The history of the angiogenic switch concept. Leukemia 2007;21:44-52.

184. Hanahan D, Folkman J. Patterns and emerging mechanisms of the angiogenic switch during tumorigenesis. Cell 1996;86:353-64.

185. Srivastava A, Laidler P, Davies RP, Horgan K, Hughes LE. The prognostic significance of tumor vascularity in intermediate-thickness $(0.76-4.0 \mathrm{~mm}$ thick) skin melanoma. A quantitative histologic study. Am J Pathol 1988;133:419-23.

186. Detmar M. Tumor angiogenesis. J Investig Dermatol Symp Proc 2000;5:20-3.

187. Folkman J. Tumor angiogenesis. Adv Cancer Res 1985;43:175-203.

188. Bergers G, Benjamin LE. Tumorigenesis and the angiogenic switch. Nat Rev Cancer 2003;3:401-10.

189. Potente $M$, Gerhardt $\mathrm{H}$, Carmeliet $\mathrm{P}$. Basic and therapeutic aspects of angiogenesis. Cell 2011;146:873-87.

190. Senger DR, Van de Water L, Brown LF, Nagy JA, Yeo KT, Yeo TK, Berse $B$, Jackman RW, Dvorak AM, Dvorak HF. Vascular permeability factor (VPF, VEGF) in tumor biology. Cancer Metastasis Rev 1993;12:303-24. 
191. Ishida A, Murray J, Saito Y, Kanthou C, Benzakour O, Shibuya M, Wijelath ES. Expression of vascular endothelial growth factor receptors in smooth muscle cells. J Cell Physiol 2001;188:359-68.

192. Ferrara N, Gerber HP, LeCouter J. The biology of VEGF and its receptors. Nat Med 2003;9:669-76.

193. Cébe-Suarez S, Zehnder-Fjällman A, Ballmer-Hofer K. The role of VEGF receptors in angiogenesis; complex partnerships. Cell Mol Life Sci 2006;63:601-15.

194. Yancopoulos GD, Davis S, Gale NW, Rudge JS, Wiegand SJ, Holash J. Vascular-specific growth factors and blood vessel formation. Nature 2000;407:242-8.

195. Papetti M, Herman IM. Mechanisms of normal and tumor-derived angiogenesis. Am J Physiol Cell Physiol 2002;282:C947-70.

196. Plum SM, Holaday JW, Ruiz A, Madsen JW, Fogler WE, Fortier AH. Administration of a liposomal FGF-2 peptide vaccine leads to abrogation of FGF-2-mediated angiogenesis and tumor development. Vaccine 2000;19:1294-303.

197. Odorisio T, Cianfarani F, Failla CM, Zambruno G. The placenta growth factor in skin angiogenesis. J. Dermatol. Sci.2006;41:11-9.

198. Bar-Eli M. Role of interleukin-8 in tumor growth and metastasis of human melanoma. Pathobiology 1999;67:12-8.

199. Mahabeleshwar GH, Byzova T V. Angiogenesis in Melanoma. Semin Oncol 2007;34:555-65.

200. Melnikova VO, Bar-Eli M. Bioimmunotherapy for melanoma using fully human antibodies targeting MCAM/MUC18 and IL-8. Pigment Cell Res.2006;19:395-405.

201. Delbaldo C, Masouye I, Saurat JH, Vassalli JD, Sappino AP. Plasminogen activation in melanocytic neoplasia. Cancer Res 1994;54:4547-52.

202. Curran S, Murray GI. Matrix metalloproteinases: molecular aspects of their roles in tumour invasion and metastasis. Eur J Cancer 2000;36:1621-30.

203. Ribatti D, Vacca A, Dammacco $F$. The role of the vascular phase in solid tumor growth: a historical review. Neoplasia 1999;1:293-302. 
204. Bedogni B, Powell MB. Hypoxia, melanocytes and melanoma - survival and tumor development in the permissive microenvironment of the skin. Pigment Cell Melanoma Res.2009;22:166-74.

205. Lee JW, Bae SH, Jeong JW, Kim SH, Kim KW. Hypoxia-inducible factor (HIF-1)alpha: its protein stability and biological functions. Exp Mol Med 2004;36:1-12.

206. Kuphal S, Winklmeier A, Warnecke C, Bosserhoff AK. Constitutive HIF-1 activity in malignant melanoma. Eur J Cancer 2010;46:1159-69.

207. Valencak J, Kittler H, Schmid K, Schreiber M, Raderer M, GonzalezInchaurraga M, Birner $\mathrm{P}$, Pehamberger $\mathrm{H}$. Prognostic relevance of hypoxia inducible factor-1alpha expression in patients with melanoma. Clin Exp Dermatol 2009;34:e962-4.

208. Mills CN, Joshi SS, Niles RM. Expression and function of hypoxia inducible factor-1 alpha in human melanoma under non-hypoxic conditions. Mol Cancer 2009;8:104.

209. Zbytek B, Peacock DL, Seagroves TN, Slominski A. Putative role of HIF transcriptional activity in melanocytes and melanoma biology. Dermatoendocrinol 2013;5:239-51.

210. Treviño-Villarreal JH, Cotanche DA, Sepúlveda R, Bortoni ME, Manneberg $\mathrm{O}$, Udagawa T, Rogers RA. Host-derived pericytes and Sca-1+ cells predominate in the MART-1- stroma fraction of experimentally induced melanoma. J Histochem Cytochem 2011;59:1060-75.

211. Liu S, Kumar SM, Martin JS, Yang R, Xu X. Snail1 mediates hypoxiainduced melanoma progression. Am J Pathol 2011;179:3020-31.

212. Comito G, Calvani M, Giannoni E, Bianchini F, Calorini L, Torre E, Migliore C, Giordano S, Chiarugi P. HIF-1 $\alpha$ stabilization by mitochondrial ROS promotes Met-dependent invasive growth and vasculogenic mimicry in melanoma cells. Free Radic Biol Med 2011;51:893-904.

213. Bedogni B, Welford SM, Cassarino DS, Nickoloff BJ, Giaccia AJ, Powell MB. The hypoxic microenvironment of the skin contributes to Akt-mediated melanocyte transformation. Cancer Cell 2005;8:443-54.

214. Maniotis AJ, Folberg R, Hess A, Seftor EA, Gardner LM., Pe'er J, Trent $J M$, Meltzer PS, Hendrix MJ. Vascular channel formation by human melanoma cells in vivo and in vitro: vasculogenic mimicry. Am J Pathol 1999;155:739-52. 
215. Folberg R, Hendrix MJ, Maniotis AJ. Vasculogenic mimicry and tumor angiogenesis. Am J Pathol 2000;156:361-81.

216. Mihic-Probst D, Ikenberg K, Tinguely M, Schraml P, Behnke S, Seifert B, Civenni G, Sommer L, Moch H, Dummer R. Tumor Cell Plasticity and Angiogenesis in Human Melanomas. PLoS One 2012;7:e33571.

217. Folberg R, Arbieva Z, Moses J, Hayee A, Sandal T, Kadkol S, Lin AY, Valyi-Nagy K, Setty S, Leach L, Chévez-Barrios P, Larsen P, et al. Tumor cell plasticity in uveal melanoma: microenvironment directed dampening of the invasive and metastatic genotype and phenotype accompanies the generation of vasculogenic mimicry patterns. Am J Pathol 2006;169:137689.

218. Han C, Sun B, Wang W, Cai W, Lou D, Sun Y, Zhao X. Overexpression of microtubule-associated protein-1 light chain 3 is associated with melanoma metastasis and vasculogenic mimicry. Tohoku J Exp Med 2011;223:24351.

219. Kirschmann DA, Seftor EA, Hardy KM, Seftor RE, Hendrix MJ. Molecular pathways: vasculogenic mimicry in tumor cells: diagnostic and therapeutic implications. Clin Cancer Res 2012;18:2726-32.

220. Marjanovic ND, Weinberg RA, Chaffer CL. Cell plasticity and heterogeneity in cancer. Clin Chem 2013;59:168-79.

221. Barnhart BC, Simon MC. Metastasis and stem cell pathways. Cancer Metastasis Rev 2007;26:261-71.

222. Grichnik JM. Melanoma, nevogenesis, and stem cell biology. J Invest Dermatol 2008;128:2365-80.

223. Reya T, Morrison SJ, Clarke MF, Weissman IL. Stem cells, cancer, and cancer stem cells. Nature 2001;414:105-11.

224. Hoek KS, Eichhoff OM, Schlegel NC, Döbbeling U, Kobert N, Schaerer L, Hemmi S, Dummer R. In vivo switching of human melanoma cells between proliferative and invasive states. Cancer Res 2008;68:650-6.

225. Huang $X$, Saint-Jeannet JP. Induction of the neural crest and the opportunities of life on the edge. Dev. Biol 2004;275:1-11.

226. Knecht AK, Bronner-Fraser M. Induction of the neural crest: a multigene process. Nat Rev Genet 2002;3:453-61. 
227. Le Douarin N, Kalcheim C. The Neural Crest. 1999. Cambridge New York Cambridge University Press, New York NY.

228. Dupin E, Calloni G, Real C, Gonçalves-Trentin A, Le Douarin NM. Neural crest progenitors and stem cells. Comptes Rendus - Biol 2007;330:521-9.

229. Kalcheim C, Burstyn-Cohen T. Early stages of neural crest ontogeny: formation and regulation of cell delamination. Int J Dev Biol 2005;49:10516.

230. Meulemans D, Bronner-Fraser M. Gene-regulatory interactions in neural crest evolution and development. Dev. Cell 2004;7:291-9.

231. Krispin S, Nitzan E, Kassem Y, Kalcheim C. Evidence for a dynamic spatiotemporal fate map and early fate restrictions of premigratory avian neural crest. Development 2010;137:585-95.

232. Selleck MA, Bronner-Fraser M. Origins of the avian neural crest: the role of neural plate-epidermal interactions. Development 1995;121:525-38.

233. Monsoro-Burq AH, Wang E, Harland R. Msx1 and Pax3 cooperate to mediate FGF8 and WNT signals during Xenopus neural crest induction. Dev Cell 2005;8:167-78.

234. Hornyak TJ, Hayes DJ, Chiu LY, Ziff EB. Transcription factors in melanocyte development: distinct roles for Pax-3 and Mitf. Mech Dev 2001;101:47-59.

235. Hou L, Panthier JJ, Arnheiter H. Signaling and transcriptional regulation in the neural crest-derived melanocyte lineage: interactions between KIT and MITF. Development 2000;127:5379-89.

236. Gupta PB, Kuperwasser C, Brunet JP, Ramaswamy S, Kuo WL, Gray JW, Naber SP, Weinberg RA. The melanocyte differentiation program predisposes to metastasis after neoplastic transformation. Nat Genet 2005;37:1047-54.

237. Bailey CM, Morrison JA, Kulesa PM. Melanoma revives an embryonic migration program to promote plasticity and invasion. Pigment Cell Melanoma Res 2012;25:573-83.

238. Jeffs AR, Glover AC, Slobbe LJ, Wang L, He S, Hazlett JA, Awasthi A, Woolley AG, Marshall ES, Joseph WR, Print CG, Baguley BC, et al. A gene expression signature of invasive potential in metastatic melanoma cells. PLoS One 2009;4:e8461. 
239. Strizzi L, Hardy KM, Kirsammer GT, Gerami P, Hendrix MJ. Embryonic signaling in melanoma: potential for diagnosis and therapy. Lab Invest 2011;91:819-24.

240. Huggins JP, Pelton JT, Miller RC. The structure and specificity of endothelin receptors: their importance in physiology and medicine. Pharmacol Ther 1993;59:55-123.

241. Barton M, Yanagisawa M. Endothelin: 20 years from discovery to therapy. Can J Physiol Pharmacol 2008;86:485-98.

242. Mazzuca MQ, Khalil RA. Vascular Endothelin Receptor Type B: structure, function and dysregulation in vascular disease. Biochem Pharmacol 2012;84:147-62.

243. Inoue A, Yanagisawa M, Kimura S, Kasuya Y, Miyauchi T, Goto K, Masaki T. The human endothelin family: three structurally and pharmacologically distinct isopeptides predicted by three separate genes. Proc Natl Acad Sci U S A 1989;86:2863-7.

244. Schulz H, Dale GE, Karimi-Nejad Y, Oefner C. Structure of human endothelin-converting enzyme I complexed with phosphoramidon. $\mathrm{J} \mathrm{Mol}$ Biol 2009;385:178-87.

245. Gomazkov OA. Endothelin-converting enzyme: its functional aspect. Biochemistry (Mosc) 1998;63:125-32.

246. Emoto N, Yanagisawa M. Endothelin-converting enzyme-2 is a membranebound, phosphoramidon-sensitive metalloprotease with acidic $\mathrm{pH}$ optimum. J Biol Chem 1995;270:15262-8.

247. Xu D, Emoto N, Giaid A, Slaughter C, Kaw S, DeWit D, Yanagisawa M. ECE-1: A membrane-bound metalloprotease that catalyzes the proteolytic activation of big endothelin-1. Cell 1994;78:473-85.

248. Boyd R, Rätsep MT, Ding LL, Wang HD. ETA and ETB receptors are expressed in vascular adventitial fibroblasts. AJP Hear Circ Physiol 2011;301:H2271-8.

249. Sakamoto A, Yanagisawa M, Sawamura T, Enoki T, Ohtani T, Sakurai T, Nakao K, Toyo-oka T, Masaki T. Distinct subdomains of human endothelin receptors determine their selectivity to endothelinA-selective antagonist and endothelinB-selective agonists. J Biol Chem 1993;268:8547-53. 
250. Gregan B, Jürgensen J, Papsdorf G, Furkert J, Schaefer M, Beyermann M, Rosenthal W, Oksche A. Ligand-dependent differences in the internalization of endothelin A and endothelin B receptor heterodimers. $J$ Biol Chem 2004;279:27679-87.

251. Kitamura K, Shiraishi N, Singer WD, Handlogten ME, Tomita K, Miller RT. Endothelin-B receptors activate Galpha13. Am J Physiol 1999;276:C9307.

252. Masaki T. The discovery of endothelins. Cardiovasc Res 1998;39:530-3.

253. Morishita R, Ueda H, Ito H, Takasaki J, Nagata K, Asano T. Involvement of $\mathrm{Gq} / 11$ in both integrin signal-dependent and -independent pathways regulating endothelin-induced neural progenitor proliferation. Neurosci Res 2007;59:205-14.

254. Saldana-Caboverde A, Kos L. Roles of endothelin signaling in melanocyte development and melanoma. Pigment Cell Melanoma Res 2010;23:16070 .

255. Haynes WG, Strachan FE, Webb DJ. Endothelin ETA and ETB receptors cause vasoconstriction of human resistance and capacitance vessels in vivo. 1995. 357-363p

256. D'Orléans-Juste P, Labonté J, Bkaily G, Choufani S, Plante M, Honoré JC. Function of the endothelinB receptor in cardiovascular physiology and pathophysiology. Pharmacol Ther 2002;95:221-38.

257. Edery P, Attié T, Amiel J, Pelet A, Eng C, Hofstra RM, Martelli H, Bidaud C, Munnich A, Lyonnet $S$. Mutation of the endothelin-3 gene in the Waardenburg-Hirschsprung disease (Shah-Waardenburg syndrome). Nat Genet 1996;12:442-4.

258. Hofstra RM, Osinga J, Tan-Sindhunata G, Wu Y, Kamsteeg EJ, Stulp RP, van Ravenswaaij-Arts C, Majoor-Krakauer D, Angrist M, Chakravarti A, Meijers $\mathrm{C}$, Buys $\mathrm{CH}$. A homozygous mutation in the endothelin-3 gene associated with a combined Waardenburg type 2 and Hirschsprung phenotype (Shah-Waardenburg syndrome). Nat Genet 1996;12:445-7.

259. Sangkhathat $S$, Chiengkriwate $P$, Kusafuka $T$, Patrapinyokul $S$, Fukuzawa $M$. Novel mutation of Endothelin-B receptor gene in WaardenburgHirschsprung disease. Pediatr Surg Int 2005;21:960-3. 
260. Shin MK, Levorse JM, Ingram RS, Tilghman SM. The temporal requirement for endothelin receptor-B signalling during neural crest development. Nature 1999;402:496-501.

261. Reid K, Turnley AM, Maxwell GD, Kurihara Y, Kurihara H, Bartlett PF, Murphy M. Multiple roles for endothelin in melanocyte development: regulation of progenitor number and stimulation of differentiation. Development 1996;122:3911-9.

262. Baynash AG, Hosoda K, Giaid A, Richardson JA, Emoto N, Hammer RE, Yanagisawa $M$. Interaction of endothelin-3 with endothelin-B receptor is essential for development of epidermal melanocytes and enteric neurons. Cell 1994;79:1277-85.

263. Hosoda K, Hammer RE, Richardson JA, Baynash AG, Cheung JC, Giaid A, Yanagisawa M. Targeted and natural (piebald-lethal) mutations of endothelin-B receptor gene produce megacolon associated with spotted coat color in mice. Cell 1994;79:1267-76.

264. Druckenbrod NR, Powers PA, Bartley CR, Walker JW, Epstein ML. Targeting of endothelin receptor-B to the neural crest. Genesis 2008;46:396-400.

265. Lee HO, Levorse JM, Shin MK. The endothelin receptor-B is required for the migration of neural crest-derived melanocyte and enteric neuron precursors. Dev Biol 2003;259:162-75.

266. Gariepy CE, Williams SC, Richardson JA, Hammer RE, Yanagisawa M. Transgenic expression of the endothelin-B receptor prevents congenital intestinal aganglionosis in a rat model of Hirschsprung disease. J Clin Invest 1998;102:1092-101.

267. Hou L, Pavan WJ, Shin MK, Arnheiter H. Cell-autonomous and cell nonautonomous signaling through endothelin receptor $\mathrm{B}$ during melanocyte development. Development 2004;131:3239-47.

268. Nataf $\mathrm{V}$, Amemiya a., Yanagisawa $\mathrm{M}$, Le Douarin NM. The expression pattern of endothelin 3 in the avian embryo. Mech Dev 1998;73:217-20.

269. Lahav R, Dupin E, Lecoin L, Glavieux C, Champeval D, Ziller C, Le Douarin NM. Endothelin 3 selectively promotes survival and proliferation of neural crest-derived glial and melanocytic precursors in vitro. Proc Natl Acad Sci U S A 1998;95:14214-9. 
270. Lahav R, Ziller C, Dupin E, Le Douarin NM. Endothelin 3 promotes neural crest cell proliferation and mediates a vast increase in melanocyte number in culture. Proc Natl Acad Sci U S A 1996;93:3892-7.

271. Dupin E, Glavieux C, Vaigot P, Le Douarin NM. Endothelin 3 induces the reversion of melanocytes to glia through a neural crest-derived glialmelanocytic progenitor. Proc Natl Acad Sci U S A 2000;97:7882-7.

272. Hou L, Pavan WJ, Shin MK, Arnheiter H. Cell-autonomous and cell nonautonomous signaling through endothelin receptor B during melanocyte development. Development 2004;131:3239-47.

273. Opdecamp K, Kos L, Arnheiter H, Pavan WJ. Endothelin signalling in the development of neural crest-derived melanocytes. Biochem Cell Biol 1998;76:1093-9.

274. Demunter A, De Wolf-Peeters C, Degreef H, Stas M, van Den Oord JJ. Expression of the endothelin-B receptor in pigment cell lesions of the skin: Evidence for its role as tumor progression marker in malignant melanoma. Virchows Arch 2001;438:485-91.

275. Kikuchi K, Nakagawa H, Kadono T, Etoh T, Byers HR, Mihm MC, Tamaki $\mathrm{K}$. Decreased $\mathrm{ET}(\mathrm{B})$ receptor expression in human metastatic melanoma cells. Biochem Biophys Res Commun 1996;219:734-9.

276. Eberle J, Fecker LF, Orfanos CE, Geilen CC. Endothelin-1 decreases basic apoptotic rates in human melanoma cell lines. J Invest Dermatol 2002;119:549-55.

277. Bittner M, Meltzer P, Chen Y, Jiang Y, Seftor E, Hendrix M, Radmacher M, Simon R, Yakhini Z, Ben-Dor A, Sampas N, Dougherty E, et al. Molecular classification of cutaneous malignant melanoma by gene expression profiling. Nature 2000;406:536-40.

278. Lahav R, Heffner G, Patterson PH. An endothelin receptor B antagonist inhibits growth and induces cell death in human melanoma cells in vitro and in vivo. Proc Natl Acad Sci U S A 1999;96:11496-500.

279. Lahav R, Suvà M, Rimoldi D, Patterson PH, Stamenkovic I. Endothelin receptor $B$ inhibition triggers apoptosis and enhances angiogenesis in melanomas. Cancer Res 2004;64:8945-53. 
280. Bagnato A, Rosanò L, Spinella F, Di Castro V, Tecce R, Natali PG. Endothelin $B$ receptor blockade inhibits dynamics of cell interactions and communications in melanoma cell progression. Cancer Res 2004;64:143643.

281. Lin N, Huang C, Tian J, Tao J, Zhang J, Yang L, Li Y, Liu Y, Chen S, Shen G, Li J, Wang C, et al. The expression of endothelin receptor B in melanoma cells A375 and Sk-mel-1 and the proliferative effects of endothelin 3 on A375 cells. J Huazhong Univ Sci Technol Med Sci 2007;27:611-3.

282. Cruz-Muñoz W, Jaramillo ML, Man S, Xu P, Banville M, Collins C, Nantel A, Francia G, Morgan SS, Cranmer LD, O'Connor-McCourt MD, Kerbel RS. Roles for endothelin receptor B and BCL2A1 in spontaneous CNS metastasis of melanoma. Cancer Res 2012;72:4909-19.

283. Tang L, Su M, Zhang Y, Ip W, Martinka M, Huang C, Zhou Y. Endothelin-3 is produced by metastatic melanoma cells and promotes melanoma cell survival. J Cutan Med Surg 2008;12:64-70.

284. Rosanò L, Spinella F, Genovesi G, Di Castro V, Natali PG, Bagnato A. Endothelin-B receptor blockade inhibits molecular effectors of melanoma cell progression. J Cardiovasc Pharmacol 2004;44:Suppl 1:S136-9.

285. Bagnato A, Natali PG. Endothelin receptors as novel targets in tumor therapy. J Transl Med 2004;2:16.

286. Bagnato A, Spinella F. Emerging role of endothelin-1 in tumor angiogenesis. Trends Endocrinol Metab 2003;14:44-50.

287. Noiri E, Hu Y, Bahou WF, Keese CR, Giaever I, Goligorsky MS. Permissive role of nitric oxide in endothelin-induced migration of endothelial cells. $J$ Biol Chem 1997;272:1747-52.

288. Spinella F, Garrafa E, Castro V Di, Rosanò L, Nicotra MR, Caruso A, Natali $P G$, Bagnato A. Endothelin-1 stimulates lymphatic endothelial cells and lymphatic vessels to grow and invade. Cancer Res 2009;69:2669-76.

289. Spinella F, Rosanò L, Di Castro V, Decandia S, Nicotra MR, Natali PG, Bagnato A. Endothelin-1 and endothelin-3 promote invasive behavior via hypoxia-inducible factor-1 $\alpha$ in human melanoma cells. Cancer Res 2007;67:1725-34. 
290. Spinella F, Caprara V, Di Castro V, Rosanò L, Cianfrocca R, Natali PG, Bagnato A. Endothelin-1 induces the transactivation of vascular endothelial growth factor receptor-3 and modulates cell migration and vasculogenic mimicry in melanoma cells. J Mol Med (Berl) 2013;91:395-405.

291. Wren AD, Hiley CR, Fan TP. Endothelin-3 mediated proliferation in wounded human umbilical vein endothelial cells. Biochem Biophys Res Commun 1993;196:369-75.

292. Kumasaka MY, Yajima I, Hossain K, lida M, Tsuzuki T, Ohno T, Takahashi $\mathrm{M}$, Yanagisawa M, Kato M. A novel mouse model for de novo melanoma. Cancer Res 2010;70:24-9.

293. Kumasaka MY, Yajima I, lida M, Takahashi H, Inoue Y, Fukushima S, Ihn $\mathrm{H}$, Takeda K, Naito Y, Yoshikawa T, Kato M. Correlated expression levels of endothelin receptor B and Plexin C1 in melanoma. Am J Cancer Res 2015;5:1117-23.

294. Soufir N, Meziani R, Lacapère JJ, Bertrand G, Fumeron F, Bourillon A, Gérard B, Descamps V, Crickx B, Ollivaud L, Archimbaud A, Lebbe C, et al. Association between endothelin receptor $B$ nonsynonymous variants and melanoma risk. J Natl Cancer Inst 2005;97:1297-301.

295. Berger Y, Bernasconi CC, Juillerat-Jeanneret L. Targeting the endothelin axis in human melanoma: combination of endothelin receptor antagonism and alkylating agents. Exp Biol Med (Maywood) 2006;231:1111-9.

296. Kefford R, Beith JM, Van Hazel GA, Millward M, Trotter JM, Wyld DK, Kusic R, Shreeniwas R, Morganti A, Ballmer A, Segal E, Nayler O, et al. A Phase II study of bosentan, a dual endothelin receptor antagonist, as monotherapy in patients with stage IV metastatic melanoma. Invest New Drugs 2007;25:247-52.

297. Bagnato A, Loizidou M, Pflug BR, Curwen J, Growcott J. Role of the endothelin axis and its antagonists in the treatment of cancer. $\mathrm{Br} \mathrm{J}$ Pharmacol 2011;163:220-33.

298. Pollock PM, Cohen-Solal K, Sood R, Namkoong J, Martino JJ, Koganti A, Zhu H, Robbins C, Makalowska I, Shin SS, Marin Y, Roberts KG, et al. Melanoma mouse model implicates metabotropic glutamate signaling in melanocytic neoplasia. Nat Genet 2003;34:108-12.

299. Shin SS, Namkoong J, Wall BA, Gleason R, Lee HJ, Chen S. Oncogenic activities of metabotropic glutamate receptor 1 (Grm1) in melanocyte transformation. Pigment Cell Melanoma Res 2008;21:368-78. 


\subsection{Figure Legends}

Figure 1 Cutaneous melanoma may arise from precursor lesions, either a benign nevus or a dysplastic nevus. It is also believed that melanoma can develop directly from abnormal stem cells and not from an existing nevus. Melanomas can then progress to the radial growth phase characterized by proliferation of tumorigenic cells and invasion limited only to the epidermis. The vertical growth phase can then follow, in which the tumorigenic cells begin to grow vertically and invade the deeper tissue of the dermis. Once the melanoma invades the dermis, the tumorigenic cells and can enter into the lymphatic or circulatory system to colonize other organs leading to the metastatic phase of the skin cancer.

Figure 2 The tumor microenvironment includes various cells that have been recruited and inducted by tumorigenic cells such as carcinoma associated fibroblasts, immune cells such as neutrophils, macrophages and lymphocytes, cells that contribute to neovascularization such as endothelial cells and the modified extracellular matrix termed the 'reactive stroma'. (A) The different cells in the tumor microenvironment are influenced by factors secreted by the tumorigenic cells, and in turn produce factors that contribute to the development, growth, invasion and metastasis of melanoma (B). 
Figure 1 Melanoma Progression.

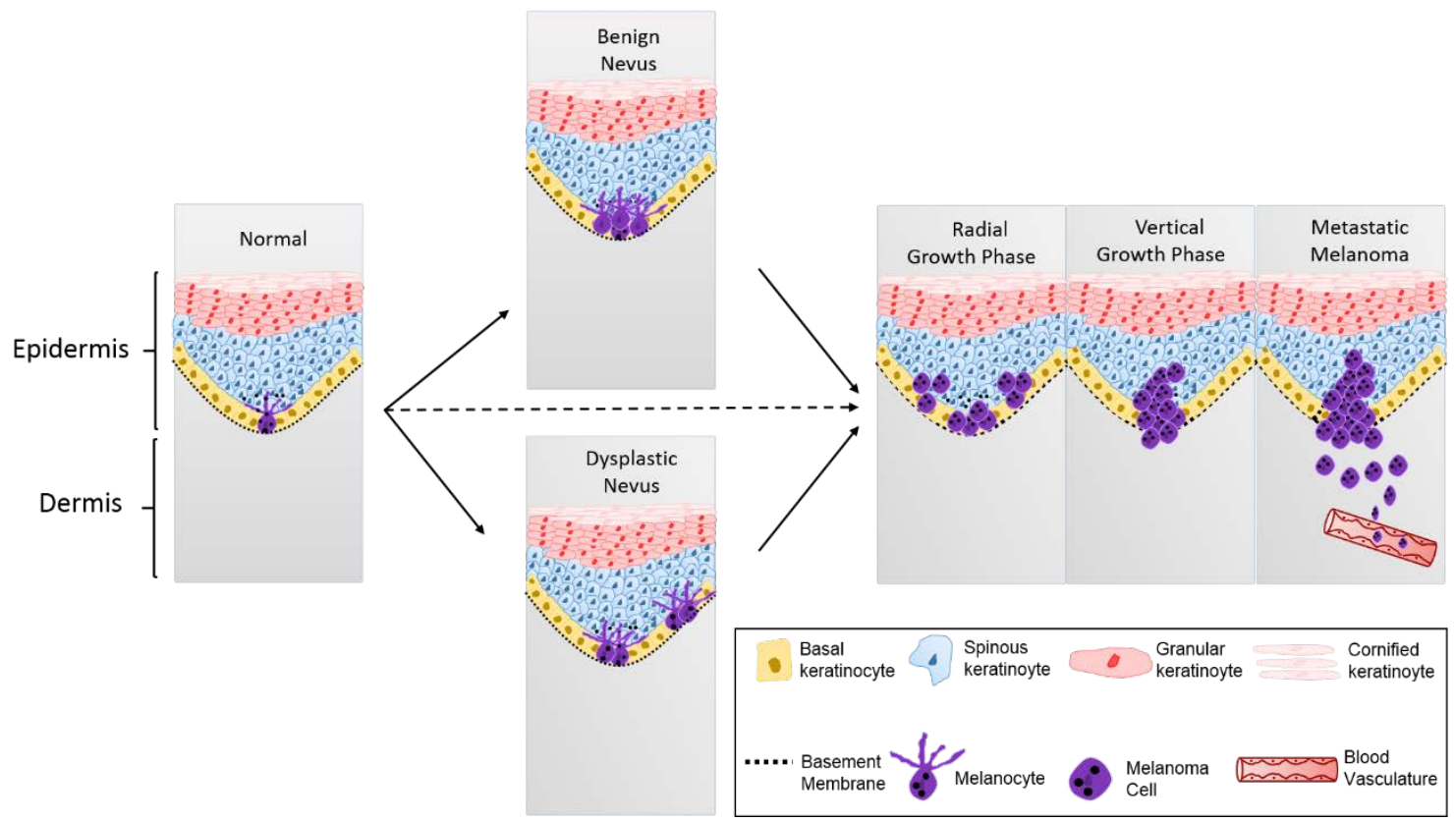

Figure 2 Melanoma Tumor Microenvironment.

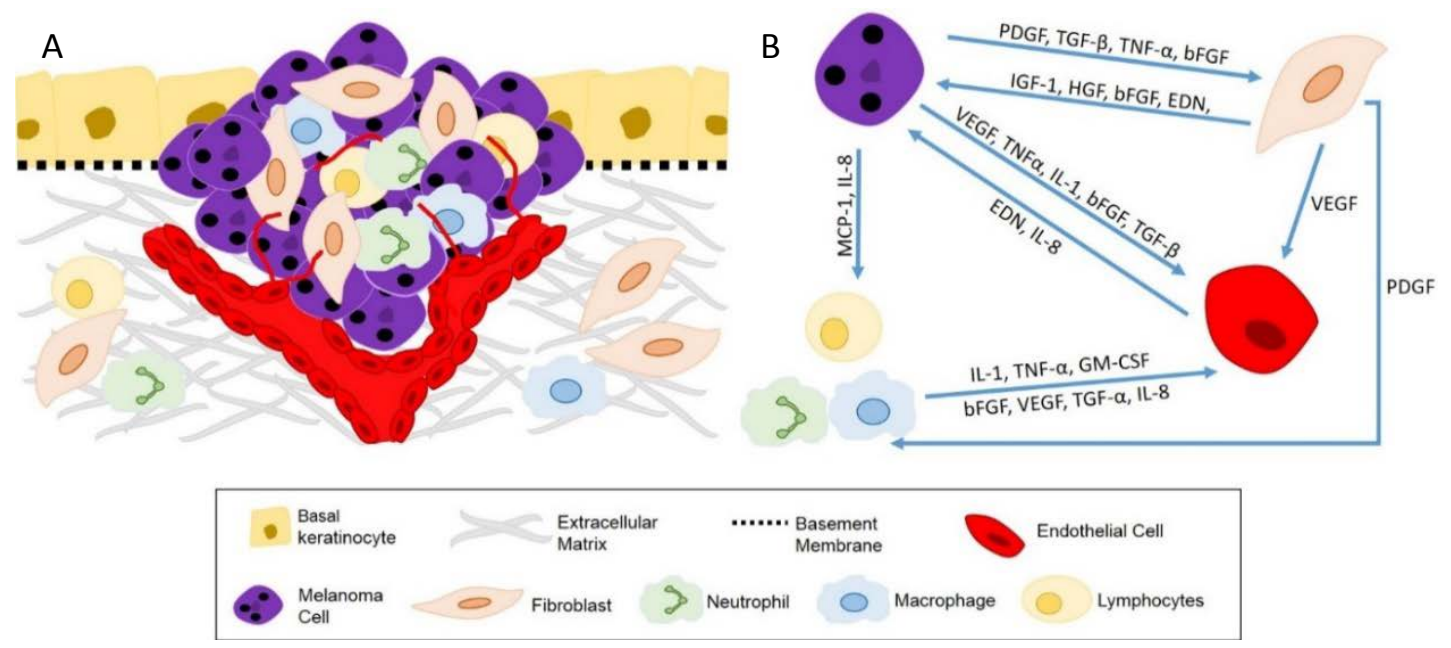




\section{CHAPTER II}

\section{ENDOTHELIN SIGNALING PROMOTES TUMOR PROGRESSION AND}

METASTASIS IN A MOUSE MODEL OF MELANOMA 


\section{ENDOTHELIN SIGNALING PROMOTES TUMOR PROGRESSION AND METASTASIS IN A MOUSE MODEL OF MELANOMA}

\subsection{Introduction}

Tumors are comprised not only of transformed malignant cells but also of a complex system of stroma and various other cell types. This niche is commonly referred to as the 'tumor microenvironment', and each part is integral in promoting malignancy and metastasis ${ }^{1,2}$. Melanoma results from the initial transformation of epithelial melanocytes and subsequent alteration in the associated stroma. Melanoma lesions encompass cells such as fibroblasts, keratinocytes, endothelial and immune cells, all of which inherit dysfunctional cytokine pathways that facilitate malignancy. The tumorigenic cells acquire the ability to reprogram the normal functions of these neighboring cells in the tumor microenvironment, and establish a number of paracrine and autocrine signaling loops to promote angiogenesis, epithelial to mesenchymal transformation and metastasis. The exact mechanisms of the signaling loops are not yet fully understood, but many of them are regulated by growth factors and G-protein coupled receptors (GPCRs) ${ }^{3-5}$.

G Protein Coupled Receptors can become tumorigenic either by acquiring intrinsic mutations that make the receptors constitutively active or by being exposed to excessive amounts of their ligands ${ }^{5-7}$. Endothelin receptor b (EDNRB) is a GPCR that has been implicated in melanoma progression. Endothelin receptor $B$ ligands, endothelins 1, 2, and 3 (EDN1, 2, 3) are primarily involved in vascularization, by acting as vasoconstrictors and vasodilators, 
promoting endothelial cell survival and migration as well as in the mitogenesis of endothelial cells, vascular smooth muscle cells, fibroblasts, and pericytes ${ }^{8,9}$. Additionally, during embryonic development EDNRB and EDN3 are critical for melanocyte proliferation and survival. Endothelin receptor B has also been implicated in melanocyte differentiation before the cells migrate into the epidermis, while EDN3 may be able to delay the differentiation of the melanocytes ${ }^{10}$. Mice carrying mutations of either Ednrb or Edn3 exhibit pigmentation defects such as those seen in the spontaneous mouse mutants piebald lethal and lethal spotting, respectively ${ }^{11-13}$.

In vitro studies using melanoma cell lines, along with gene expression analysis and immunohistochemistry on melanoma biopsies have found that Ednrb expression is progressively up-regulated from dysplastic nevi to metastatic melanomas ${ }^{14-17}$. Tang and colleagues found that EDN3 was up-regulated more than 10-fold at the mRNA level in metastatic melanoma biopsies when compared to benign nevi, while EDN1 and EDN2 expression remained low. They also showed that six out of seven cultured melanoma cell lines expressed EDN3 while human epidermal melanocytes did not ${ }^{18}$.

Treatment of melanoma cell lines with the EDNRB antagonist BQ788 resulted in decreased cell viability by inhibiting proliferation ${ }^{14,19}$ and sensitivity to the inhibitor was more intense in the metastatic malignant cells ${ }^{20}$. The antagonist BQ788 also induced signs of differentiation such as increased dendricity and pigmentation of cultured melanoma cells as well as reduced tumor growth in nude mice implanted with melanoma cell grafts ${ }^{14}$. Other in vitro studies suggest 
that EDN3 may be relevant to specific tumor-host interactions, as treatment of melanoma cell lines with EDN1 and EDN3 resulted in decreased levels of the cell adhesion molecule E-cadherin and increased levels of $\mathrm{N}$-cadherin, which allow the tumorigenic cells to interact with other cell types such as fibroblasts and endothelial cells ${ }^{21}$.

The purpose of our study was to develop melanoma metastasis mouse models to characterize the EDN3/EDNRB axis in melanoma progression and the tumor-host relationships it is involved in to promote metastasis. Transgenic mice that present with spontaneous melanocytic lesions in regions such as the ears and tails with limited metastatic capability $\left(\operatorname{Tg}(\mathrm{Grm} 1) \mathrm{Epv}(\mathrm{E})^{22-24}\right)$ were crossed to transgenic mice that over-express EDN3 by keratinocytes (K5-tTA;TRE-Edn3lac ${ }^{25}$ ), transgenic mice that over-express EDNRB in melanocytes ( $T g(E d n r b) 1 L k)$, or both. The over-expression of Edn3 in the skin microenvironment or of Ednrb in melanocytes led to the formation of rapidly growing highly metastatic lesions allowing for the direct evaluation of the role played by EDN3 in the process of melanomagenesis in vivo.

\subsection{Materials and Methods}

\subsubsection{Mice and Genotyping}

The K5-tTA;TRE-Edn3-lacZ (K5-Edn3 used here for simplicity) and $T g(E d n r b) 1 L k$ mice (Dct-Ednrb used here for simplicity), which were generated in our laboratory ${ }^{25}$, were crossed with the $T g(G r m 1) E p v(E)$ mice (Dct-Grm1used here for simplicity, a gift from Dr. William Pavan, NIH) ${ }^{22}$. Briefly, the K5-Edn3 mice (C57BL/6XSJL/FVB/N) were generated using the tetracycline regulatory 
inducible system and harbors the tTA activator in the regulatory region of the Bos Taurus gene for Keratin 5 to drive the constitutively active expression of End3. The Dct-Ednrb transgenic mice were generated by microinjection of a transgene containing the full length Ednrb cDNA (1958bp, genbank accession \# U32329) under the regulation of $3431 \mathrm{bp}$ of the mouse $\mathrm{Dct}$ promoter and the BGH poly adenylation signal into FVB $F_{1}$ zygotes. The founder line was propagated subsequently for over 10 generations by crosses with C57BL/6J mice. Dct-Grm1 transgenic mice express the metabotropic glutamate receptor 1 under the regulation of the melanocyte specific Dopachrome tautomerase promoter.

Deoxyribonucleic acid (DNA) from tail biopsies were extracted using standard techniques from the progeny of the Dct-Grm1, K5-Edn3, and Dct-Ednrb matings, and Polymerase Chain Reaction (PCR) was used to genotype the mice using the following primers: Dct-Grm1 5'-CCGGGTCCGCATTAATCTTATCTA3'and 5'-GGTAGCATACGGTTCCACGCA-3' which yield a 1700bp PCR product; the K5-tTA primers 5'-CCAGGTGGAGTCACAGGATT-3' and 5'ACAGAGACTGTGGACCACCC-3'and the primers for the tetO-Edn3 yield a 463 bp product and bind to the 3' end of the Edn3 cDNA (5'GGCCTGTGCACACTTCTGT-3') and to non-coding DNA (5'TCCTTGTGAAACTGGAGCCT-3'); Dct-Ednrb 5'ACAAGGAAGACTGGCGAGAA-3' and 5'-TCCTCCCCCTTGCTGTCCTGC-3' which produce a $2218 \mathrm{bp}$ fragment flanking the Dct promoter. Mice were housed in the University Animal Care Facility at Florida International University. The animal protocol was approved by the Committee on Animal Care and Use and 
Office of Sponsored Research at Florida International University and all Institutional Animal Care and Use Committee regulations were followed.

\subsubsection{Tumor Measurements}

After the genotypes of the mice were determined at approximately four weeks of age, mice from the experimental Dct-Grm1/K5-Edn3 and Dct-Grm1/DctEdnrb, and control (Dct-Grm1/ K5, Dct-Grm1/ Edn3 and Dct-Grm1) groups were monitored on a weekly basis for tumor development. The time of tumor appearance for each mouse was calculated as the time between the date of birth of the mouse and the date of the appearance of the first raised melanocytic lesion. The data was plotted as a Kaplan-Meier graph using the Statistical Package for the Social Sciences (SPSS) program Version 13.0 and a log rank test was used for statistical analysis.

Tumor growth of the experimental mice and their control counterparts were measured weekly for 16 weeks using calipers to calculate tumor volume using the equation: length $X$ breadth $^{2} \times 0.5^{14}$. Student's t-test was used for the statistical comparisons. Differences were considered statistically significant at $p<0.05$.

\subsubsection{Metastasis Analysis}

At approximately 9-12 months of age, tumor burdened mice were examined for the presence of metastases in the lymph nodes as well as other common sites of melanoma metastasis such as the lungs and brain. Lymph nodes and organs considered to contain metastatic lesions were fixed overnight in $4 \%$ paraformaldehyde in phosphate buffered solution (PBS, $\mathrm{pH} 7.4$ ), subjected 
to $10 \%$ sucrose (in PBS, pH 7.4 ) for six hours, followed by $20 \%$ sucrose (in PBS, $\mathrm{pH}$ 7.4) overnight and finally embedded in OCT medium (Ted-Pella, CA) and stored at $-80^{\circ} \mathrm{C}$. Samples were sectioned and processed for immunofluorescence.

\subsubsection{Immunofluorescence}

For the analysis of proliferating tumor cells, cryosections (10 $\mu \mathrm{m}$ thick) of tail tumors at three different stages of tumor development were obtained. The stages were classified as: Stage 1- when the tumor became a raised lesion at approximately $0.5 \mathrm{~mm}$ in height, Stage 2 - at approximately $25-30 \mathrm{~mm}^{3}$, and Stage 3- after the tumor developed for 9-12 months. The sections were bleached overnight in $10 \%$ hydrogen peroxide in PBS $(\mathrm{pH} 7.4)$ in order to decolorize melanin. After bleaching, the sections were washed with PBS $(\mathrm{pH} 7.4)$ three times for 15 minutes and then blocked for 1 hour and 15 minutes in a solution of 10\% Goat Serum (Gibco), 0.1\% Triton X-100 (Sigma, MO) in PBS (pH 7.4). For immunolabeling, the sections were incubated overnight at $4^{\circ} \mathrm{C}$ with Anti Ki-67 polyclonal antibody (1:100, Abcam, MA), for one hour with secondary antibody Alexa Flour 488 Goat Anti-Rabbit (1:200, Invitrogen, NY) and counterstained with Hoechst. The Ki-67 positive cells were counted in 10 different sections, 5 fields of view each section, per tumor, using Image $\mathrm{J}$ and shown as a percentage of the total number of cells identified by Hoechst.

To confirm the presence of metastatic lesions in lymph nodes and visceral organs, cryosections (10 $\mu \mathrm{m}$ thick) were labeled with antibodies against the melanoma marker S-100 (1:200, Dako, CA) and the melanocyte marker Trp1 
(1:200, polyclonal rabbit antibody Pep1 provided by Vincent Hearing, NIH). The secondary antibody used was Alexa Flour 488 Goat Anti-Rabbit (1:200, Invitrogen, NY) and the sections were counterstained with propidium iodide. Images were obtained and analyzed with a Leitz DMRB fluorescent microscope and photographed with a Leica DC 500 camera.

\subsubsection{Real-time RT-PCR}

RNA was extracted from tail tumors at stages 1, 2, and 3 of tumor development ( $\mathrm{n}=5$ for each stage). The RNA extraction and purification were conducted using TRIzol Reagent (Invitrogen, NY), the RNeasy Mini Kit (Qiagen, CA) and RNase Free DNase Set (Qiagen, CA). The RNA quality and quantity were assessed using absorbance readings at $260 \mathrm{~nm}, 280 \mathrm{~nm}$ and $230 \mathrm{~nm}$ with the Nano Drop (ND-1000) spectrophotometer. First strand cDNA synthesis of RNA was performed using the Maxima Reverse Transcriptase Kit (Fermentas, $M A)$.

Semiquantitative analysis of transcripts encoding $\alpha_{v}, \alpha_{2}, \beta_{1}, \beta_{3}$, VEGF-A, VEGF-B, Hif-1a, N-cadherin, E-Cadherin, EDNRB, MITF , MCAM, Galectin 3, and GAPDH was conducted by real-time Polymerase Chain Reaction using the Applied Biosystems 7300 Real-Time PCR System. All primer sequences are listed in Table 1 of the Supplementary Data. The real-time PCR reaction was performed in triplicates with SYBR Green I dye, for a total volume of $26 \mu$ l per reaction which included $1 \mu \mathrm{l}$ of $\mathrm{cDNA}$, and $0.44 \mu \mathrm{M}$ of each primer and $12.5 \mu \mathrm{l}$ of Maxima ${ }^{\circledR}$ SYBR Green/ROX qPCR Master Mix (Fermentas, MA). 'No template' controls were also used in the real time experiments. The threshold cycle $(\mathrm{Ct})$ 
values quantified for the target transcripts and the housekeeping gene, Gapdh, were used to derive the fold change for each transcript between the DctGrm1/K5-Edn3 experimental group and Dct-Grm1 controls.

\subsection{Results}

\subsubsection{Edn3 Promotes Early and Rapid Melanoma Growth}

The Dct-Grm1 mice acquire melanocytic lesions that mature into overt melanomas on the tails and ears as a result of the aberrant glutamate signaling. However, the spontaneous acquired melanomas do not give rise to metastatic lesions in distant organs ${ }^{22}$. The melanoma mouse model was therefore a suitable candidate to assess a putative role for EDN3 in tumor progression and metastasis. The Dct-Grm1 mice were crossed with the K5-Edn3 mice to generate an experimental population of transgenic Dct-Grm1/ K5-Edn3 animals as well as a population of control counterparts that lack the over-expression of EDN3 (DctGrm1, Dct-Grm1/K5, Dct-Grm1/Edn3). The K5-Edn3 mice produce higher levels of Edn3 in the skin starting at around embryonic day 12.5 that persist into adulthood. The elevated levels of EDN3 lead to an increase in the number of melanocyte precursors and their maintenance in the adult skin resulting in a hyperpigmentation phenotype ${ }^{25}$. The experimental Dct-Grm1/K5-Edn3 mice $(\mathrm{n}=25)$ and the control mice (Dct-Grm1, Dct-Grm1/K5, Dct-Grm1/Edn3) $(\mathrm{n}=25)$

were monitored weekly to observe differences in tumor development between the two groups. The time it took for the first melanocytic lesion to develop on the mice was calculated from the date of birth of the mice to the date when the first tumor appeared. The data plotted on a Kaplan Meier graph, revealed that the 
Dct-Grm1/K5-Edn3 mice acquired their first melanocytic lesion significantly earlier $(\mathrm{p}<0.001)$ than the Dct-Grm1 control mice (Fig.1A). The Dct-Grm1/K5Edn3 mice acquired their first tumor on average at about 23 weeks after birth, while the average time for the Dct-Grm1 control mice to acquire their first tumor was at approximately 31 weeks after birth.

Once present, the tumors of the Dct-Grm1/K5-Edn3 mice grew faster than the Dct-Grm1 tumors. Ear tumors grew 13 times faster in the experimental mice $(n=20)$ than in the control mice $(n=20)(p=1.3864 E-06)$. The size of the tumors at each week was also significantly different between experimental and control groups ( $p \leq 0.009$ ) (Fig. 1B-D). The tail tumors of the Dct-Grm1/K5-Edn3 mice grew 5 times faster than those of the Dct-Grm1 mice. Over the 16 week period, the size of the Dct-Grm1/K5-Edn3 tail tumors $(\mathrm{n}=20)$ were significantly larger $(p=0.004)$ than the controls $(n=20)$ (Supplementary Fig. S1).

In order to determine the underlying mechanism for the difference in tumor

growth between the control and experimental animals, we counted the number of proliferating tumorigenic cells by labeling the lesions at Stages 1 and 2 with an antibody against Ki-67 (Fig. 2A-L). At both stages the Dct-Grm1/K5-Edn3 mice had a higher percentage of Ki-67 positive cells than the Dct-Grm1 controls (Fig. $2 \mathrm{M}, \mathrm{N}$ ), but the difference was only significantly greater for the Dct-Grm1/ K5Edn3 group at Stage $2(\mathrm{p}=0.01)$.

\subsubsection{Edn3 Promotes the Formation of Dorsal Skin Tumors}

Apart from the ear and tail tumors Dct-Grm1/K5-Edn3 transgenic mice also acquired pigmented melanocytic lesions on their dorsal skin (Supplementary 
Fig. S2), a condition not observed or previously described in the Dct-Grm1 control mice. The dorsal skin lesions were observed in $75 \%$ of the Dct-Grm1/K5Edn3 mice $(n=40)$ and could be detected as early as 12 weeks after the mice were born. Like the ear and tail tumors, the dorsal lesions first appeared as nonraised skin lesions and continued to form large overt tumors on the skin. The dorsal lesions stained positive for S100 and Trp1, thus confirming these lesions were of melanocytic origin and were spontaneous melanomas similar to the tail and ear tumors.

\subsubsection{Edn3 Promotes Melanoma Metastasis to Lymph Nodes and Visceral Organs}

The Dct-Grm1/K5-Edn3 and the Dct-Grm1 control mice were examined for signs of metastasis after the first melanocytic tumor had been present for approximately 6.5 to 9 months. Eight-one percent of the Dct-Grm1/K5-Edn3 $(n=37)$ mice presented with metastases in lymph nodes and distant organs while none of the Dct-Grm1 control counterparts $(\mathrm{n}=35)$ did. The Dct-Grm1 mice showed micrometastases, on average two per lung $(n=3)$, but the areas where they were found were not labeled with antibodies against Trp-1 and S100. All experimental animals showed enlarged highly pigmented lymph nodes. Although some control animals also displayed enlarged lymph nodes, they never stained positive for Trp1 indicating the absence of cells of melanocytic origin (Supplementary Fig. 3A-F). The lymph nodes of the Dct-Grm1/K5-Edn3 were significantly larger $(p \leq 0.001)$ than those of the Dct-Grm1 control mice (Supplementary Fig. 3G). The most common site where secondary lesions were 
observed was the lungs (23/37) (Fig.3A-B). The lungs' pigmented lesions ranged from large overt metastatic tumors, smaller pigmented lesions that were clearly visible with the naked eye, to much smaller micrometastases that were only visible under a dissecting microscope. These lesions labeled positive for Trp1 and S100 confirming their melanoma nature (Figure 3C). The brain was the second most common site for melanoma metastasis (14/37) (Fig. 3D-F). Metastatic lesions were also found in the salivary glands (9/37), spleen (2/37) and kidney (1/37) of the Dct-Grm1/ K5-Edn3 mice. The lesions found in these organs were also positive for S100 or Trp1 $(\mathrm{n}=5)$. The Dct-Grm1/K5-Edn3 mice often had metastatic lesions in multiple organs concomitantly, for example, in the brain and lungs (Supplementary Table 2).

\subsubsection{Edn3 Alters the Expression of Genes Involved in Metastasis}

Because the Dct-Grm1/K5-Edn3 mice had a more aggressive metastatic phenotype than the Dct-Grm1 controls we assessed for differences in the expression of genes implicated in melanoma metastasis that included cell adhesion and cell-matrix interaction proteins, angiogenic factors, and relevant melanocytic developmental genes. At Stage 1 there was significant upregulation of $\alpha_{v}, \alpha_{2}, \beta_{3}$ integrin subunits, VEGF-A, both E-cadherin and $N$ cadherin as well as Galectin 3 in the Dct-Grm1/ K5-Edn3 tumors when compared to the controls (Fig. 4A). At Stage 2, only VEGF-B and Hif-1a were significantly up-regulated in the experimental tail tumors (Fig. 4B), while at Stage 3 the expression levels of $\mathrm{N}$-cadherin, E-cadherin, Galectin 3, Mitf and MCAM were 
found to be significantly higher in the Dct-Grm1/ K5-Edn3 mice than the control group (Fig. 4C).

\subsubsection{EDNRB Promotes Early and Rapid Melanoma Growth, and Strong Metastatic Properties}

Since we did not observe much up-regulation of Ednrb in the lesions of Dct-Grm1/ K5-Edn3 in comparison to those of control Dct-Grm1 animals we investigated if forced Ednrb over-expression in melanocytes under the Dct promoter would also alter the dynamics of tumor growth and the metastatic potential of the tumorigenic cells. The Dct-Grm1 mice were crossed with the DctEdnrb mice to generate an experimental population of transgenic Dct-Grm1/ DctEdnrb animals as well as a population of control counterparts that lack the overexpression of Ednrb (Dct-Grm1). As for the Dct-Grm1/K5-Edn3 mice, Dct-Grm1/ Dct-Ednrb acquired their first melanocytic lesion significantly earlier $(p=0.004)$ than the Dct-Grm1 control mice (Fig.5A). The Dct-Grm1/Dct-Ednrb mice acquired their first tumor on average at about 26 weeks after birth, while the average time for the Dct-Grm1 control mice to acquire their first tumor was at approximately 45 weeks after birth. The tumors of the Dct-Grm1/Dct-Ednrb mice grew faster than the Dct-Grm1 tumors. Ear tumors grew 70 times faster in the experimental mice $(n=11)$ than in the control mice $(n=7)(p=3.365 E-05)$. The size of the tumors at each week (except for week 1, 2 and 4) was also significantly different between experimental and control groups ( $p \leq 0.04)$ (Fig. 5B). The tail tumors of the DctGrm1/Dct-Ednrb mice grew 22 times faster than those of the Dct-Grm1 mice. Over the 16 week period, the size of the Dct-Grm1/Dct-Ednrb tail tumors ( $\mathrm{n}=15)$ 
were significantly larger $(p=0.001)$ than the controls $(n=10)$ (Supplementary Fig. S4). Seventy six percent $(\mathrm{n}=25)$ of $D c t-G r m 1 / D c t-E d n r b$ mice presented with metastasis by 1 year of age. Interestingly, the percentage of Dct-Grm1/Dct-Ednrb animals that had metastasis in the brain (60\%, Supplementary Fig. S5) was almost double that of Dct-Grm1/ K5-Edn3 animals (37\%).

We also generated a small number of animals over-expressing both Edn3 and Ednrb by crossing Dct-Grm1/K5-Edn3 with Dct-Grm1/Dct-Ednrb animals. Dct-Grm1/K5-Edn3/Dct-Ednrb mice ( $\mathrm{n}=19)$ acquired their first melanocytic lesion significantly earlier than the Dct-Grm1-K5-Edn3 $(\mathrm{n}=16 ; \mathrm{p}=0.001)$ and DctGrm1/Dct-Ednrb ( $\mathrm{n}=4 ; \mathrm{p}=0.006)$ mice (Supplementary Fig. S6). The DctGrm1/K5-Edn3/Dct-Ednrb mice acquired their first tumor on average at about 13 weeks after birth, while the average time for the Dct-Grm1/K5-Edn3 mice to acquire their first tumor was at 22 weeks and for the Dct-Grm1/Dct-Ednrb was at 24 weeks after birth. All Dct-Grm1/K5-Edn3/Dct-Ednrb animals had metastasis in the lungs by 1 year of age. These results clearly demonstrate that the upregulation of the $E d n 3 / E d n r b$ signaling pathway in melanocytes accelerates the process of melanomagenesis and stimulates malignancy.

\subsection{Discussion}

In this study we created novel metastasis melanoma mouse models in order to evaluate the role of the Ednrb /Edn3 axis in melanoma progression. The Dct-Grm1/ K5-Edn3 mouse model showed that excessive Edn3 paracrine signaling from keratinocytes affects melanoma progression and metastasis. There have been very few genetically engineered mouse models of melanoma 
with visceral metastasis reported ${ }^{26}$. To our knowledge, the Dct-Grm1/ K5-Edn3 is the first spontaneous metastasis melanoma mouse model that is dependent on the presence of a signaling molecule exclusively in the tumor microenvironment. The Dct-Grm1/ Dct-Ednrb model further supports a role for the endothelin signaling pathway in melanoma progression and corroborates recent findings that over-expression of Ednrb may be an important factor driving melanoma brain metastases $^{27}$.

Previous studies using melanoma cell lines showed that inhibition of Ednrb resulted in the decrease of tumor growth ${ }^{14,21,28}$. Thus, EDN3 may be one of the critical mitogenic factors directly affecting melanoma growth as its upregulation in the Dct-Grm1/ K5-Edn3 mouse not only significantly shortened the length of time it took for the development of melanocytic lesions but also increased how fast both ear and tail tumors grew. Comparative immunofluorescence analysis of Ki-67 using two different stages of melanoma development also showed significantly higher amounts of proliferating cells in the tail tumors of the Dct-Grm1/ K5-Edn3 mice. Thus, in vivo over-expression of End3 alters melanoma progression kinetics leading to an increase in growth rate. Since endothelins are known to participate in angiogenesis, the effect of EDN3 in melanoma growth rate may be due to an increase in neovascularization that is necessary to provide the tumor with adequate supplies of nutrients and oxygen in order to survive and grow past $2 \mathrm{~mm}^{29}$.

Endothelin receptor $\mathrm{B}$ has been closely associated with the melanoma metastatic phenotype. Endothelin receptor B gene expression is higher in 
metastatic melanoma cell lines and biopsies in comparison to nevi and primary melanomas ${ }^{17,20,30}$. It was suggested that Edn1 was the primary ligand acting on EDNRB to promote melanoma progression while EDN3 was not as vital since it was not found to be up-regulated by ultraviolet light $17,31,32$. Notwithstanding, Tang and colleagues (2008) found that EDN3, and not EDN1, was significantly up-regulated more than 10 fold in metastatic melanoma biopsies when compared to benign nevi and promoted melanoma cell survival ${ }^{18}$. Additionally, EDN3 was required along with other growth factors and ultraviolet light to transform human melanocytes into melanoma in vivo ${ }^{33}$. Combined with our results, these findings show that the presence of Edn3 in the tumor microenvironment contributes to melanoma progression.

To further characterize the effects of EDN3 on melanoma metastasis we examined whether its presence would enhance melanoma malignancy in the DctGrm1/ K5-Edn3 mouse model when compared to the Dct-Grm1 mice that have limited metastatic capability. It was recently reported that the Dct-Grm1 mice have pigmented Grm1/Dct positive disseminated cells in the lymph nodes and non-pigmented Dct positive cells in the lung and liver ${ }^{24}$. Nevertheless, the DctGrm1/K5-Edn3 mice have a considerable more aggressive melanoma phenotype than the Dct-Grm1 control mice. Thus, EDN3 in the tumor microenvironment must lead to cellular and molecular changes required for the metastatic process. The occurrence of distant metastases in the Dct-Grm1/Dct-Ednrb mice, albeit with smaller penetrance when compared to the Dct-Grm1/K5-Edn3 animals, indicates that the levels of ligand available in the skin and/or lesions is not 
limiting for the changes required to enhance the metastatic potential of the tumorigenic cells.

Gene expression analysis of Dct-Grm1/K5-Edn3 tail tumor development indicated that changes were stage specific and that the metastatic process was occurring as early as the lesions were noticeable. One of the most surprising findings was that the expression levels of cadherins, in any of the stages examined did not follow the E-cadherin to $\mathrm{N}$-cadherin switch that has been widely accepted as a key component in melanomagenesis ${ }^{34-36}$. Except for the 2-3mm stage where $E$-cadherin was slightly down-regulated and $N$-cadherin was slightly up-regulated, both cadherins showed similar expression levels in the other two stages. One possible explanation for the failure to detect the cadherin switch is that we compared gene expression levels between two types of tumors and not between normal and transformed melanocytes where the switch normally occurs. Another possible explanation is that unlike human skin, mouse melanocytes are not found in the epidermis but reside primarily in hair follicles. Even though the melanocytes in the Dct-Grm1/K5-Edn3 mice are localized around the epidermaldermal junction, they may not be under the same type of control from the keratinocytes. Therefore E-cadherin levels may not need to be drastically reduced in these tumors.

The potential role of Edn3 in tumor angiogenesis is supported by the expression changes in VEGF-A, VEGF-B and Hif-1a. The observed up-regulation of VEGF-A in tumors at Stage 1 suggests its involvement in the recruitment, proliferation, and differentiation of endothelial cells that are important to the tumor 
microenvironment ${ }^{37}$. More striking is the fact that the only two genes upregulated at Stage 2, when the Dct-Grm1/ K5-Edn3 tail tumors begin to grow faster than those in the Dct-Grm1 controls, were VEGF-B and Hif-1a. These results corroborate previous studies that showed that Edn1 and Edn3 up-regulate the expression of VEGF and Hif-1 $\alpha^{38,39}$.

The changes in the expression of cell-matrix and cell adhesion molecules such as integrin $\alpha_{v}, \beta_{3}$ and $\alpha_{2}$ subunits as well as Galectin 3 in Dct-Grm1/ K5Edn3 lesions at stage 1 suggest that the tumorigenic cells gain migratory and metastatic properties very early in tumor development. The up-regulation of integrin $\beta_{3}$ subunit is normally used to characterize the melanoma vertical growth phase (VGP), is found on $80 \%$ of VGP's, $100 \%$ of metastatic melanomas ${ }^{40}$, and correlates to the presence of lung metastases. Both the $\alpha_{v} \beta_{3}$ subunits and Galectin 3 function as receptors for elastins and elastin-derived peptides that have been shown to promote tumor progression and metastasis ${ }^{41}$. Galectin 3 was also up-regulated at stage 3 along with MCAM, when melanoma lesions in distant organs were detected indicating that Edn3 may exert its effects throughout the metastatic process. A previous study showed that the silencing of Galectin 3 in metastatic melanoma cells in nude mice significantly decreased the number of lung metastases ${ }^{42}$. Melanoma cell adhesion molecule gene expression progressively increases during melanoma progression until it is at its highest in metastatic melanoma cells ${ }^{43-45}$, and MCAM aids in the later stages of metastasis including extravasation and establishing new foci of growth ${ }^{46}$. 
The other gene found to be up-regulated at stage 3 was the transcription factor Mitf. This result is in accordance with some but not all expression studies performed with human biopsies and cell lines. Microphthalmia associated transcription factor (MITF) was sometimes found to be highly expressed in benign nevi, and either absent or expressed at high levels in metastatic melanomas ${ }^{47-49}$. The expression of MITF in melanoma specimens has been inversely correlated to that of Hif1- $\alpha$ and the induction of Hif1- $\alpha$ in melanoma cell lines led to a decrease in the levels of MITF ${ }^{50}$. We observed the same relationship at all stages examined: when the expression of Hif1- $\alpha$ was high, Mitf levels were very low (stages 1 and 2) and vice-versa (stage 3).

Together, our findings show that increased signaling via Ednrb, either by higher levels of the receptor on melanocytes or the ligand in the microenvironment, promotes a more malignant melanoma phenotype, and can stimulate tumor growth and metastasis. The Dct-Grm1/ K5-Edn3 and DctGrm1/Dct-Ednrb melanoma mouse models can be employed to further our understanding of changes that lead to melanoma progression and test strategies to prevent these changes in order to inhibit metastasis.

\subsection{References}

1. Albini A, Sporn MB. The tumour microenvironment as a target for chemoprevention. Nat Rev Cancer 2007;7: 139-47.

2. Hanahan D, Weinberg RA. The hallmarks of cancer. Cell 2000;100: 57-70. 3. Lee JT, Herlyn M. Microenvironmental influences in melanoma progression. J Cell Biochem 2007;101: 862-72.

4. Li S, Huang S, Peng SB. Overexpression of G protein-coupled receptors in cancer cells: involvement in tumor progression. Int J Oncol 2005;27: 1329-39. 
5. Lee HJ, Wall B, Chen S. G-protein-coupled receptors and melanoma. Pigment Cell Melanoma Res 2008;21: 415-28.

6. Gutkind JS, Novotny EA, Brann MR, Robbins KC. Muscarinic acetylcholine receptor subtypes as agonist-dependent oncogenes. Proc Natl Acad Sci U S A 1991;88: 4703-7.

7. Allen LF, Lefkowitz RJ, Caron MG, Cotecchia S. G-protein-coupled receptor genes as protooncogenes: constitutively activating mutation of the alpha $1 \mathrm{~B}$ adrenergic receptor enhances mitogenesis and tumorigenicity. Proc Natl Acad Sci U S A 1991;88: 11354-8.

8. Yanagisawa H, Hammer RE, Richardson JA, Williams SC, Clouthier DE, Yanagisawa M. Role of Endothelin-1/Endothelin-A receptor-mediated signaling pathway in the aortic arch patterning in mice. J Clin Invest 1998;102: 22-33.

9. Bagnato A, Rosano L. The endothelin axis in cancer. Int J Biochem Cell Biol 2008;40: 1443-51.

10. Saldana-Caboverde A, Kos L. Roles of endothelin signaling in melanocyte development and melanoma. Pigment Cell Melanoma Res;23: 160-70.

11. Baynash AG, Hosoda K, Giaid A, et al. Interaction of endothelin-3 with endothelin-B receptor is essential for development of epidermal melanocytes and enteric neurons. Cell 1994;79: 1277-85.

12. Hosoda K, Hammer RE, Richardson JA, et al. Targeted and natural (piebaldlethal) mutations of endothelin-B receptor gene produce megacolon associated with spotted coat color in mice. Cell 1994;79: 1267-76.

13. Tachibana M, Kobayashi Y, Matsushima Y. Mouse models for four types of Waardenburg syndrome. Pigment Cell Res 2003;16: 448-54.

14. Lahav R, Heffner G, Patterson PH. An endothelin receptor B antagonist inhibits growth and induces cell death in human melanoma cells in vitro and in vivo. Proc Natl Acad Sci U S A 1999;96: 11496-500.

15. Lahav R. Endothelin receptor $B$ is required for the expansion of melanocyte precursors and malignant melanoma. Int J Dev Biol 2005;49: 173-80.

16. Bittner M, Meltzer $\mathrm{P}$, Chen $\mathrm{Y}$, et al. Molecular classification of cutaneous malignant melanoma by gene expression profiling. Nature 2000;406: 536-40. 
17. Demunter A, De Wolf-Peeters C, Degreef H, Stas M, van den Oord JJ. Expression of the endothelin-B receptor in pigment cell lesions of the skin. Evidence for its role as tumor progression marker in malignant melanoma. Virchows Arch 2001;438: 485-91.

18. Tang L, Su M, Zhang Y, et al. Endothelin-3 is produced by metastatic melanoma cells and promotes melanoma cell survival. J Cutan Med Surg 2008;12: 64-70.

19. Ishikawa K, Ihara M, Noguchi K, et al. Biochemical and pharmacological profile of a potent and selective endothelin B-receptor antagonist, BQ-788. Proc Natl Acad Sci U S A 1994;91: 4892-6.

20. Lahav R, Suva ML, Rimoldi D, Patterson PH, Stamenkovic I. Endothelin receptor $B$ inhibition triggers apoptosis and enhances angiogenesis in melanomas. Cancer Res 2004;64: 8945-53.

21. Bagnato A, Rosano L, Spinella F, Di Castro V, Tecce R, Natali PG. Endothelin $B$ receptor blockade inhibits dynamics of cell interactions and communications in melanoma cell progression. Cancer Res 2004;64: 1436-43.

22. Pollock PM, Cohen-Solal K, Sood R, Namkoong J, Martino JJ, Koganti A, Zhu H, Robbins C, Makalowska I, Shin SS, Marin Y, Roberts KG, et al. Melanoma mouse model implicates metabotropic glutamate signaling in melanocytic neoplasia. Nat Genet 2003;34: 108-12.

23. Marin YE, Chen S. Involvement of metabotropic glutamate receptor 1 , a $\mathrm{G}$ protein coupled receptor, in melanoma development. J Mol Med (Berl) 2004;82: 735-49.

24. Schiffner S, Chen S, Becker JC, Bosserhoff AK. Highly pigmented Tg(Grm1) mouse melanoma develops non-pigmented melanoma cells in distant metastases. Exp Dermatol;21: 786-8.

25. Garcia RJ, Ittah A, Mirabal S, Figueroa J, Lopez L, Glick AB, Kos L. Endothelin 3 induces skin pigmentation in a keratin-driven inducible mouse model. J Invest Dermatol 2008;128: 131-42.

26. Walker GJ, Soyer HP, Terzian T, Box NF. Modelling melanoma in mice. Pigment Cell Melanoma Res 2011;24: 1158-76.

27. Cruz-Muñoz W, Jaramillo ML, Man S, Xu P, Banville M, Collins C, Nantel A, Francia G, Morgan SS, Cranmer LD, O'Connor-McCourt MD, Kerbel RS.. Roles for endothelin receptor B and BCL2A1 in spontaneous CNS metastasis of melanoma. Cancer Res 2012;72: 4909-19. 
28. Kikuchi K, Nakagawa H, Kadono T, Etoh T, Byers HR, Mihm MC, Tamaki K. Decreased ET(B) receptor expression in human metastatic melanoma cells.

Biochem Biophys Res Commun 1996;219: 734-9.

29. Folkman J. Tumor angiogenesis: a possible control point in tumor growth. Ann Intern Med 1975;82: 96-100.

30. Yohn JJ, Smith C, Stevens T, Hoffman TA, Morelli JG, Hurt DL, Yanagisawa M, Kane MA, Zamora MR. Human melanoma cells express functional endothelin1 receptors. Biochem Biophys Res Commun 1994;201: 449-57.

31. Imokawa G, Yada Y, Miyagishi M. Endothelins secreted from human keratinocytes are intrinsic mitogens for human melanocytes. J Biol Chem 1992;267: 24675-80.

32. Imokawa G, Miyagishi M, Yada Y. Endothelin-1 as a new melanogen: coordinated expression of its gene and the tyrosinase gene in UVB-exposed human epidermis. J Invest Dermatol 1995;105: 32-7.

33. Berking C, Takemoto R, Satyamoorthy K, Shirakawa T, Eskandarpour M, Hansson J, VanBelle PA, Elder DE, Herlyn M. Induction of melanoma phenotypes in human skin by growth factors and ultraviolet B. Cancer Res 2004;64: 807-11.

34. Tang A, Eller MS, Hara M, Yaar M, Hirohashi S, Gilchrest BA. E-cadherin is the major mediator of human melanocyte adhesion to keratinocytes in vitro. $J$ Cell Sci 1994;107: 983-92.

35. Hsu MY, Meier FE, Nesbit M, Hsu JY, Van Belle P, Elder DE, Herlyn M. Ecadherin expression in melanoma cells restores keratinocyte-mediated growth control and down-regulates expression of invasion-related adhesion receptors. Am J Pathol 2000;156: 1515-25.

36. Hsu MY, Wheelock MJ, Johnson KR, Herlyn M. Shifts in cadherin profiles between human normal melanocytes and melanomas. J Investig Dermatol Symp Proc 1996;1: 188-94.

37. Zhu Z, Witte L. Inhibition of tumor growth and metastasis by targeting tumorassociated angiogenesis with antagonists to the receptors of vascular endothelial growth factor. Invest New Drugs 1999;17: 195-212.

38. Pedram A, Razandi M, Hu RM, Levin ER. Vasoactive peptides modulate vascular endothelial cell growth factor production and endothelial cell proliferation and invasion. J Biol Chem 1997;272: 17097-103. 
39. Spinella F, Rosano L, Di Castro V, et al. Endothelin-1 and endothelin-3 promote invasive behavior via hypoxia-inducible factor-1alpha in human melanoma cells. Cancer Res 2007;67: 1725-34.

40. Albelda SM, Mette SA, Elder DE, Stewart R, Damjanovich L, Herlyn M, Buck $\mathrm{CA}$. Integrin distribution in malignant melanoma: association of the beta 3 subunit with tumor progression. Cancer Res 1990;50: 6757-64.

41. Pocza P, Suli-Vargha H, Darvas Z, Falus A. Locally generated VGVAPG and VAPG elastin-derived peptides amplify melanoma invasion via the galectin-3 receptor. Int J Cancer 2008;122: 1972-80.

42. Mourad-Zeidan AA, Melnikova VO, Wang H, Raz A, Bar-Eli M. Expression profiling of Galectin-3-depleted melanoma cells reveals its major role in melanoma cell plasticity and vasculogenic mimicry. Am J Pathol 2008;173: 183952.

43. Johnson JP, Rummel MM, Rothbacher U, Sers C. MUC18: A cell adhesion molecule with a potential role in tumor growth and tumor cell dissemination. Curr Top Microbiol Immunol 1996;213: 95-105.

44. Shih IM, Elder DE, Hsu MY, Herlyn M. Regulation of Mel-CAM/MUC18 expression on melanocytes of different stages of tumor progression by normal keratinocytes. Am J Pathol 1994;145: 837-45.

45. Xie S, Luca M, Huang S, Gutman M, Reich R, Johnson JP, Bar-Eli M. Expression of MCAM/MUC18 by human melanoma cells leads to increased tumor growth and metastasis. Cancer Res 1997;57: 2295-303.

46. Schlagbauer-Wadl H, Jansen B, Müller M, Polterauer P, Wolff K, Eichler HG, Pehamberger H, Konak E, Johnson JP. Influence of MUC18/MCAM/CD146 expression on human melanoma growth and metastasis in SCID mice. Int $\mathrm{J}$ Cancer 1999;81: 951-5.

47. Salti GI, Manougian T, Farolan M, Shilkaitis A, Majumdar D, Das Gupta TK. Micropthalmia transcription factor: a new prognostic marker in intermediatethickness cutaneous malignant melanoma. Cancer Res 2000;60: 5012-6.

48. Selzer E, Wacheck V, Lucas T, Heere-Ress E, Wu M, Weilbaecher KN, Schlegel W, Valent P, Wrba F, Pehamberger H, Fisher D, Jansen B. The melanocyte-specific isoform of the microphthalmia transcription factor affects the phenotype of human melanoma. Cancer Res 2002;62: 2098-103.

49. Garraway LA, Widlund HR, Rubin MA, Getz G, Berger AJ, Ramaswamy S, Beroukhim R, Milner DA, Granter SR, Du J, Lee C, Wagner SN, et al. Integrative 
genomic analyses identify MITF as a lineage survival oncogene amplified in malignant melanoma. Nature 2005;436: 117-22.

50. Buscà R, Berra E, Gaggioli C, Khaled M, Bille K, Marchetti B, Thyss $R$, Fitsialos G, Larribère L, Bertolotto $C$, Virolle $T$, Barbry $P$, et al. Hypoxiainducible factor 1 alpha\} is a new target of microphthalmia-associated transcription factor (MITF) in melanoma cells. J Cell Biol 2005;170: 49-59.

\subsection{Figure Legends}

Figure 1 Time to tumor appearance and tumor growth rate in Dct-Grm1/K5-Edn3 mice. (A) Kaplan-Meier curve of tumor-free survival. The tumor free-survival period of Dct-Grm1/K5-Edn3 mice $(\mathrm{n}=25)$ was significantly shorter $(\mathrm{p}=0.001$, logrank test) than that of Dct-Grm1 controls ( $\mathrm{n}=25)$. (B-C) Dct-Grm1 and DctGrm1/K5-Edn3 mice with same age ear tumors (arrows). (D) Weekly tumor size of Dct-Grm1/K5-Edn3 $(\mathrm{n}=20)$ ear tumors is significantly larger $(\mathrm{p}=1.3864 \mathrm{E}-06, \mathrm{~T}$ test) than that of Dct-Grm1 controls $(n=20)$ Error bars, s.e.m. The sizes of the Dct-Grm1/K5-Edn3 and Dct-Grm1 control group ear tumors were significantly different at each week $\left({ }^{*} p \leq 0.009\right.$, T-test).

Figure 2 Proliferation analysis of $D c t-G r m 1 / K 5-E d n 3$ mouse tumors. (A-L) Representative sections of Dct-Grm1/K5-Edn3 and Dct-Grm1 tail tumors at Stage 1 and 2 labeled with Ki-67 antibody (green) and counterstained with Hoescht (blue). Scale bar: $50 \mu \mathrm{m}$. (M and N) Quantification of the ratio of Ki-67 positive cells to total number of cells $(n=5)$. The number of Ki-67 positive cells was significantly higher $\left({ }^{\star} \mathrm{p}=0.01\right)$ in the $D c t-G r m 1 / K 5-E d n 3$ tumors when compared to those of Dct-Grm1 controls only at Stage 2 . 
Figure 3 Metastatic lesions in Dct-Grm1/K5-Edn3 mice. Metastases in lung (A) and brain (D). Scale bar: $2 \mathrm{~mm}$. Cryosections $(10 \mu \mathrm{m})$ of lung $(B, C)$ and brain $(E$, F) metastases stained with Hematoxilin and Eosin (B, E) and labeled with Trp1

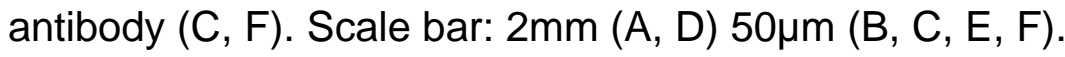

Figure 4 Gene expression analysis of $D c t-G r m 1 / K 5-E d n 3$ mouse tumors. Semiquantitative real time RT-PCR analysis comparing tail tumors taken at three different stages of tumor progression from Dct-Grm1/K5-Edn3 and Dct-Grm1 controls. Expression levels determined to be significant when equal or larger than 2 fold.

Figure 5 Time to tumor appearance and tumor growth rate in Dct-Grm1/DctEdnrb mice. (A) Kaplan-Meier curve of tumor-free survival. The tumor freesurvival period of Dct-Grm1/Dct-Ednrb mice ( $\mathrm{n}=18)$ was significantly shorter ( $p=0.004$, log-rank test) than that of Dct-Grm1controls $(n=18) .(B)$ Weekly tumor size of Dct-Grm1/Dct-Ednrb ( $\mathrm{n}=11)$ ear tumors is significantly larger $(\mathrm{p}=3.365 \mathrm{E}-$ 05, T-test) than that of Dct-Grm1 controls ( $\mathrm{n}=7)$ Error bars, s.e.m. The sizes of the Dct-Grm1/Dct-Ednrb and Dct-Grm1 control group ear tumors were significantly different at each week ( ${ }^{*} p \leq 0.04$, T-test) except for week 1,2 and 4. Supplementary Figure 1 Tail tumor growth rate in Dct-Grm1/K5-Edn3 mice. Weekly tumor size of $D c t-G r m 1 / K 5-E d n 3(n=20)$ tail tumors is significantly faster $(p=0.004, T$-test) than that of Dct-Grm1 controls $(n=20)$ Error bars, s.e.m. The sizes of the Dct-Grm1/K5-Edn3 and Dct-Grm1 control group tail tumors were significantly different at each week ( ${ }^{*} p \leq 0.02$, T-test). 
Supplementary Figure 2 Dorsal tumors in Dct-Grm1/K5-Edn3 mice. DctGrm1/K5-Edn3 mice $(n=30)$ developed tumors on the dorsal skin $(A)$ that stained positive for the S100 melanoma marker (B). Scale bar: $50 \mu \mathrm{m}$.

Supplementary Figure 3 Lymph node metastasis. (A-F) Representative sections of cervical lymph nodes labeled with Trp1 antibody (green). Scale bar:

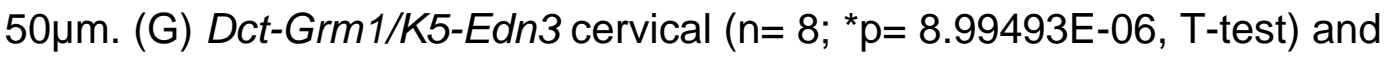
inguinal lymph nodes $\left(n=6 ;{ }^{*} \mathrm{p}=1.14 \mathrm{E}-04, T\right.$-test $)$ were significantly larger than those of Dct-Grm1 controls. Error bars, s.e.m.

Supplementary Figure 4 Tail tumor growth rate in Dct-Grm1/Dct-Ednrb mice. Weekly tumor size of $D c t-G r m 1 / K 5-E d n 3(n=15)$ tail tumors is significantly faster $(p=0.001, T$-test) than that of Dct-Grm1 controls $(n=10)$ Error bars, s.e.m. The sizes of the Dct-Grm1/Dct-Ednrb and Dct-Grm1 control group tail tumors were significantly different at each week except for week 1 ( ${ }^{*} p \leq 0.01$, T-test).

Supplementary Figure 5 Brain metastatic lesions in Dct-Grm1/Dct-Ednrb mice. (A) Metastases in the brain (arrows). (B) Hematoxilin and Eosin stained

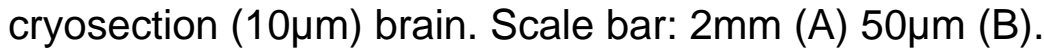

Supplementary Figure 6 Time to tumor appearance in Dct-Grm1/K5-Edn3/DctEdnrb mice. Kaplan-Meier curve of tumor-free survival. The tumor free-survival period of Dct-Grm1/K5-Edn3/Dct-Ednrb mice $(\mathrm{n}=19)$ was significantly shorter than that of Dct-Grm1/K5-Edn3 $(\mathrm{n}=16)$ and Dct-Grm1/Dct-Ednrb $(\mathrm{n}=4)$ mice $(p=0.001$ and $p=0.006$, respectively; log-rank test).

Supplementary Table 1: Location of metastases found in Dct-Grm1/K5-Edn3 mice. 
Supplementary Table 2: Primers used for Real Time PCR gene expression analysis 


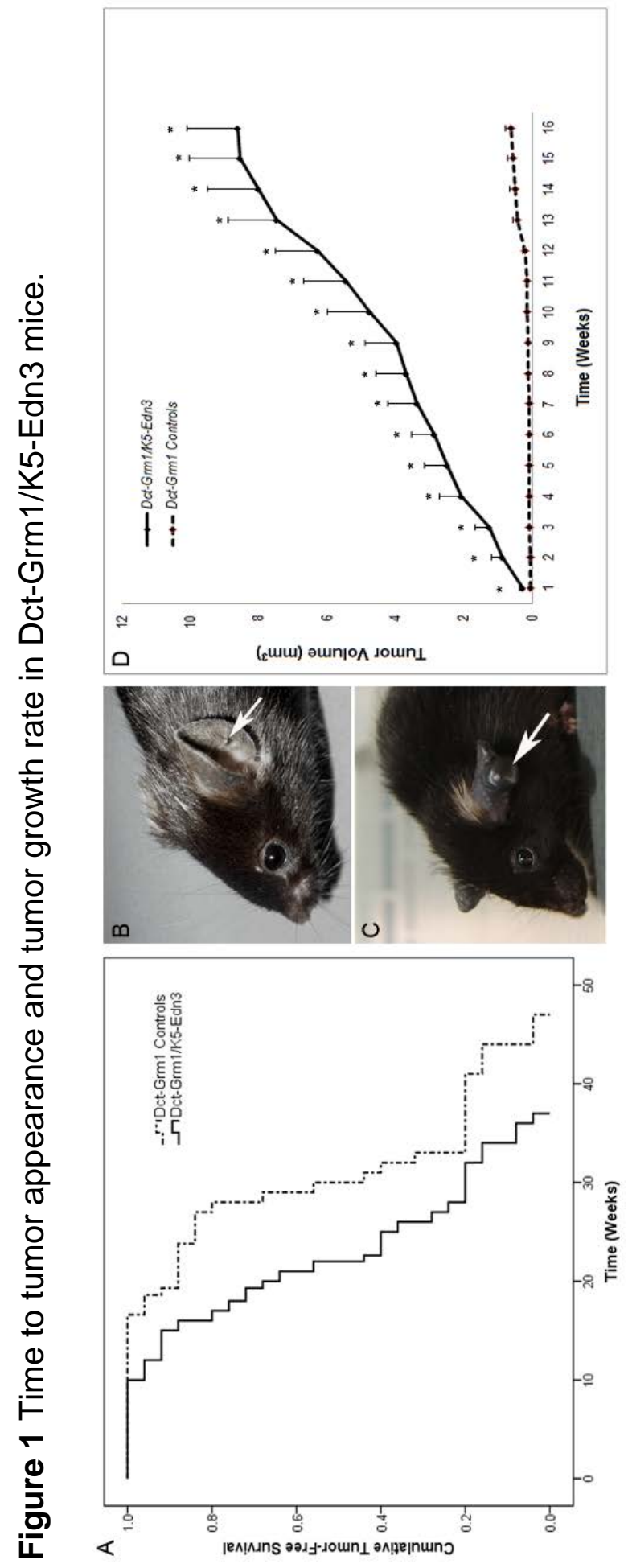




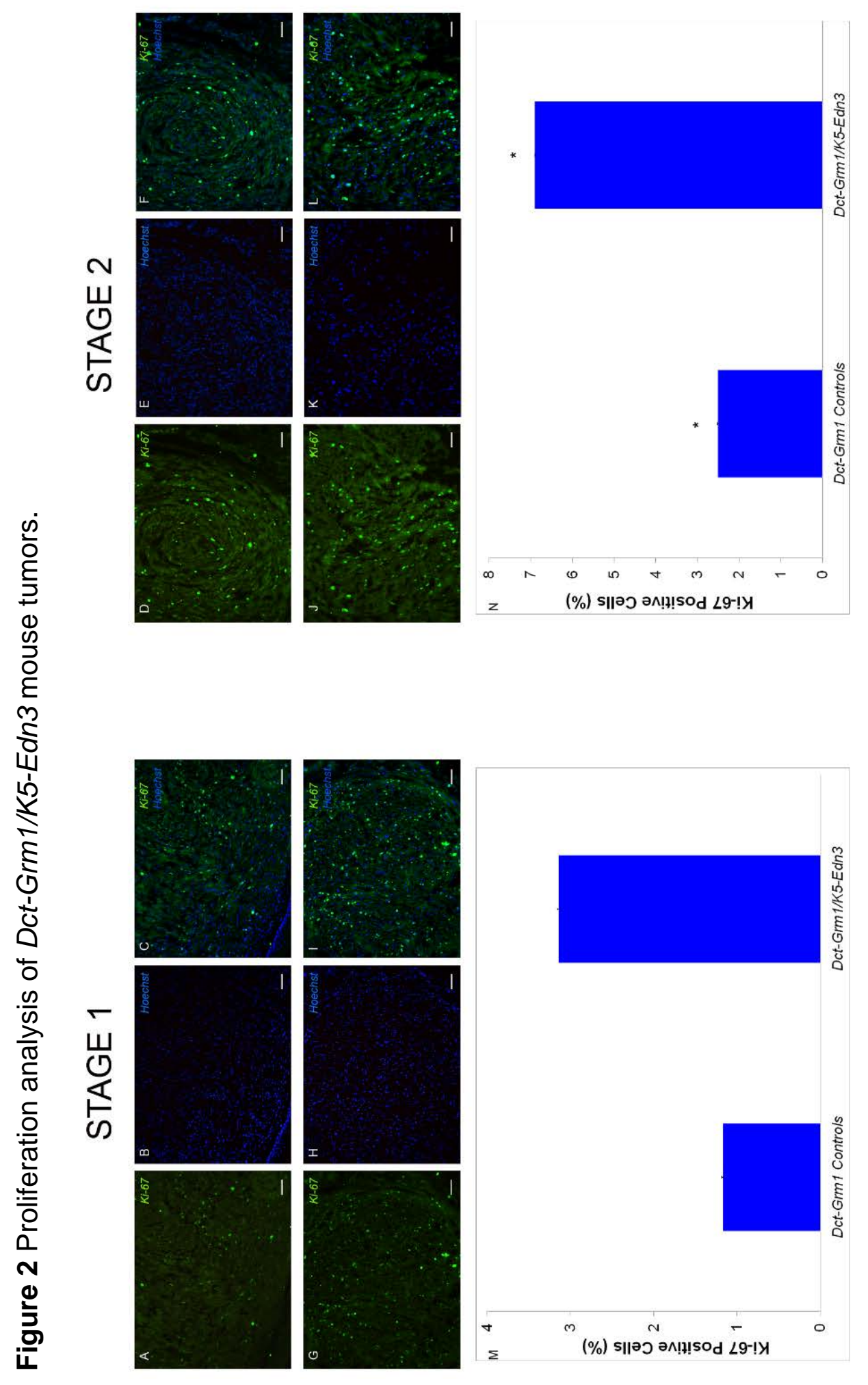




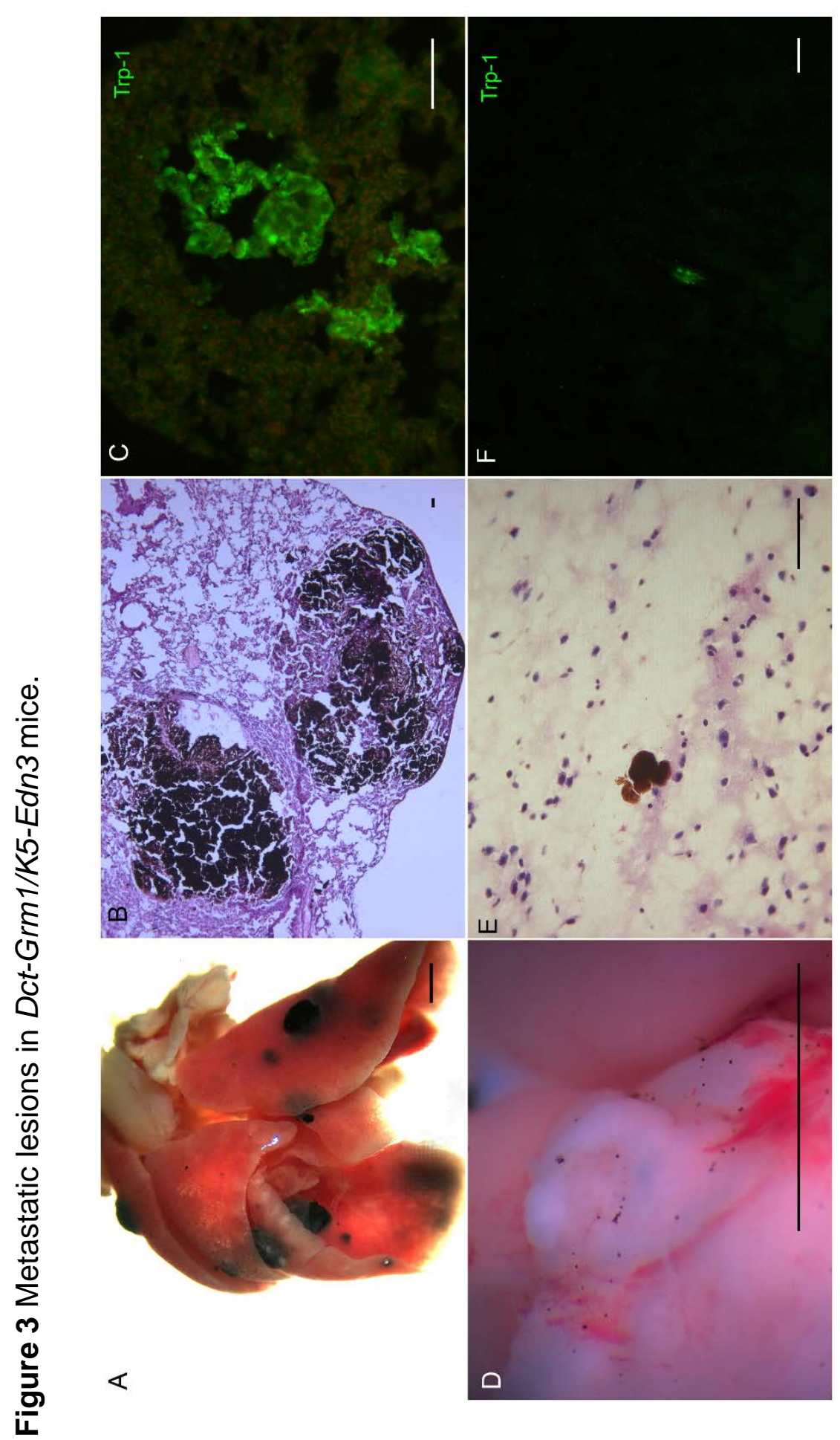



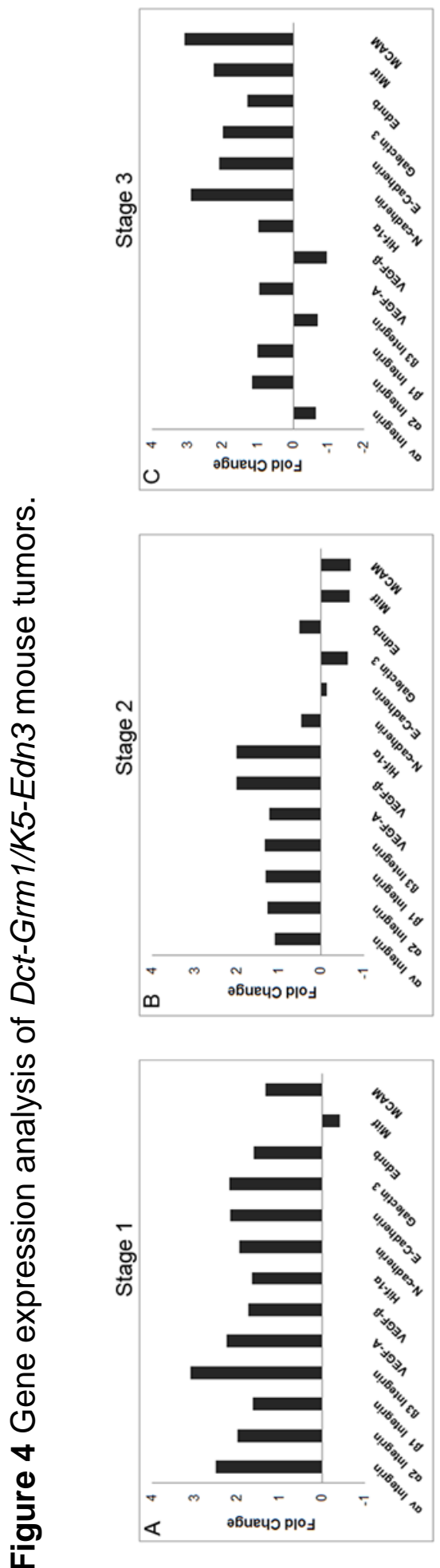
Supplementary Figure 1 Tail tumor growth rate in Dct-Grm1/K5-Edn3 mice.

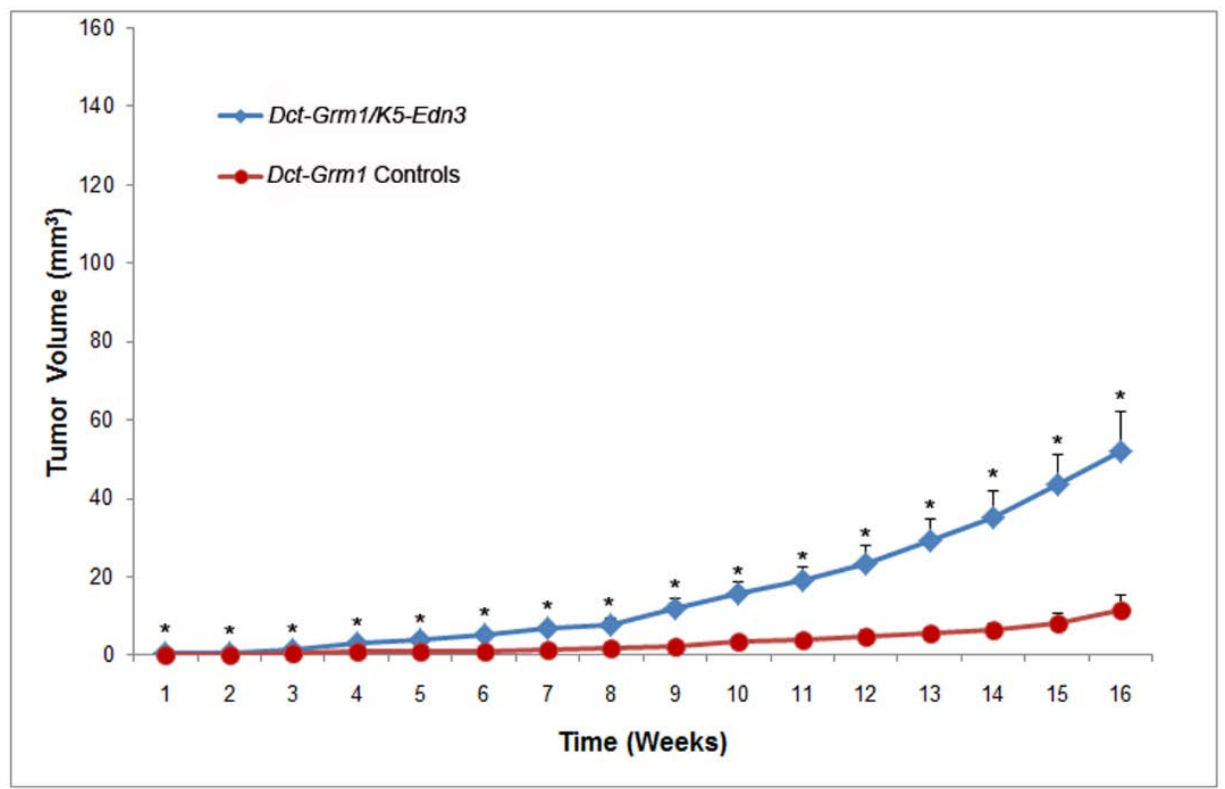

Supplementary Figure 2 Dorsal tumors in Dct-Grm1/K5-Edn3 mice.

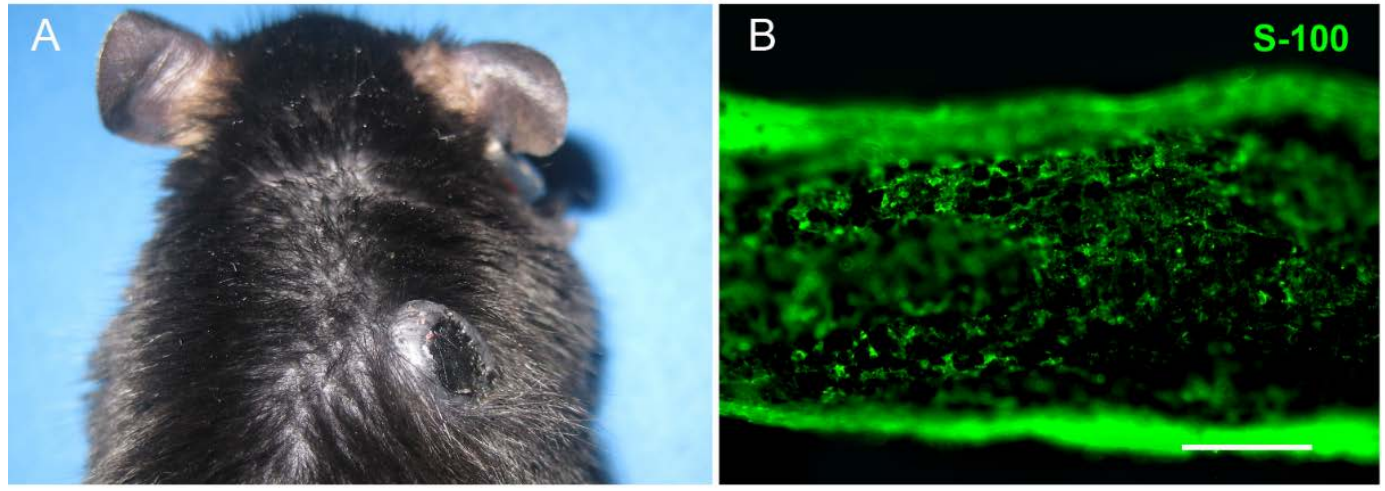


Supplementary Figure 3 Lymph node metastasis.

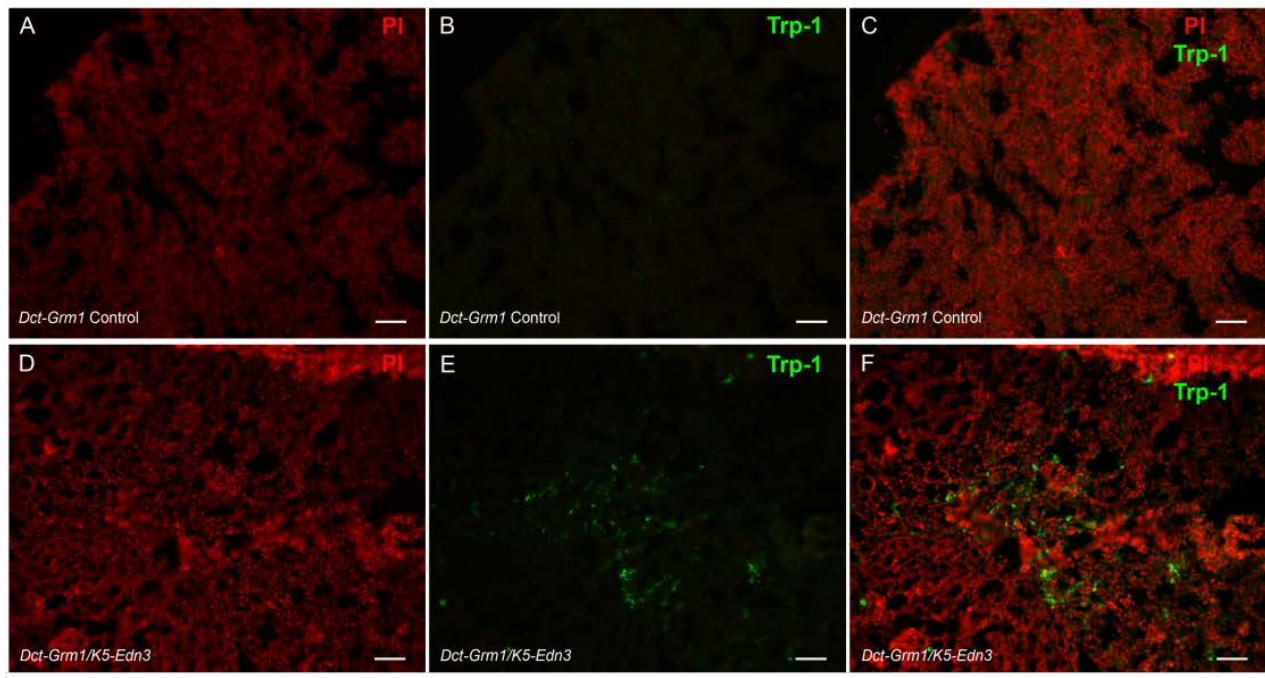

G $\quad 70$

$60=$ Dct-Grm1 Controls $=$ Dct-Grm1/K5-Edn3

50

$n=6$

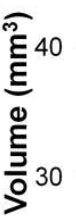

20

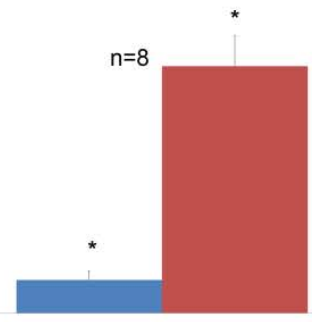

Cervical Lymph Nodes

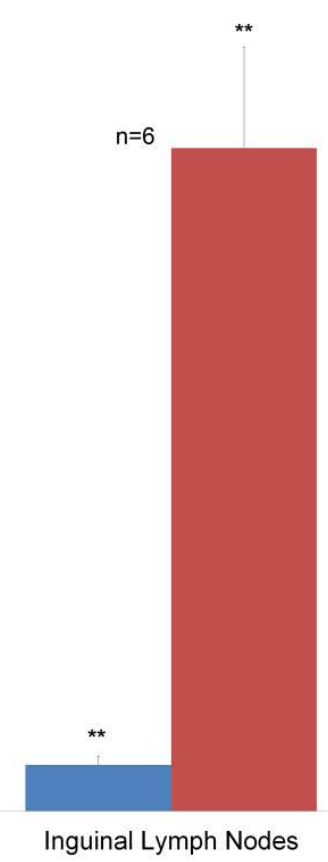


Supplementary Figure 4 Tail tumor growth rate in Dct-Grm1/Dct-Ednrb mice.

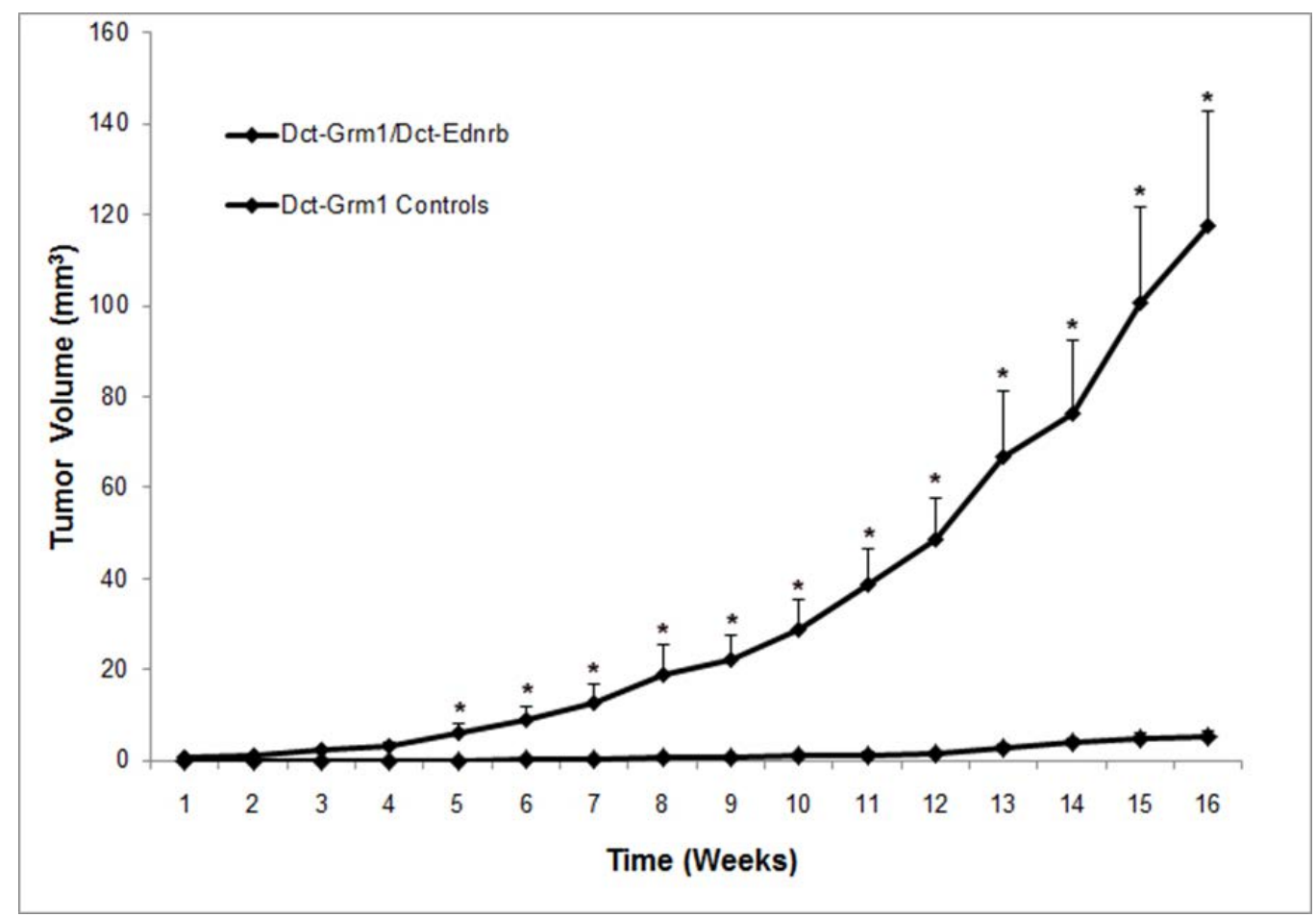

Supplementary Figure 5 Brain metastatic lesions in Dct-Grm1/Dct-Ednrb mice.
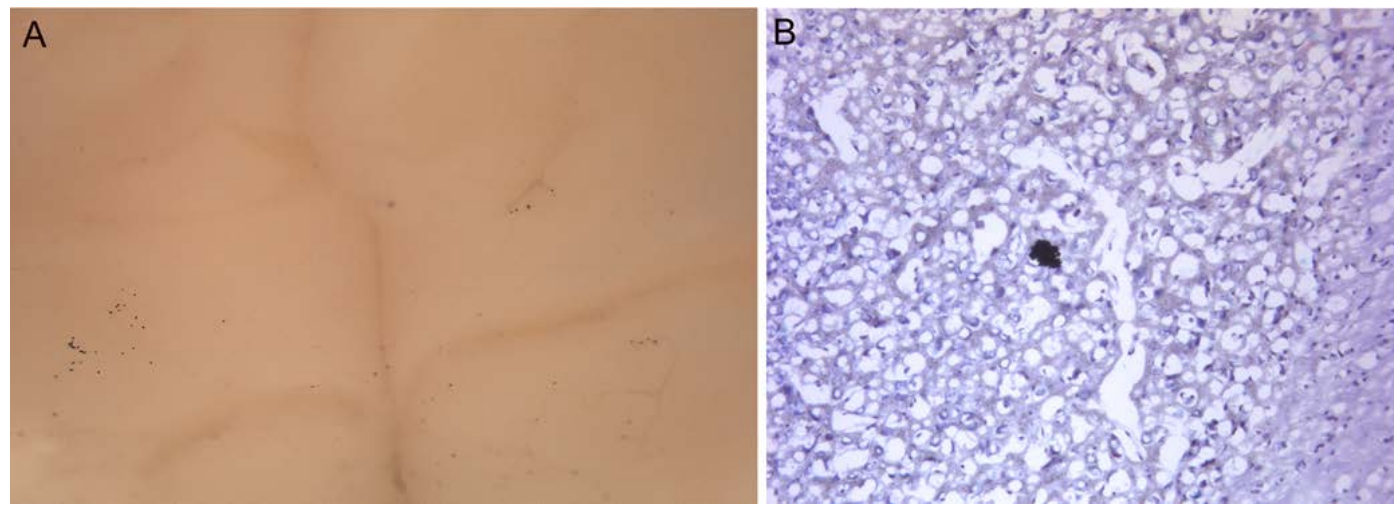
Supplementary Figure 6 Time to tumor appearance in Dct-Grm1/K5-Edn3/Dct-Ednrb mice.

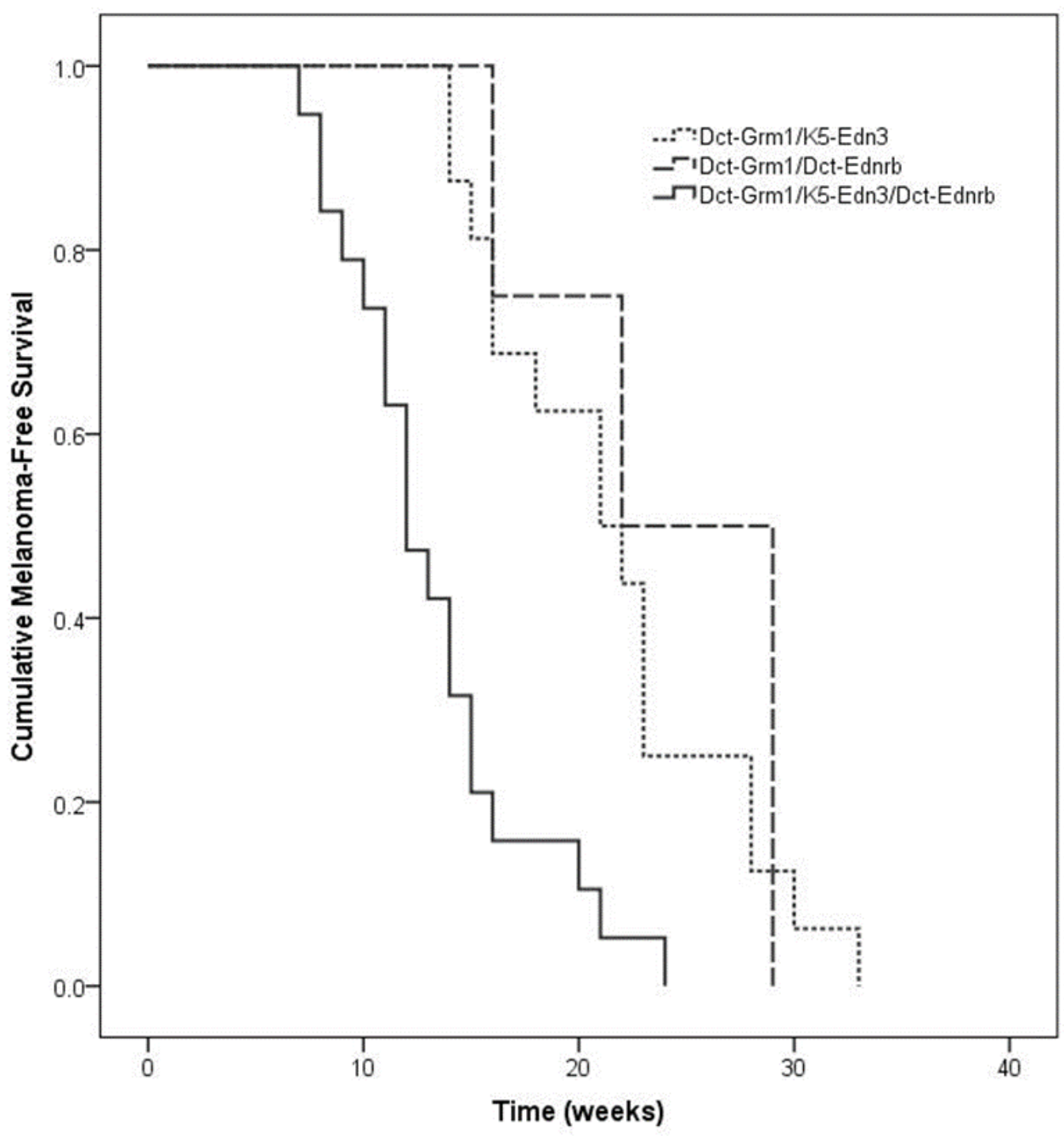


Supplementary Table 1 Location of metastases in Dct-Grm1/K5-Edn3 mice.

\begin{tabular}{|c|c|c|c|c|c|c|c|c|}
\hline & Genotype & Lungs & Brain & Spleen & $\begin{array}{c}\text { Salivary } \\
\text { Gland }\end{array}$ & Liver & Kidney & $\begin{array}{c}\text { Preputial } \\
\text { Gland }\end{array}$ \\
\hline 1 & Dct-Grm1/K5-Edn3 & $\mathbf{X}$ & & & $\mathbf{X}$ & & & \\
\hline 2 & Dct-Grm1/K5-Edn3 & & & & $\mathbf{X}$ & & & \\
\hline 3 & Dct-Grm1/K5-Edn3 & & & & $\mathbf{X}$ & & & $\mathbf{X}$ \\
\hline 4 & Dct-Grm1/K5-Edn3 & & & $\mathbf{X}$ & & & & \\
\hline 5 & Dct-Grml/K5-Edn3 & & & & & & & \\
\hline 6 & Dct-Grm1/K5-Edn3 & $\mathbf{X}$ & & & & & & \\
\hline 7 & Dct-Grm1/K5-Edn3 & & & & $\mathbf{X}$ & & & \\
\hline 8 & Dct-Grml/K5-Edn3 & & & & $\bar{X}$ & & & \\
\hline 9 & Dct-Grm1/K5-Edn3 & $\mathbf{X}$ & & & & & & \\
\hline 10 & Dct-Grm1/K5-Edn3 & $\mathbf{X}$ & $\mathbf{X}$ & & & & $\mathbf{X}$ & \\
\hline 11 & Dct-Grm1/K5-Edn3 & & & & & & & \\
\hline 12 & Dct-Grml/K5-Edn3 & & & & & & & \\
\hline 13 & Dct-Grm1/K5-Edn3 & $\mathbf{X}$ & & & & & & \\
\hline 14 & Dct-Grml/K5-Edn3 & $\mathbf{X}$ & & & & & & \\
\hline 15 & Dct-Grm1/K5-Edn3 & $\mathrm{X}$ & & & & & & \\
\hline 16 & Dct-Grm1/K5-Edn3 & $\mathrm{X}$ & & & & & & \\
\hline 17 & Dct-Grm1/K5-Edn3 & $\mathbf{X}$ & & & & & & \\
\hline 18 & Dct-Grm1/K5-Edn3 & & & & & & & \\
\hline 19 & Dct-Grm1/K5-Edn3 & & & & & & & \\
\hline 20 & Dct-Grm1/K5-Edn3 & $\mathbf{X}$ & & & & & & \\
\hline 21 & Dct-Grm1/K5-Edn3 & $\mathbf{X}$ & $\mathbf{X}$ & & & & & \\
\hline 22 & Dct-Grm1/K5-Edn3 & $\mathbf{X}$ & & & & & & \\
\hline 23 & Dct-Grm1/K5-Edn3 & $\mathbf{X}$ & $\mathbf{X}$ & & & & & \\
\hline 24 & Dct-Grm1/K5-Edn3 & & $\mathrm{X}$ & & & & & \\
\hline 25 & Dct-Grm1/K5-Edn3 & $\mathbf{X}$ & $\mathrm{X}$ & & $\mathbf{X}$ & & & \\
\hline 26 & Dct-Grm1/K5-Edn3 & $\mathbf{X}$ & $\mathbf{X}$ & & & & & \\
\hline 27 & Dct-Grm1/K5-Edn3 & $\mathbf{X}$ & $\mathbf{X}$ & & & & & \\
\hline 28 & Dct-Grm1/K5-Edn3 & $\mathbf{X}$ & $\mathbf{X}$ & & $\mathbf{X}$ & & & \\
\hline 29 & Dct-Grm1/K5-Edn3 & $\mathrm{X}$ & $\mathrm{X}$ & & & & & \\
\hline 30 & Dct-Grml/K5-Edn3 & $\mathbf{X}$ & $\mathbf{X}$ & & & & & \\
\hline 31 & Dct-Grm1/K5-Edn3 & & & & & & & \\
\hline 32 & Dct-Grm1/K5-Edn3 & $\mathbf{X}$ & $\mathbf{X}$ & & & & & \\
\hline 33 & Dct-Grm1/K5-Edn3 & & $\mathbf{X}$ & & & & & \\
\hline 34 & Dct-Grm1/K5-Edn3 & $\mathbf{X}$ & & & $\mathbf{X}$ & & & \\
\hline 35 & Dct-Grm1/K5-Edn3 & & & & & & & \\
\hline 36 & Dct-Grm1/K5-Edn3 & $\mathbf{X}$ & $\mathbf{X}$ & & & & & \\
\hline 37 & Dct-Grm1/K5-Edn3 & $\mathrm{X}$ & $\mathrm{X}$ & & $\mathbf{X}$ & & & \\
\hline
\end{tabular}




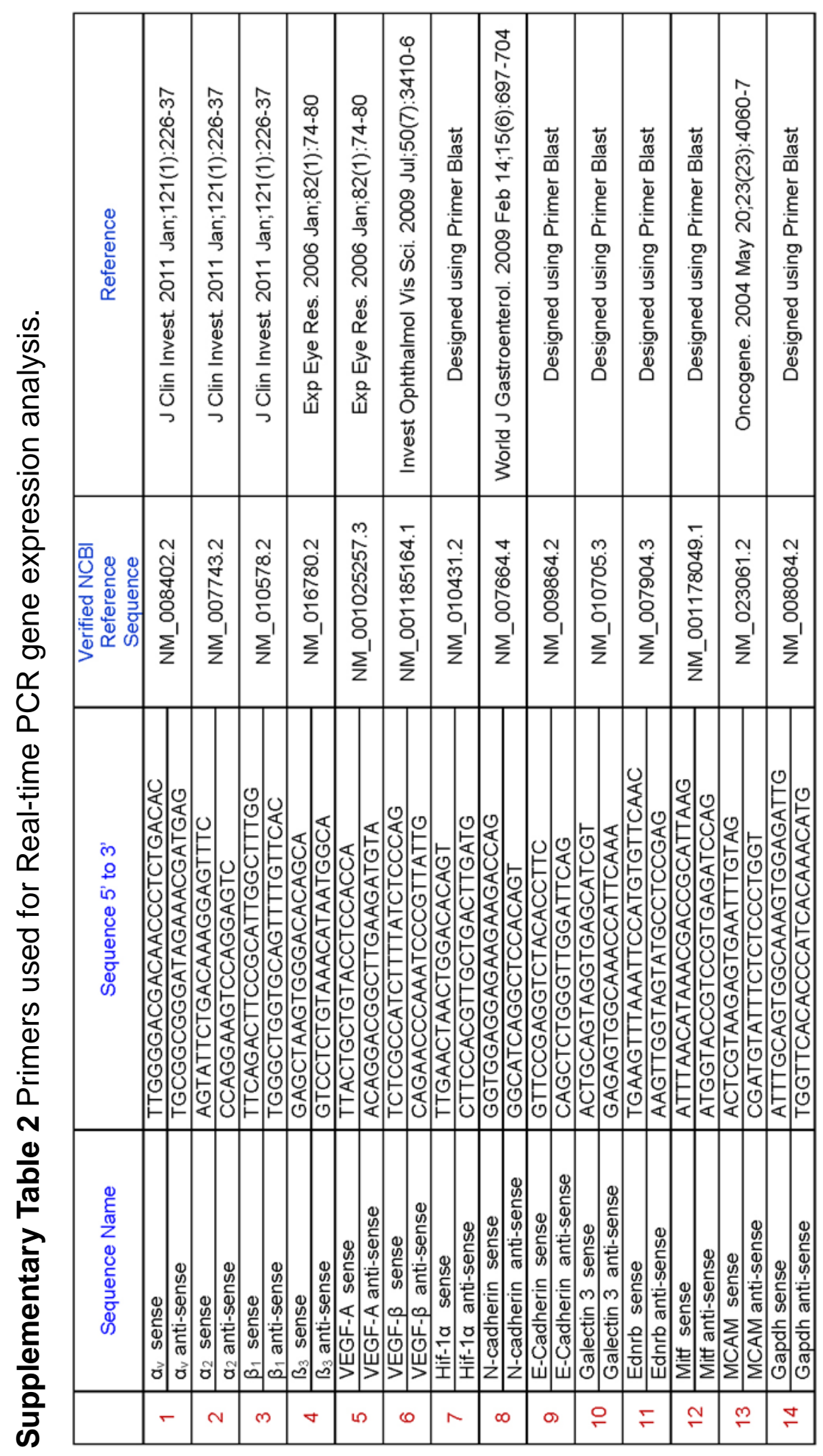




\section{CHAPTER III}

ENDOTHELIN 3 ENHACES TUMOR ANGIOGENESIS IN AN EDN3 DEPENDENT MELANOMA MOUSE MODEL 
III. ENDOTHELIN 3 ENHANCES TUMOR ANGIOGENESIS IN AN EDN3 DEPENDENT MELANOMA MOUSE MODEL

\subsection{INTRODUCTION}

Angiogenesis is a critical step triggered in response to hypoxic conditions, by the tumorigenic cells in melanoma malignancy ${ }^{1-4}$. The process encompasses the formation of new blood vasculature from pre-existing vessels located in close proximity to the tumors. The new vasculature can surround as well as enroot inside tumors, providing it with nutrients and oxygen to promote survival, growth and metastasis ${ }^{5-7}$. The melanoma cells initiate the tumor 'angiogenic switch' disrupting the balance between pro-angiogenic and anti-angiogenic factors, by secreting a number of pro-angiogenic factors such as vascular endothelial growth factor (VEGF), basic fibroblast growth factor (bFGF), platelet derived growth factor (PDGF) and transforming growth factors $\alpha$ and $\beta$ (TGF $\alpha$ and TGF $\beta)^{8-11}$. These pro-angiogenic factors stimulate the proliferation, migration and survival of endothelial cells. Endothelial cells can then in turn secrete a number of autocrine and paracrine growth factors along with the tumor to recruit and activate pericytes, inflammatory cells and remodel the extracellular matrix to allow blood vessel formation ${ }^{8-11}$. One of the growth factors linked to angiogenesis in melanoma is Endothelin receptor B (EDNRB), a seven transmembrane G-protein coupled receptor ${ }^{12,13}$.

Endothelin receptor b binds its three ligands endothelins 1, 2, 3 (EDN1, EDN2 and EDN3) with equal affinity ${ }^{14,15}$. Endothelins are important in melanocyte differentiation and survival as well as in endothelial localization and 
vasoconstriction of blood vessels ${ }^{16-18}$. During melanomagenesis, EDNRB expression increases in malignant melanomas when compared to melanocytic nevi. Furthermore both 'in vivo' and 'in vitro' experiments blocking EDNRB with its antagonist BQ788 restricted melanoma growth and induced apoptosis of the tumorigenic cells ${ }^{17,19,20}$. Spinella and colleagues (2007) using both primary (1007) and metastatic (M10) cell lines of melanoma showed binding of EDN1 and EDN3 to EDNRB could enhance both VEGF, Hif-1a transcript levels and increase cyclooxygenase (COX)-1/COX-2 protein expression, COX-2 promoter activity and prostaglandin E2 (PGE2), all factors important in angiogenesis ${ }^{21}$. Although the EDNRB/EDN1 axis has been implicated in melanoma, little is known about the effect of the upregulation of EDN3 in the tumor microenvironment in melanoma progression. Tang and colleagues found that EDN3 was upregulated at both the mRNA and protein level almost 10 fold in malignant melanomas, while the other two ligands EDN1 and EDN2 did not show much change ${ }^{22}$. In Chapter 2 I described a novel EDN3 dependent melanoma mouse model, Dct-Grm1-/K5-Edn3 mice, whose overexpression of EDN3 actuated melanocytic lesions with limited metastatic capability to a more aggressive form. The Dct-Grm1/K5-Edn3 are hyperpigmented mice that constitutively overexpress Edn3 under the Keratin 5 promoter and have aberrant expression of metabotropic glutatamate receptor $1(\mathrm{Grm} 1)$ under the Dopachrome tautomerase promoter. Real time RT-PCR studies on the melanocytic tumors of the Dct-Grm1/K5-Edn3 mice revealed a significant fold increase in angiogenic related genes Vegf, Hif-1 $\alpha$ and integrins $\alpha_{v} \beta_{1}$ and $\alpha_{2} \beta_{3}$ at 
different stages of tumor progression when compared to the Dct-Grm1 control group that do not overexpress EDN3. In this chapter I further examined the effects EDN3 plays in the angiogenic switch and tumor neovascularization, that may be contributing to the more characteristic aggressive phenotype of melanoma observed in the Dct-Grm1/K5-Edn3 mice.

\subsection{MATERIALS AND METHODS}

\subsubsection{Animal Model}

The $\operatorname{Tg}(\mathrm{Grm1}) E p v / \mathrm{K} 5-E d n 3$ mice generated in our laboratory were crossed and genotyped. Deoxyribonucleic acid (DNA) from tail biopsies were extracted using standard techniques from the albino progeny of the matings, and Polymerase Chain Reaction (PCR) was used to genotype the mice using the following primers: Dct-Grm1 5'-CCGGGTCCGCATTAATCTTATCTA-3'and 5'GGTAGCATACGGTTCCACGCA-3' which yields a 1700bp PCR product; the K5tTA primers 5'-CCAGGTGGAGTCACAGGATT-3' and 5'-

ACAGAGACTGTGGACCACCC-3'and the primers for the tet-O Edn3 yield a 463 bp product and bind to the 3' end of the Edn3 cDNA (5'-

GGCCTGTGCACACTTCTGT-3') and to non-coding DNA (5'TCCTTGTGAAACTGGAGCCT-3'). The mice were housed in the University Animal Care Facility at Florida International University. The animal protocol was approved by the Committee on Animal Care and Use and Office of Sponsored Research at Florida International University and all Institutional Animal Care and Use Committee regulations were followed. 


\subsubsection{Immunofluorescence}

Primary tail tumors $\left(25-30 \mathrm{~mm}^{3}\right)$ from Dct-Grm1/K5-Edn3 mice $(\mathrm{n}=5)$ and Dct-Grm1 control mice $(\mathrm{n}=5)$ were excised, fixed and embedded in OCT medium (Ted-Pella, CA) following the protocol previously described in Chapter 2.

Cryosections (10 $\mathrm{mm}$ thick) of the tail tumors were later decolorized of melanin by incubating overnight in $10 \%$ hydrogen peroxide in 1 X PBS (pH 7.4). Ten sections from each tumor were immunolabeled with either the antibody Anti-CD31 (Abcam, MA) (1:50), an endothelial cell marker to visualize and quantify the vascular network of the tumor. Positive staining was identified with the secondary antibody Alexa Flour 488 Goat Anti-Rabbit antibody (Invitrogen, NY) (1:200) and the sections were counterstained with propidium iodide. A Leica Leitz DMRB florescent microscope and a Leica DC 500 camera was utilized to observe and take pictures of five fields of view at 200X of each of the ten sections for both the Dct-Grm1/K5-Edn3 mice and the Dct-Grm1 controls samples. The area of staining was analyzed using the pixel density feature of ImageJ software and compared between the experimental and control population using the Student T-test.

\subsubsection{Angiogenesis Array}

Proteome profiling using the 'Multianalyte Profiling Angiogenesis Kit' from R\&D Systems (R\&D Systems, MN) was used to analyze the relative expression of 53 mouse angiogenesis related proteins in tail tumors of $D c t-G r m 1 / K 5-E d n 3$ experimental mice and their corresponding Dct-Grm1 controls (Dct-Grm1, Dct-Grm1/K5, DctGrm1/Edn3). Primary tail tumors $\left(25-30 \mathrm{~mm}^{3}\right)$ were excised from Dct-Grm1/K5Edn3 mice $(\mathrm{n}=4)$ and Dct-Grm1 controls $(\mathrm{n}=4)$ and homogenized in PBS with 
protease inhibitors aprotinin (Sigma, MO), leupeptin (Sigma, MO), and Pepstatin (Sigma, MO). Protein was extracted from each of the samples and concentrations were quantified using the 'BCA Protein Assay Kit' (Thermo Scientific). Nitrocellulose membranes spotted with both control and capture antibodies for the mouse angiogenic proteins were incubated overnight, after which the membranes were washed. Streptavidin-HRP and chemiluminescent reagents were then used to detect the signal produced at each spot corresponding to the amount of bound protein, and the array data was developed onto an X-ray film for analysis using the Protein Array Analyzer program in Image J. Student's t-test was used for the statistical comparisons. Differences were considered statistically significant at $\mathrm{P}<0.05$.

\subsection{RESULTS}

\subsubsection{Edn3 Overexpression Increases the Vascular Density in Melanocytic Tumors}

Tail tumor cryosections showed significantly $(p=0.044)$ higher levels of Anti-CD31 (Abcam, MA) staining in the Dct-Grm1/K5-Edn3 mice $(\mathrm{n}=5)$ when compared to the Dct-Grm1mice ( $\mathrm{n}=5)$ (Fig.1).

\subsubsection{Edn3 Overexpression Affects the Levels of Expression of Angiogenic Proteins.}

The Multianalyte Profiling Angiogenesis Kit' from R\&D Systems (R\&D Systems, $\mathrm{MN}$ ) allowed for the parallel observation of the relative levels of 53 different mouse angiogenic proteins (Fig. 2) involved with neovascularization. When I compared protein extracts from primary tail tumors $\left(25-30 \mathrm{~mm}^{3}\right)$ of both $D c t-G r m 1 / K 5-E d n 3$ mice $(\mathrm{n}=4)$ and Dct-Grm1 control mice $(\mathrm{n}=4)$, I found $(\mathrm{p} \leq 0.05)$ that the expression of the angiogenic 
proteins Endoglin, Heparin-binding Epidermal growth factor (HB-EGF), Matrix metalloproteinase-9 (MMP-9), Angiogenin, Insulin-like growth factor-binding protein 2 and 3 (IGFBP-2 and IGFBP-3), CCN intercellular signaling protein 3 (CCN3), Edn-1 and Chemokine (C-X-C motif) ligand 16 (CXCL16) in the DctGrm1/K5-Edn3 tumors was significantly higher than in the controls (Fig. 3).

\subsection{DISCUSSION}

During angiogenesis, endothelial cells are recruited by tumorigenic cells, whereby they dissever their normal cell-cell adhesions, migrate, proliferate, and form new cellular attachments to establish neovascularization. Platelet endothelial cell adhesion molecule (PECAM-1), also known as 'cluster of differentiation 31' (CD31) is a member of the Immunoglobin family that comprises most of endothelial intercellular junctions. The Dct-Grm1/K5-Edn3 primary tail tumors showed significantly more CD31 immunofluorescence staining than primary tail tumors with the same average tumor volume of the Dct-Grm1 control group. Greater levels of CD31 staining in the Dct-Grm1/K5-Edn3 primary tail tumors suggest a greater degree of vascularization within tumors exposed to high levels of EDN3 in the tumor microenvironment. Endothelin signaling via EDNRB is reported as having direct effects on endothelial cell proliferation and neovascularization by enhancing Hif-1 $\alpha$ mediated events ${ }^{13,21}$. It would be interesting to evaluate and compare the levels of hypoxia in the tail tumors of the Dct-Grm1/K5-Edn3 mice and the Dct-Grm1 control mice as tumorigenic cells found close to hypoxic regions have been observed to become more aggressive and metastatic ${ }^{23}$. 
The results obtained from the analysis of Dct-Grm1/K5-Edn3 mice suggest one mechanism by which EDN3 in the tumor microenvironment increases melanoma malignancy. We profiled the expression of 53 mouse angiogenic related proteins and also found a significant increase in several angiogenic related factors, including MMP-9 and nephroblastoma overexpressed (NOV/CCN3) protein. Matrix metalloproteinases (MMP's), proteases are responsible for degrading and remodeling the ECM while matricellular proteins such as galectins, thrombospondin, osteopontin and nephroblastoma overexpressed (NOV/CCN) proteins regulate cell-matrix interaction as well as proliferation, differentiation and survival of particular cell types ${ }^{24}$. Both groups cooperate to facilitate the recruitment of cells involved in the neoangiogenic process as well as altering the migration of tumorigenic cells. Matrix metallopeptidase -9 along with Matrix metalloproteinase -2 are main degraders of collagen Type IV which comprises majority of basement membrane ECM ${ }^{2526}$. Matrix metallopeptidase -9 activity has been connected to melanomagenesis. Microarray gene chip analysis comparing cell lines of highly aggressive and poorly aggressive forms of melanoma performed by Seftor and colleagues (2001) found significant upregulation of MMP-9 ${ }^{27}$. Shellman and colleagues examined active secretions of normal melanocytes and cell lines of different melanoma stages using zymography techniques. They too positively correlated an increase in active MMP-9 secretions with malignancy. Matrix metallopeptidase -9 was only detected in the vertical growth phase and metastatic melanoma cell lines ${ }^{28}$. Matrix metallopeptidase -9 has also been associated with vascular mimicry in melanoma. Vascular mimicry is a process first described by Mantois et al. 1999, whereby tumorigenic cells of highly metastatic melanomas are able to form their own acellular microcirculatory channels, 
founded of ECM and tumorigenic cells ${ }^{29}$. The vasculature does not include endothelial cells, instead mimic the neoangiogenic vessels formed during tumor angiogenesis. The vascular mimics connect to the host microcirculatory system and supply the tumor with nutrient rich oxygenated blood and a metastatic route ${ }^{29,30}$. Vascular mimicry is often linked to poor prognosis in melanoma patients ${ }^{31}$. When both endothelial cellular and vascular mimicry vessel number were decreased 'in vivo', MMP-9 gene and protein expression was also reduced, suggesting a role for MMP-9 in vascular mimicry and a more metastatic phenotype ${ }^{31-34}$.

Studies on the role of matricellular protein CCN3 with respect to melanoma have been somewhat contradictory. CCN3 encoded by the NOV gene belongs to a family of ECM associated growth and differentiation regulators. NOV mediates its effects by binding to receptors such as integrin receptors and $\mathrm{NOTCH}^{35,36}$. In one study, gene and protein expression analysis revealed that co-culturing melanocytes with keratinocytes led to an increase of CCN3 levels, melanocyte proliferation was inhibited, as well as correct spatial localization of the melanocytes to the basement membrane was disrupted ${ }^{37}$. Melanocytes transduced with siRNA knocking down CCN3 showed decrease in their growth rates and attachment to Collagen IV when compared to cells transduced with control vectors. Later experiments using immunohistochemical analysis on different stages of melanoma progression found lower CCN3 expression levels in advanced melanomas. The '1205Lu' melanoma cell line overexpressing CCN3 became less proliferative and invasive on 3D skin reconstructs. However, no difference was observed in migration assays in the absence of Matrigel between 
CCN3 overexpressing cells and controls. Matrix metalloproteinase -2 and matrix metallopeptidase -9 expression levels were also decreased in CCN3 overexpressing cells ${ }^{38}$. These results suggest an inverse relationship between CCN3 expression and melanoma progression.

Vallachi and colleagues (2008) however presented a positive function for CCN3 in fostering melanoma progression. A cDNA library constructed from primary and metastatic melanoma cell lines from the same patient was analyzed with Northern analysis and RT-PCR. Higher expression levels of CCN3 were found in the metastatic melanomas when compared to primary tumor cells ${ }^{39}$. The CCN3 protein expression was also higher in a large panel of visceral and nodal melanoma metastases of patients with short term survival or relapse patients compared to those patients with long term survival ${ }^{39,40}$. Immunocompromised mice transfected with melanoma cells expressing CCN3 further showed more visceral metastatic growth ${ }^{39,40}$.

Several studies have established that the functions of CCN3 are dependent on the cellular and tissue context ${ }^{24,37,41}$. CCN3 is linked to prostate cancer progression ${ }^{42}$, tumor differentiation in cartilage tumors ${ }^{43}$ and yet has an anti-proliferative function in gliomas ${ }^{44}$. It is not surprising therefore that CCN3 activity in melanoma may be very complex depending on the stage of disease progression. The tumor microenvironment is also a very important facet when trying to characterize the importance or exact mechanism by which a particular factor might be involved in, especially one like CCN3 whose role has been inconsistent. In the 'in vivo' EDN3 dependent metastatic melanoma Dct-Grm1/K5- 
Edn3 mouse model CCN3 was upregulated at the same stage when Hif-1a, MMP-9, and angiogenic related genes linked to melanoma such as angiogenin ${ }^{45}$ and endoglin 46,47. The angiogenic protein array also detected the upregulation of several Insulin-like growth factor binding proteins (IGFBPS). IGFPs are major regulators of the NOV family 39,40. In the presence of EDN3 in the tumor microenvironment CCN3 may be elevated to enhance angiogenesis and malignancy in melanoma.

The heparin binding CXC chemokines are factors involved in inflammation and immunity that have also emerged as agents in tumorigenic angiogenesis for a number of cancers including melanoma ${ }^{48}$. The significance of CXCL 16 , the ligand for the receptor CXCR6, has not yet been studied in melanoma or its relationship with endothelins. More research should be done to elucidate the importance of this molecule in melanoma progression.

Angiogenesis is a critical process in tumor survival and metastasis. Although it has been explored as a target of many cancer therapeutics ${ }^{49}$, the tumor microenvironment along with the complexity of its mechanisms, that seem to vary depending on the type of cancer, diminishes or abolishes the effectiveness of treatments. A study conducted by Lahav and colleagues (2004) contradicts our findings, having reported that EDNRB signaling may have a negative effect on tumor angiogenesis as inhibition of EDNRB increased VEGF expression and suppressed angiogenic inhibitor Gravin ${ }^{50}$. The different results may be because Lahav and colleagues' study (2004) utilized human melanoma cell lines treated with the EDNRB antagonist BQ788 in culture, which differs from our methods that used an 'in vivo' melanoma model that also encompasses 
changes EDN3 has on the tumor microenvironment and its subsequent effects on the tumorigenic cells. Melanocytic tumors in the Dct-Grm1/K5-Edn3 melanoma mouse model tumors grow faster and display increased metastatic capability, hence EDN3 may be either directly or indirectly augmenting angiogenic related factors needed to not only increase vascularization but increase the metastatic capability of the melanocytic tumors in these mice when compared to the controls. Blocking EDN3 in the tumor microenviroement or $E D N R B$ expression in the tumorigenic cells may decrease the angiogenic response in melanoma and help prevent the metastatic process. Thus the DctGrm1/K5-Edn3 melanoma mouse model that has metastatic primary tumors with a strong angiogenic tumor response is a very useful tool to elucidate further the role EDNRB/EDN3 signaling plays in melanoma angiogenesis.

\subsection{References}

1. Mills CN, Joshi SS, Niles RM. Expression and function of hypoxia inducible factor-1 alpha in human melanoma under non-hypoxic conditions. Mol Cancer 2009;8: 104.

2. Sullivan $\mathrm{R}$, Graham $\mathrm{CH}$. Hypoxia-driven selection of the metastatic phenotype. Cancer Metastasis Rev 2007;26: 319-31.

3. Valencak J, Kittler H, Schmid K, Schreiber M, Raderer M, GonzalezInchaurraga M, Birner P, Pehamberger H. Prognostic relevance of hypoxia inducible factor-1alpha expression in patients with melanoma. Clin Exp Dermatol 2009;34: e962-4.

4. Hartmann A, Kunz M, Köstlin S, Ko S, Gillitzer R, Toksoy A, Bröcker EB, Klein CE. Hypoxia-induced up-regulation of angiogenin in human malignant melanoma. Cancer Res 1999;59: 1578-83.

5. Folkman J. Tumor angiogenesis. Adv Cancer Res 1985;43: 175-203. 
6. Ria R, Reale A, Castrovilli A, Mangialardi G, Dammacco F, Ribatti D, Vacca A. Angiogenesis and progression in human melanoma. Dermatol Res Pract 2010;2010: 185687.

7. Bergers G, Benjamin LE. Tumorigenesis and the angiogenic switch. Nat Rev Cancer 2003;3: 401-10.

8. Ribatti D, Nico B, Crivellato E, Roccaro AM, Vacca A. The history of the angiogenic switch concept. Leukemia 2007;21: 44-52.

9. Papetti M, Herman IM. Mechanisms of normal and tumor-derived angiogenesis. Am J Physiol Cell Physiol 2002;282: C947-70.

10. McMahon G. VEGF receptor signaling in tumor angiogenesis. Oncologist 2000;5 Suppl 1:3-10.

11. Gupta MK, Qin RY. Mechanism and its regulation of tumor-induced angiogenesis. World J Gastroenterol 2003;9:1144-55.

12. Spinella F, Rosanò L, Di Castro V, Natali PG, Bagnato A. Endothelin-1 induces vascular endothelial growth factor by increasing hypoxia-inducible factor-1alpha in ovarian carcinoma cells. J Biol Chem 2002;277: 27850-5.

13. Spinella F, Garrafa E, Castro V Di, Rosanò L, Nicotra MR, Caruso A, Natali PG, Bagnato A. Endothelin-1 stimulates lymphatic endothelial cells and lymphatic vessels to grow and invade. Cancer Res 2009;69: 2669-76.

14. Inoue A, Yanagisawa M, Kimura S, Kasuya Y, Miyauchi T, Goto K, Masaki T. The human endothelin family: three structurally and pharmacologically distinct isopeptides predicted by three separate genes. Proc Natl Acad Sci U S A 1989;86: 2863-7.

15. Huggins JP, Pelton JT, Miller RC. The structure and specificity of endothelin receptors: their importance in physiology and medicine. Pharmacol Ther 1993;59: 55-123.

16. Imokawa G, Yada Y, Miyagishi M. Endothelins secreted from human keratinocytes are intrinsic mitogens for human melanocytes. J Biol Chem 1992;267: 24675-80.

17. Lahav R. Endothelin receptor $B$ is required for the expansion of melanocyte precursors and malignant melanoma. Int J Dev Biol 2005;49: 173-80.

18. Saldana-Caboverde A, Kos L. Roles of endothelin signaling in melanocyte development and melanoma. Pigment Cell Melanoma Res 2010;23:16070 . 
19. Lahav R, Heffner G, Patterson PH. An endothelin receptor B antagonist inhibits growth and induces cell death in human melanoma cells in vitro and in vivo. Proc Natl Acad Sci U S A 1999;96: 11496-500.

20. Rosanò L, Spinella F, Genovesi G, Di Castro V, Natali PG, Bagnato A. Endothelin-B receptor blockade inhibits molecular effectors of melanoma cell progression. J Cardiovasc Pharmacol 2004;44 Suppl 1:S136-9.

21. Spinella F, Rosanò L, Di Castro V, Decandia S, Nicotra MR, Natali PG, Bagnato A. Endothelin-1 and endothelin-3 promote invasive behavior via hypoxia-inducible factor-1 $\alpha$ in human melanoma cells. Cancer Res 2007;67: 1725-34.

22. Tang L, Su M, Zhang Y, Ip W, Martinka M, Huang C, Zhou Y. Endothelin-3 is produced by metastatic melanoma cells and promotes melanoma cell survival. J Cutan Med Surg 2008;12: 64-70.

23. Nurwidya F, Takahashi F, Minakata K, Murakami A, Takahashi K. From tumor hypoxia to cancer progression: the implications of hypoxia-inducible factor-1 expression in cancers. Anat Cell Biol 2012;45: 73-8.

24. Brigstock DR. The connective tissue growth factor/cysteine-rich 61/nephroblastoma overexpressed (CCN) Family. Endocr Rev 1999;20: 189-206.

25. Curran S, Murray GI. Matrix metalloproteinases molecular aspects of their roles in tumour invasion and metastasis. Eur J Cancer 2000;36: 1621-30.

26. Sun B, Zhang S, Zhang D, Gu Y, Zhang W, Zhao X. The influence of different microenvironments on melanoma invasiveness and microcirculation patterns: an animal experiment study in the mouse model. J Cancer Res Clin Oncol 2007;133: 979-85.

27. Seftor RE, Seftor EA, Koshikawa N, Meltzer PS, Gardner LM, Bilban M, Stetler-Stevenson WG, Quaranta V, Hendrix MJ. Cooperative interactions of laminin 5 y2 chain, matrix metalloproteinase-2, and membrane type-1matrix/metalloproteinase are required for mimicry of embryonic vasculogenesis by aggressive melanoma. Cancer Res 2001;61: 6322-7.

28. Shellman YG, Makela M, Norris DA. Induction of secreted matrix metalloproteinase-9 activity in human melanoma cells by extracellular matrix proteins and cytokines. Melanoma Res 2006;16: 207-11. 
29. Maniotis AJ, Folberg R, Hess A, Seftor EA, Gardner LM., Pe'er J, Trent $\mathrm{JM}$, Meltzer PS, Hendrix MJ. Vascular channel formation by human melanoma cells in vivo and in vitro: vasculogenic mimicry. Am J Pathol 1999;155: 739-52.

30. Folberg R, Hendrix MJ, Maniotis AJ. Vasculogenic mimicry and tumor angiogenesis. Am J Pathol 2000;156: 361-81.

31. Sun B, Zhang S, Zhang D, Yin X, Wang S, Gu Y, Wang Y. Doxycycline influences microcirculation patterns in B16 melanoma. Exp Biol Med (Maywood) 2007;232: 1300-7.

32. Zhang S, Li M, Gu Y, Liu Z, Xu S, Cui Y, Sun B. Thalidomide influences growth and vasculogenic mimicry channel formation in melanoma. J Exp Clin Cancer Res 2008;27: 60.

33. Hendrix MJC, Seftor EA, Kirschmann DA, Quaranta V, Seftor REB. Remodeling of the microenvironment by aggressive melanoma tumor cells. Ann N Y Acad Sci 2003;995: 151-61.

34. Hendrix MJC, Seftor EA, Hess AR, Seftor RE. Molecular plasticity of human melanoma cells. Oncogene 2003;22: 3070-5.

35. Gupta R, Hong D, Iborra F, Sarno S, Enver T. NOV (CCN3) functions as a regulator of human hematopoietic stem or progenitor cells. Science 2007;316: 590-3.

36. Lin CG, Leu SJ, Chen N, Tebeau CM, Lin SX, Yeung CY, Lau LF. CCN3 (NOV) is a novel angiogenic regulator of the CCN protein family. $\mathrm{J}$ Biol Chem 2003;278: 24200-8.

37. Fukunaga-Kalabis M, Martinez G, Liu ZJ, Kalabis J, Mrass P, Weninger W, Firth SM, Planque N, Perbal B, Herlyn M. CCN3 controls 3D spatial localization of melanocytes in the human skin through DDR1. J Cell Biol 2006;175: 563-9.

38. Fukunaga-Kalabis M, Martinez G, Telson SM, Liu ZJ, Balint K, Juhasz I, Elder DE, Perbal B, Herlyn M. Downregulation of CCN3 expression as a potential mechanism for melanoma progression. Oncogene 2008;27: 2552-60.

39. Vallacchi V, Daniotti M, Ratti F, Di Stasi D, Deho P, De Filippo A, Tragni G, Balsari A, Carbone A, Rivoltini L, Parmiani G, Lazar N, et al. CCN3/nephroblastoma overexpressed matricellular protein regulates 
integrin expression, adhesion, and dissemination in melanoma. Cancer Res 2008;68: 715-23.

40. Vallacchi $\mathrm{V}$, Rodolfo M. Regulatory role of CCN3 in melanoma cell interaction with the extracellular matrix. Cell Adh Migr 2009;3: 7-10.

41. Perbal B, Brigstock DR, Lau LF. Report on the second international workshop on the CCN family of genes. Mol Pathol 2003;56: 80-5.

42. Maillard M, Cadot B, Ball RY, Sethia K, Edwards DR, Perbal B, Tatoud R. Differential expression of the ccn3 (nov) proto-oncogene in human prostate cell lines and tissues. Mol Pathol 2001;54: 275-80.

43. Lafont J, Jacques C, Le Dreau G, Calhabeu F, Thibout H, Dubois C, Berenbaum F, Laurent M, Martinerie C. New target genes for NOV/CCN3 in chondrocytes: TGF-beta2 and type X collagen. J Bone Miner Res 2005;20: 2213-23.

44. Gupta N, Wang H, McLeod TL, Naus CC, Kyurkchiev S, Advani S, Yu J, Perbal B, Weichselbaum RR. Inhibition of glioma cell growth and tumorigenic potential by CCN3 (NOV). Mol Pathol 2001;54: 293-9.

45. Hartmann A, Kunz M, Köstlin S, Gillitzer R, Toksoy A, Bröcker E, Klein CE. Hypoxia-induced up-regulation of angiogenin in human malignant melanoma. Cancer Res 1999;59: 1578-83.

46. Tesic N, Kamensek U, Sersa G, Kranjc S, Stimac M, Lampreht U, Preat V, Vandermeulen G, Butinar M, Turk B, Cemazar M. Endoglin (CD105) silencing mediated by shRNA under the control of endothelin-1 promoter for targeted gene therapy of melanoma. Mol Ther Nucleic Acids 2015;4: e239.

47. Pardali E, van der Schaft DWJ, Wiercinska E, Gorter A, Hogendoorn PCW, Griffioen AW, ten Dijke P. Critical role of endoglin in tumor cell plasticity of Ewing sarcoma and melanoma. Oncogene 2011;30: 334-45.

48. Vandercappellen J, Van Damme J, Struyf S. The role of CXC chemokines and their receptors in cancer. Cancer Lett. 2008;267: 226-44.

49. Potente $\mathrm{M}$, Gerhardt $\mathrm{H}$, Carmeliet $\mathrm{P}$. Basic and therapeutic aspects of angiogenesis. Cell 2011;146: 873-87.

50. Lahav R, Suvà M, Rimoldi D, Patterson PH, Stamenkovic I. Endothelin receptor $B$ inhibition triggers apoptosis and enhances angiogenesis in melanomas. Cancer Res 2004;64: 8945-53. 


\subsection{Figure Legends}

Figure 1 Immunofluorescence detection of Anti-CD31. 10 $\mu \mathrm{m}$ sections of tail tumors (25-30mm³) from Dct-Grm1/K5-Edn3 (A) and Dct-Grm1 control counterparts (B) were stained for the endothelial cell marker CD-31 and counterstained using propidium iodide. Image $\mathrm{J}$ pixel density analysis and the Students T-test determined that Dct-Grm1/K5-Edn3 tail tumors had significantly more Anti-CD31 staining $(\mathrm{p}=0.044)$ than the Dct-Grm1 control tail tumors (C). Scale bar $50 \mu \mathrm{m} .(A, B)$.

Figure 3 Example of a labeled array demonstrating different levels of protein expression.

Figure 2 Proteome profiling of mouse angiogenic related proteins. Proteome profiling was used to analyze the relative expression of 53 mouse angiogenesis related proteins in primary tail tumors $\left(25-30 \mathrm{~mm}^{3}\right)$ of $D c t-G r m 1 / K 5-E d n 3$ experimental mice and their corresponding Dct-Grm1 controls. Dct-Grm1/K5-Edn3 mice had significantly $(p \leq 0.05)$ more expression of angiogenic proteins Endoglin, HB-EGF, MMP-9, Angiogenin, IGFBP-2, IGFBP-3, CCN3, Edn-1 and CXCL16. 
Figure 1 Analysis of tumor vascular density in Dct-Grm1/K5-Edn3 mice.

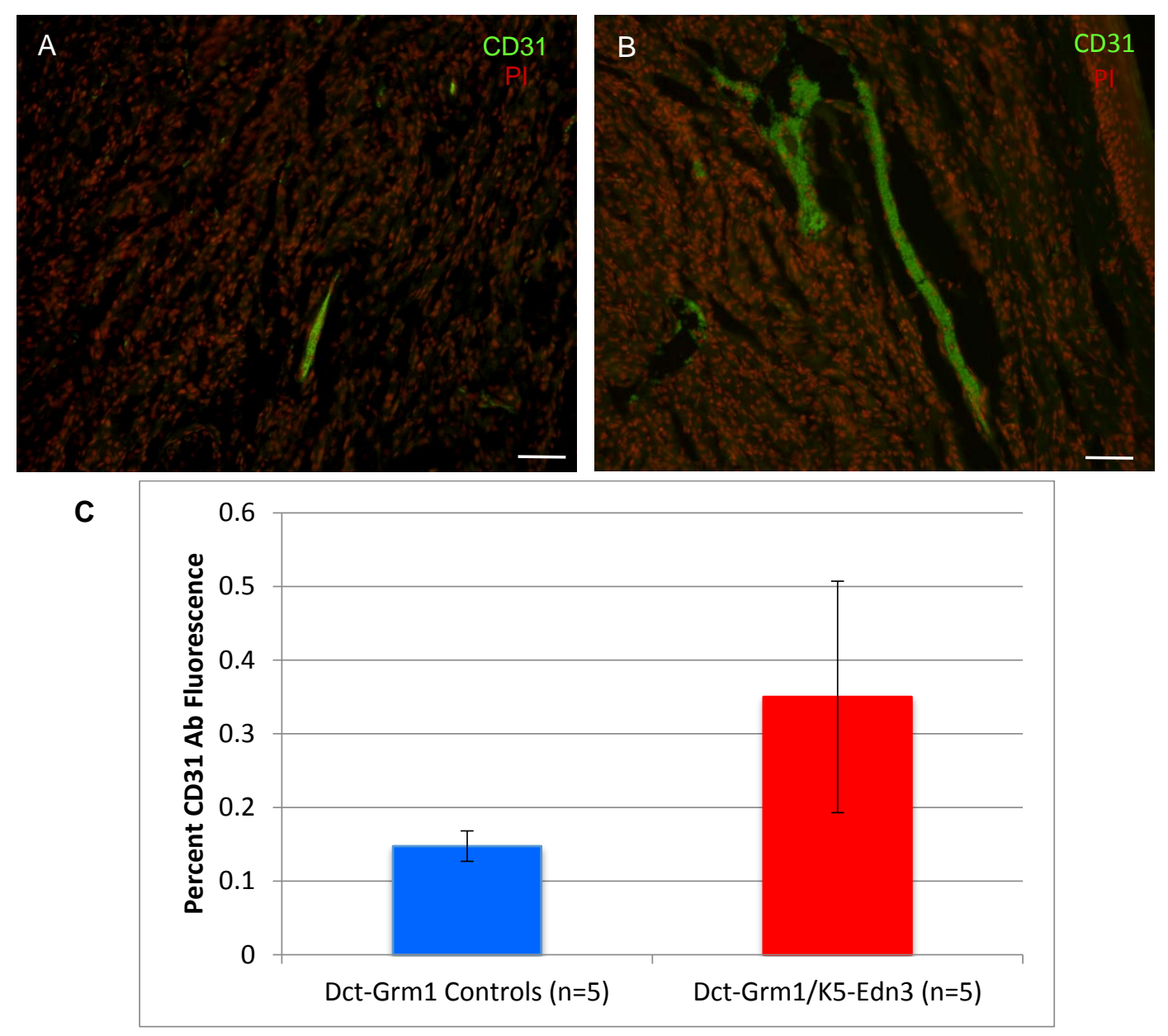

Figure 2 Example of angiogenic proteome profiling array.

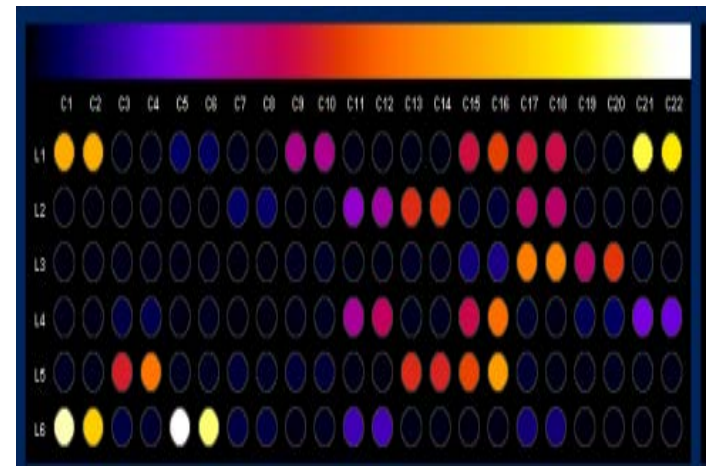

Dct-Grm1 Control

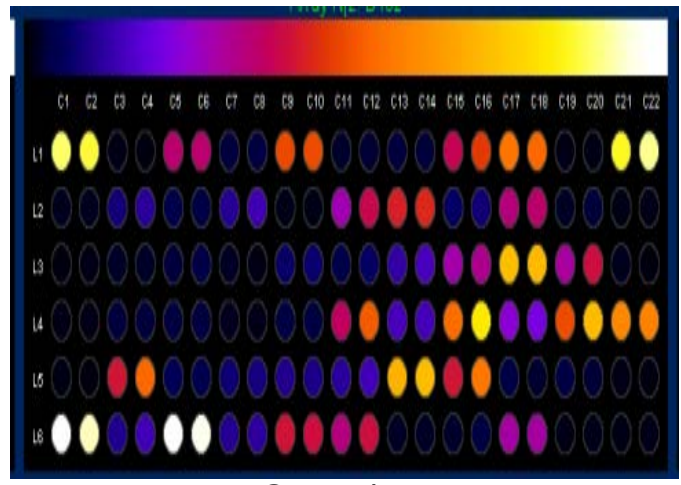

Dct-Grm1/K5-Edn3 


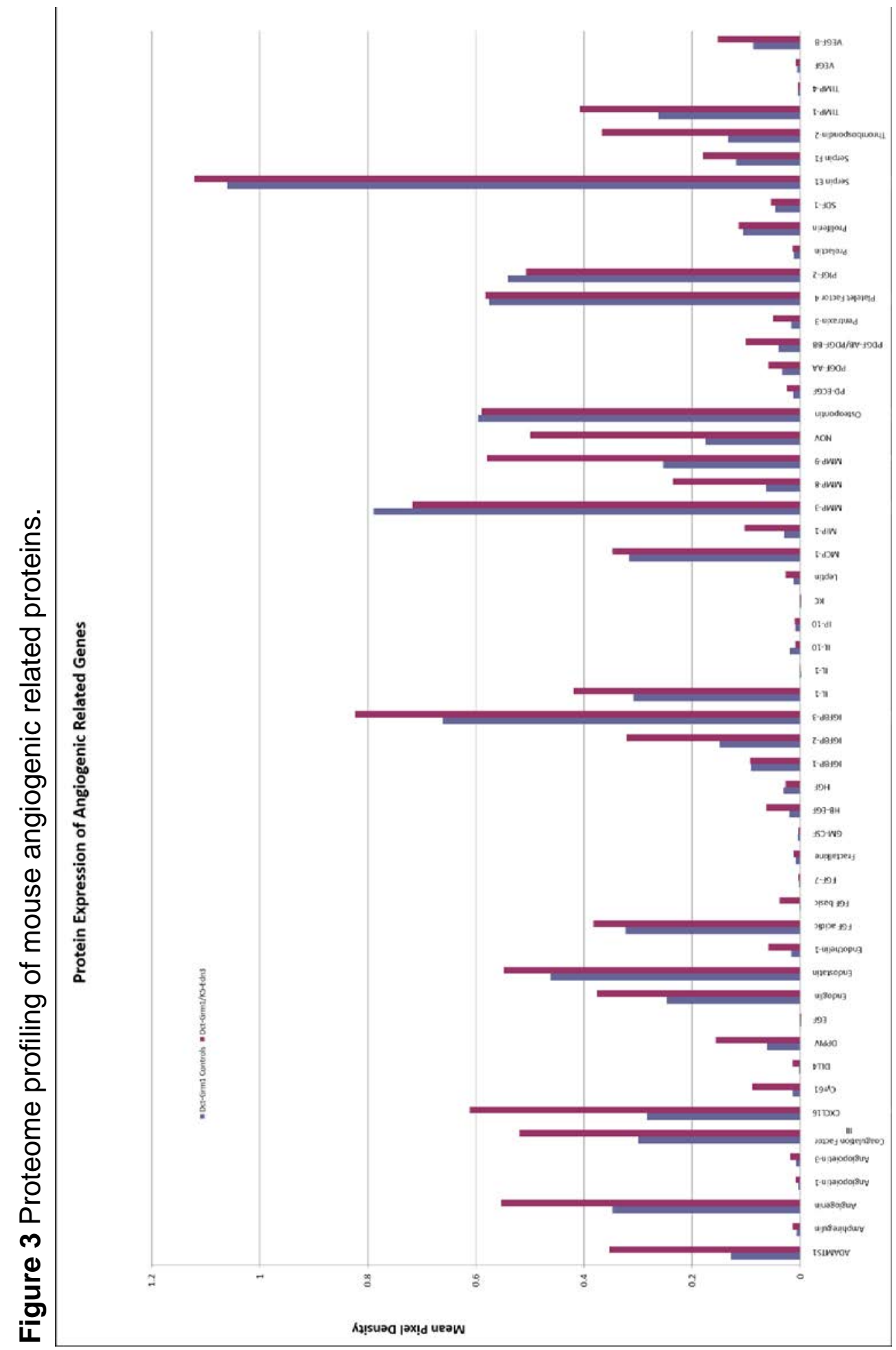


CHAPTER IV

CONCLUSIONS, FUTURE DIRECTION AND IMPLICATIONS 


\section{CONCLUSIONS, FUTURE DIRECTIONS AND IMPLICATIONS}

\subsection{Conclusions and Future Directions}

This study provided evidence that upregulation of EDN3 in the tumor microenvironment or EDNRB in transformed melanocytes can affect tumor behavior leading to a more aggressive melanoma phenotype as well as alter expression of genes involved in cell adhesion, and the tumor angiogenic response.

In this study the over-expression of EDN3 in the skin was present prior to tumor formation and throughout its development. In order to further understand the relevance of EDN3 in tumor progression and evaluate the potential of targeting this pathway during the course of human disease, it will be important to identify the exact timing the effect of EDN3 is most critical. It will also be interesting to establish if the role EDN3 plays in tumor growth can be separated from that of its role in promoting metastasis. These questions can be addressed in the future utilizing the tetracycline inducible system in the K5-Edn3 mouse model. EDN3 signaling can be switched off at different time points during melanoma tumor progression in Dct-Grm1/ K5-Edn3 mice to determine when tumor appearance, growth and spread can be stopped.

My results showed that EDN3 affected the angiogenic response of melanoma by changing gene expression and an increase in the amount of tumor vascularization. Many cancer regimens focus on targeting tumor angiogenesis and tumor vasculature, a vital component in tumor survival, growth and metastasis. Anti-angiogenic therapies include targeting either factors involved in 
angiogenesis such as VEGF or attempting to normalize the tumor vasculature. Some anti-cancer regimens are not effective because treatment cannot always be delivered to the entire tumor via its blood supply as irregular leaky vessels, associated with tumors, often do not reach all parts of the tumor ${ }^{1}$. The inadequate blood supply maintains hypoxic regions within the tumor and cancerous cells that can escape therapeutics. Often cancer patients may also exhibit anti-VEGF resistance. The mechanisms responsible for triggering resistance, and whether or not this is tumor type dependent within types of cancers has not been established.

Results from the proteome profiling array analysis showed that VEGF- $\beta$ is expressed more than VEGF in the tumors $\left(25-30 \mathrm{~mm}^{3}\right)$ of the Dct-Grm1/ K5-Edn3 mice. We will investigate whether inhibition of both VEGF receptors (VEGFR-1 and VEGFR-2) using polyclonal IgG neutralizing antibodies to VEGFR-1 (R\&D Systems; AF471) and VEGFR-2 (R\&D Systems; AF471) at different tumor stages can significantly reduce tumor size, growth rate and prevent metastasis in the tumors of the Dct-Grm1/ K5-Edn3 mice. These experiments will help us learn more about the importance of VEGF and potential VEGF therapeutics in melanoma treatment.

The tumors of Dct-Grm1/ K5-Edn3 mice are an ideal system to evaluate the efficacy of novel non-invasive tools to measure blood flow and levels of oxygenation that may be used in patients to determine the status of certain types of cancer. For example, I have started to collaborate with a group from the Department of Biomedical Engineering at Florida International University to use diffuse reflectance spectroscopy and a novel spectral interpretation algorithm ${ }^{2,3}$ 
to analyze and compare regions of hemoglobin oxygenation in tail tumors of the Dct-Grm1/ K5-Edn3 mice.

\subsection{Implications}

Although enlightening, studies on EDNRB in melanoma progression and metastasis were mostly conducted 'in vitro' using cell lines or in 'pseudomelanoma mouse models'. Therefore 'pro-tumor' effects of EDNRB are still incompletely characterized and more studies should be conducted in an 'in vivo' model to fully understand the mechanisms involved in order to develop and test effective preclinical therapeutic regimes against melanoma metastasis. The Dct-Grm1/ K5-Edn3 mouse model provides an 'in vivo' EDN3 dependent visceral metastatic melanoma model that does not require forced oncogene activation and in which EDN3 expression can be controlled using the tetracycline inducible system to examine melanomagenesis at various stages of progression associated with its tumor microenvironment. As a consequence of the nature of the K5-Edn3 mice, the Dct-Grm1/ K5-Edn3 mouse model has an increased number of melanocytes in the epidermal-dermal junction in the skin which more closely resembles the human skin phenotype which makes the model a prime candidate for investigating melanoma progression and correlating the findings to those found in humans ${ }^{4}$.

The highly aggressive nature of melanoma renders it one of the most formidable cancers to treat. Some melanoma tumors less than $2 \mathrm{~mm}$ in thickness have been diagnosed with metastatic potential, making it increasingly important to understand the molecular and genetic mechanisms of melanoma metastasis. 
There are few mouse melanoma models that demonstrate such a robust metastatic phenotype as our Dct-Grm1/ K5-Edn3 mouse model that can provide a valuable tool in understanding metastatic progression using 'in vivo' methods, as the microenvironment is indispensable when trying to fully elucidate metastasis. Park and colleagues (2011) using cross-species hybridization of microarray experiments to characterize the influence of the microenvironment on tumor cell behavior, showed that when melanoma cell line A375SM were xenografted into mouse brain organ sites, they acquired characteristics of neuronal lineage cells and began to express genes related to neurological signaling such as Synaptosomal-Associated Protein 21 (SNAP21), Synaptosomal-Associated Protein 91 (SNAP91) and Bassoon Presynaptic Cytomatrix Protein $(B S N)^{5}$. These genes were not overexpressed by the A375SM cells when they were xenografted into other metastatic sites. Thus melanoma cells may not only adopt a more undifferentiated cell type, but may also undergo transdifferentiation due to epigenetic and transcriptome reprogramming to adopt similar characteristics of cells at the metastatic sites ${ }^{5}$. This process may explain the strong chemoresistance of melanoma cells. The Dct-Grm1/K5-Edn3 metastatic melanoma mouse model may therefore be an important tool for testing potential drug therapeutics. 


\subsection{References}

1. Honstvet CA, Jones PF. Targeting Tumour Vasculature as a Cancer Treatment. Comput Math Methods Med 2007;8:1-9.

2. Chen PC, Lin WC. Spectral-profile-based algorithm for hemoglobin oxygen saturation determination from diffuse reflectance spectra. Biomed Opt Express 2011;2:1082-96.

3. Chen P, Fernald B, Lin W. Estimation of regional hemoglobin concentration in biological tissues using diffuse reflectance spectroscopy with a novel spectral interpretation algorithm. Phys Med Biol 2011;56:3985-4000.

4. Garcia RJ, Ittah A, Mirabal S, Figueroa J, Lopez L, Glick AB, Kos L. Endothelin 3 induces skin pigmentation in a keratin-driven inducible mouse model. J Invest Dermatol 2008;128:131-42.

5. Park ES, Kim SJ, Kim SW, Yoon S-L, Leem SH, Kim SB, Kim SM, Park YY, Cheong JH, Goo Woo H, Mills GB, Fidler IJ, et al. Cross-species hybridization of microarrays for studying tumor transcriptome of brain metastasis. Proc Natl Acad Sci U S A 2011;108:17456-61. 
VITA

NIKEISHA LATOYA CHIN

EDUCATION AND EXPERIENCE:

$2015 \quad$ Ph.D. Candidate

Florida International University - Miami, FL, USA.

2012 Biomedical Research Initiative (BRI) Student Summer Research Award

Funded through the MBRS RISE Biomedical Research Initiative, F.I.U ( $\$ 3,000)$

Florida International University - Miami, FL, USA

2011 Travel Award: For the International Pigment Cell Conference in Bordeaux, France

Awarded via conference fund raising and a grant from the Pan-

American Society for Pigment Cell Research (1000 euros)

2011 Biomedical Research Initiative (BRI) Student Summer Research

Award

Funded through the MBRS RISE Biomedical Research Initiative, F.I.U ( $\$ 3,000)$

Florida International University - Miami, FL, USA

2008- 2014 Minority Biomedical Research Support (MBRS) Research

Initiative for Scientific Enhancement (RISE) Doctoral Fellowship, (R25 GM 061347)

$2006 \quad$ Bachelor of Science: Biology

Florida International University - Miami, FL, USA.

PUBLICATIONS AND PRESENTATIONS:

Chin, N., Gallegos, J.C., Cruz, R., Garcia, R., Gonzalez, A., Borobia, M., Kos, L. Role of endothelin 3 in melanoma progression and metastasis. In: American Association for Cancer Research Annual Meeting 2013. Washington, DC, USA, 2013.

Chin, N., Gallegos, J.C., Cruz, R., Garcia, R., Gonzalez, A., Fernandez, D., 
Kos, L. Endothelin 3 and the angiogenic tumor response in a novel melanoma mouse model. In: $15^{\text {th }}$ Annual Biomedical and Comparative Immunology Symposium. Miami, FL, USA, 2013.

Chin, N., Gallegos, J.C., Cruz, R., Garcia, R., Gonzalez, A., Fernandez, D., Kos, L. Endothelin 3 promotes tumor progression by increasing angiogenesis in a mouse model of melanoma. In: $14^{\text {th }}$ Annual Biomedical and Comparative Immunology Symposium. Miami, FL, USA, 2013.

Chin, N., Gallegos, J.C., Cruz, R., Garcia, R., Gonzalez, A., Fernandez, D., Kos, L. The effects of endothelin 3 in a melanoma mouse model. In: Fourteenth Annual Biology Research Symposium. Miami, FL, USA, 2012.

Chin, N., Gallegos, J.C., Cruz, R., Garcia, R., Gonzalez, A., Fernandez, D., Kos, L. The effects of endothelin 3 in a melanoma mouse model. In: 8th International Congress of The Society for Melanoma Research. Tampa, FL, USA, 2011.

Chin, N., Gallegos, J.C., Cruz, R., Kos, L. The effect of endothelin 3 on melanoma progression and tumor heterogeneity in a melanoma mouse model. In: Minority Biomedical Research Support Mini-Symposium: Miami, FL, USA, 2011.

Chin, N., Gallegos, J.C., Cruz, R., Kos, L. Endothelin 3 promotes metastasis and alters tumor heterogeneity in a mouse model of melanoma. In: XXI International Pigment Cell Conference. Bordeaux, France, 2011.

Chin, N., Gallegos, J.C., Cruz, R., Kos, L. Endothelin 3 is required in the local microenvironment to accelerate tumor growth and promote metastasis in a mouse model of melanoma. In: American Society For Cell Biology Annual Meeting. Philadelphia, PA, USA, 2010.

Chin, N., Kos, L. The Role of Endothelin 3 in melanoma progression and metastasis. In: Florida International University Annual Biology Symposium. Miami, FL, USA, 2010.

Chin, N., Kos, L. The Role of Endothelin 3 in melanoma progression and metastasis. In: Minority Biomedical Research Support Mini-Symposium: Miami, FL, USA, 2010.

Chin, N., Kos, L. The Role of Endothelin 3 in melanoma progression and metastasis. In: International Congress of The Society for Melanoma Research. Boston, MA, USA, 2009. 